Aus der ehemaligen Abteilung experimentelle und klinische Neuroimmunologie

(Prof. Dr. med. R. Gold)

im Institut für Multiple-Sklerose-Forschung

der Universitätsmedizin Göttingen

\title{
ABC-Transporter-Gen-Polymorphismen sind potentielle pharmakogenetische Marker der Ansprechrate auf Mitoxantron in der Behandlung der Multiplen Sklerose
}

\author{
INAUGURAL-DISSERTATION \\ zur Erlangung des Doktorgrades \\ der Medizinischen Fakultät \\ der Georg-August-Universität zu Göttingen \\ vorgelegt von Steffi Cotte \\ aus Leinefelde \\ Göttingen 2011
}


Dekan:

I. Berichterstatter:

II. Berichterstatter/-in:

III. Berichterstatter/-in:

Tag der mündlichen Prüfung: $\quad$ 20. Februar 2012
Prof. Dr. med. Frömmel

Priv.-Doz. Dr. med. Chan

Prof. Dr. med. Brockmöller

Prof. Dr. med. Wulf 


\section{Inhaltsverzeichnis}

Abkürzungsverzeichnis

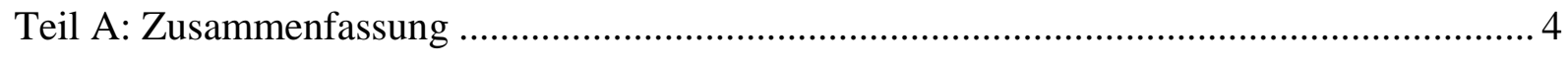

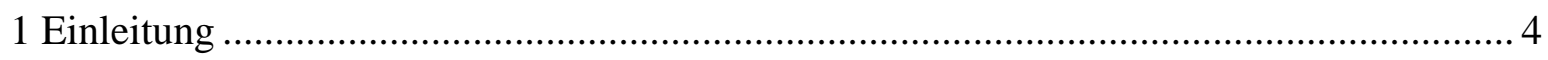

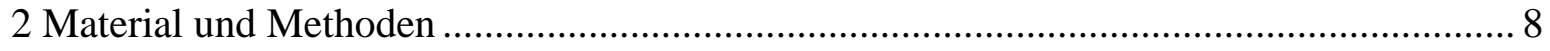

2.1 ABCB1- und ABCG2-Genotypisierung in Multiple-Sklerose-Patienten und gesunden Kontrollpersonen und Quantifizierung der Boten-Ribonukleinsäure-Expression humaner Zellen und Gewebe

2.2 In-vitro-Mitoxantron-Efflux-/-Zelltod-Assay in CD56 ${ }^{+}$-Zellen von Multiple-

Sklerose- Patienten und gesunden Kontrollen 10

2.3 In-vivo-Analyse: Induktion der experimentellen autoimmunen Enzephalomyelitis, Mitoxantron-Behandlung und Histologie....

2.4 Retrospektive klinische Korrelation funktionell-relevanter Einzelbasenaustausche in $A B C$-Transportern mit der therapeutischen Mitoxantron-Ansprechrate 22

2.5 Statistische Auswertung 24

3 Ergebnisse und Diskussion. 26

3.1 ABCB1- und ABCG2-Transporter sind hoch polymorph in Multiple-SklerosePopulationen aus zentral-europäischer Abstammung ohne große Unterschiede im Vergleich zu gesunden Spendern 26

3.2 Verschiedene, potentiell von der Mitoxantron-Therapie beeinflusste Gewebe und Organe zeigen eine hohe $A B C B 1$-/ABCG2-Boten-Ribonukleinsäure-Expression. .29

3.3 Der $A B C B 1-/ A B C G 2$-Transporter-Genotyp bestimmt in vitro den Mitoxantron-Efflux und den Mitoxantron-induzierten Zelltod in Multiple-Sklerose-Patienten und gesunden Spendern. 30

3.4 Der $A b c$-Transporter-Genotyp beeinflusst die therapeutische Ansprechrate auf Mitoxantron in der experimentellen autoimmunen Enzephalomyelitis 34

3.5 Der $A B C$-Transporter-Genotyp hat einen Effekt auf das therapeutische Ansprechen

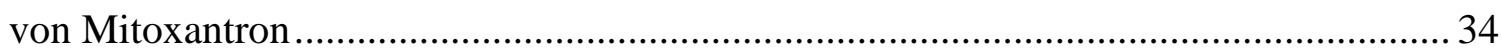

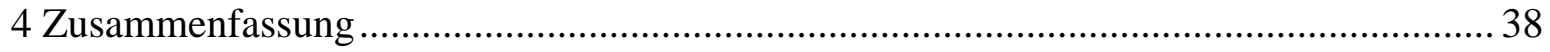

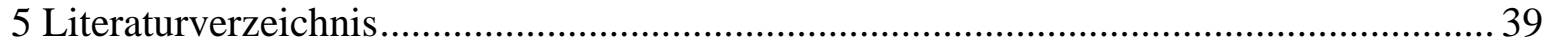

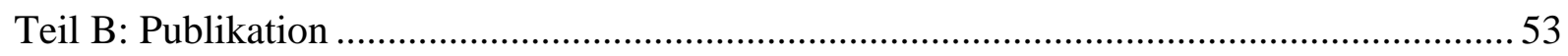

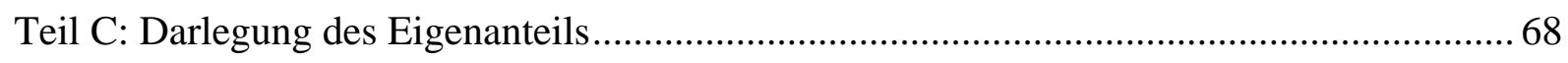




\section{Abkürzungsverzeichnis}

\begin{tabular}{|c|c|}
\hline A & Amper \\
\hline$A B C$ & $\begin{array}{l}\text { Adenosinetriphosphate-binding-cassette, Adenosintriphosphat- } \\
\text { Bindungskassette }\end{array}$ \\
\hline ad. & Auffüllen auf \\
\hline ATP & Adenosintriphosphat \\
\hline${ }^{\circ} \mathrm{C}$ & Grad Celsius \\
\hline $\mathrm{CO}_{2}$ & Kohlendioxid \\
\hline DEX & Dexamethason \\
\hline$\Delta$ & Delta \\
\hline DNS & Desoxyribonukleinsäure \\
\hline EAE & experimentelle autoimmune Enzephalomyelitis \\
\hline$E D S S$ & $\begin{array}{l}\text { Expanded Disability Status Scale, Skala zum Status des Behinderungsgrades in } \\
\text { Multipler Sklerose }\end{array}$ \\
\hline EDTA & Ethylendiamintetraessigsäure \\
\hline FACS & $\begin{array}{l}\text { Fluorescence Activated Cell Sorting, Fluoreszenz-aktivierter Zellsortierer, } \\
\text { Durchflusszytometer }\end{array}$ \\
\hline$F C S$ & Fresh Calf Serum, frisches Kälberserum \\
\hline FITC & Fluoresceinisothiocyanat \\
\hline FSC & Forward Light Scatter, Vorwärtsstreulicht \\
\hline g & Gramm \\
\hline GS & Glukokortikosteroid \\
\hline $\mathrm{h}$ & Stunden \\
\hline $\mathrm{Hz}$ & Hertz \\
\hline KOF & Körperoberfläche \\
\hline $\mathrm{kW}$ & Kilowatt \\
\hline $\mathrm{m}^{3}$ & Kubikmeter \\
\hline $\mathrm{mm}^{2}$ & Quadratmillimeter \\
\hline$M A C S$ & Magnetic Activated Cell Sorter \\
\hline
\end{tabular}




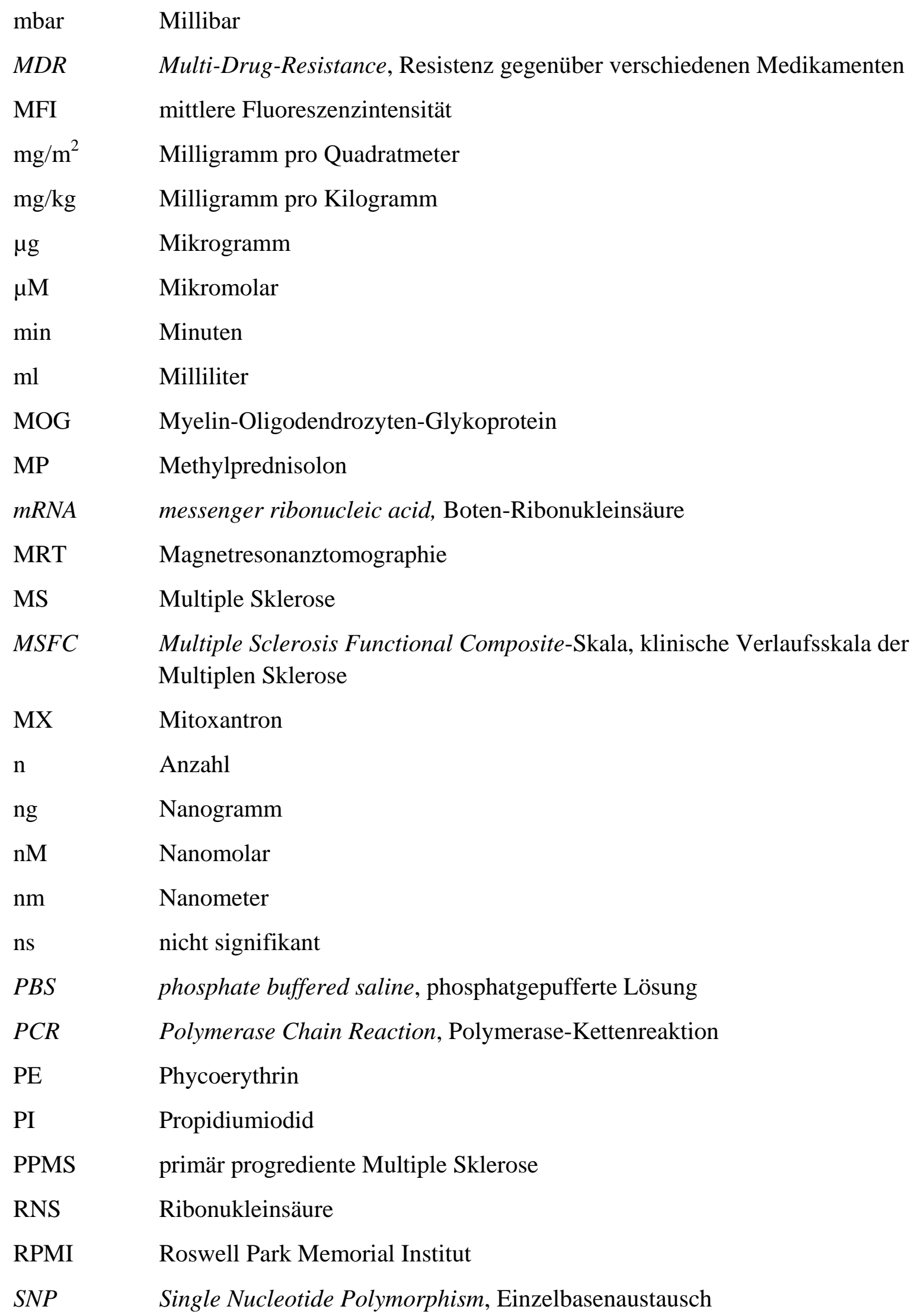



Volt

X

multipliziert mit

$\%$

Prozent

$*$

Stopp 


\section{Teil A: Zusammenfassung}

\section{Einleitung}

Bereits vor mehr als 100 Jahren beschrieben Charcot, Carswell und Cruveilhier die klinischen und pathologischen Charakteristika der Multiplen Sklerose (MS) (Pearce 2005). Die MS stellt mit einem Lebenszeitrisiko von eins zu 400 die potentiell häufigste, behindernde, neurologische Erkrankung im jungen Erwachsenenalter dar (Compston und Coles 2008, Flachenecker 2006). Insbesondere aufgrund histopathologischer und tierexperimenteller Befunde wird die MS als eine chronische autoimmune Erkrankung angesehen.

Pathogenetisch führen initial autoimmun-entzündliche Prozesse wie fokale Infiltrationen aus Lymphozyten und Makrophagen im zentralen Nervensystem (ZNS) zu einer Demyelinisierung wie von Compston und Coles (2008) und Noseworthy et al. (2000) zusammengefasst. Es kommt zur Schädigung des Axons und Bildung astrozytischer Narben. $\mathrm{Zu}$ Beginn ist die Entzündungsreaktion transient und eine Remyelinisierung findet statt, die jedoch nicht dauerhaft ist.

Die Ätiologie ist vermutlich multifaktorieller Genese. So ist die individuelle genetische Prädisposition neben dem Einfluss von Umweltfaktoren bedeutsam (Compston und Coles 2008, Kenealy et al. 2003).

Die Symptome der MS variieren in Abhängigkeit der Lokalisation der entzündlichen Plaques im ZNS und sind wie diese definitionsgemäß zeitlich und örtlich disseminiert (Frohman et al. 2006, Polman et al. 2005). Sie umfassen häufig eine Optikusneuritis, motorische Beeinträchtigungen, Harnblasenfunktionsstörungen und sexuelle Dysfunktionen und eine Ataxie (Keegan und Noseworthy 2002). Die hohe klinische Vielfältigkeit spiegelt sich in verschiedenen Verlaufsformen der Erkrankung wider sowie in definierten molekularpathologisch abgrenzbaren Subtypen (Frohman et al. 2006, Keegan und Noseworthy 2002, Lublin und Reingold 1996, Lucchinetti et al. 2000).

Die bisher überwiegend evidenzbasierte und neuroimmunologische Therapie zielt auf die besondere Bedeutung autoimmun-entzündlicher Prozesse in der Pathogenese der MS ab (Hemmer et al. 2006, MSTKG et al. 2008). Pharmakologisch-therapeutische Herangehensweisen basieren auf folgenden Prinzipien: neben der Akut-/Schubtherapie und der symptomatischen Behandlung bilden verlaufsmodifizierende Langzeittherapien die Hauptmöglichkeiten (MSTKG und Rieckmann 2006). Ansätze für eine individualisierte Therapie anhand von Surrogatparametern oder genetischen Profilen erscheinen besonders erstrebenswert. 
Mitoxantron (MX) ist ein antineoplastisches Anthrazendionderivat und ein hocheffektives, immunoaktives Agens in der Behandlung der aktiven MS (Durr et al. 1983, Hartung et al. 2002). Neben der onkologischen Indikation dient MX als evidenzbasierte Eskalationstherapie in der MS. Die Anwendung ist begrenzt auf klinisch hoch aktive schubförmige und sekundärprogrediente Verläufe, im Fall von Versagen oder Intoleranz gegenüber vorangegangenen immunmodulatorischen Behandlungen. Darüber hinaus ist es als Therapeutikum der ersten Wahl für maligne MS-Formen zugelassen (Boster et al. 2008, Esposito et al. 2010, Gonsette 2007, Hartung et al. 2002, Rieckmann 2006).

Neben anderen fassten Neuhaus et al. (2007) die funktionellen Effekte von MX zusammen: MX führt zur Hemmung der Nukleinsäuresynthese. Einerseits interkaliert es mit der Desoxyribonukleinsäure (DNS) und verursacht andererseits über eine Interaktion mit der Topoisomerase II Einzel- und Doppelstrangbrüche. Darüber hinaus wirkt MX immunsupressiv, indem es die Proliferation und Funktion von B- und T-Zellen sowie von Makrophagen beeinflusst (Neuhaus et al. 2005). Kopadze et al. beobachteten bereits 2006, dass MX die Migration inflammatorischer Zellen in das ZNS und direkt im ZNS senken kann. Weiterhin moduliert MX das Zytokin-Netzwerk und hemmt gamma-Interferon, Tumornekrosefaktor-alpha und Interleukin 2 und 10 (Fidler et al. 1986).

Wie bei anderen Anthrazyklin-verwandten Substanzen ist die Therapiedauer mit MX insbesondere durch die Kardiotoxizität bei circa $0.1 \%$ der Patienten auf zwei bis drei Jahre limitiert (Ghalie et al. 2002). Es besteht eine Assoziation der Nebenwirkungen mit der kumulativen Dosis. Deshalb ist derzeit die MX-Therapie bis zu einer kumulativen Gesamtdosis von $140 \mathrm{mg} / \mathrm{m}^{2}$ Körperoberfläche unter engmaschiger kardiologischer Kontrolle zugelassen. Dabei handelt es sich um eine maximal erlaubte Gesamtdosis während der Lebenszeit (Cohen und Mikol 2004). Das Risikoprofil umfasst außerdem eine Knochenmarksdepression, eine therapieassoziierte akute Leukämie und eine gonadale Dysfunktion. Laut einem Report des therapeutischen und technologischen UntersuchungsSubkomitees der Amerikanischen Akademie für Neurologie (2010) ist die Gefahr einer systolischer Dysfunktion mit circa 12\% und einer Leukämie mit $0.8 \%$ sogar höher als bisher angenommen (Marriott et al. 2010). Trotz der limitierten Anwendungsdauer erleiden einige Patienten bereits bei niedrigen Dosierungen kardiale oder hämatologische Nebenwirkungen. Es wurden auch Spätmanifestationen mehrere Jahre nach Abschluss der Therapie beschrieben (Morrissey et al. 2005, Paul et al. 2007). Im Gegensatz dazu sprechen einige Patienten im klinischen Alltag nur unzureichend auf eine hohe MX-Dosierung an. Prädiktoren, die eine Optimierung, eine individualisierte Dosierung und Risikostratifizierung, aber auch eine bessere Verträglichkeit dieser hochwirksamen Therapie ermöglichen, könnten potentiell zu längeren Behandlungsintervallen führen (Kieseier und Jeffery 2010). Das ist ein wichtiges Ziel, da bisher noch über evidenzbasierte Strategien nach der Ausschöpfung der kumulativen Lebenszeitdosis von MX und der Fortführung einer Immuntherapie debattiert wird (Boster et al. 2008, Gold und Rieckmann 2007). 
Potentielle Kandidaten für solche Prädiktoren könnten Mitglieder der AdenosintriphosphatBindungskassette (Adenosinetriphosphate-binding cassette, $A B C$ )-Transporter-Genfamilie sein, die zum Detoxifikationssystem des menschlichen Körpers gehören (Schinkel und Jonker 2003). Sie stellen einen pleiotropen Multi-Drug-Resistance (MDR, Resistenz gegen verschiedene Medikamente)-Mechanismus dar, der die Zellen vor endo- und exogenen toxischen Substanzen schützt. Dieses wird über einen energieabhängigen Efflux gegen einen Konzentrationsgradienten ermöglicht (Higgins 1992, Sarkadi et al. 2004, Schinkel und Jonker 2003).

Die weit verbreiteten, primär in der apikalen Plasmamembran lokalisierten Transporter erlangen eine besondere Bedeutung im ZNS, aber auch in sekretorischen Organen wie der Leber oder im kapillaren Endothel von beispielsweise Herz und Testis (Cascorbi 2006, Gottesman et al. 2002, Homolya et al. 2011, Schinkel und Jonker 2003).

Die $A B C$-Proteine bestehen aus einer einzelnen Polypeptidkette (ganzer Transporter) oder aus zwei separaten Proteinen (Halbtransporter), die sich zusammenlagern müssen, um eine funktionelle Aktivität zu erlangen. Sie setzen sich in der funktionell aktiven Einheit aus mindestens vier Domänen zusammen: zwei ATP-Bindungskassetten und zwei transmembranäre Anteile. Wenn ATP bindet, dimerisieren zwei ATP-Bindungskassetten. Die Hydrolyse von ATP zu ADP stellt Energie zur Dissoziation der Kassetten zur Verfügung. Mit einem Wechsel/Switch der transmembranen Domäne wird der Medikamenten-Efflux herbeigeführt (Hermann et al. 2006, Ni et al. 2010).

Die $A B C$-Transporter regulieren den Transport von strukturell verschiedenen Stoffen. Dadurch kontrollieren sie wichtige pharmakologische Eigenschaften, wie die orale Bioverfügbarkeit sowie die hepatobiliäre, intestinale und renale Elimination (Gottesman et al. 2002, Schinkel und Jonker 2003). Löscher und Potschka (2005) und Hermann et al. (2006) fassten zusammen, dass es bei unterschiedlichen neurologischen Erkrankungen zur Steigerung der $A B C$-Transporter-Expression im ZNS kommen kann, wie zum Beispiel bei der Schizophrenie, Depression, Epilepsie und bei zerebralen Ischämien oder ZNS-Karzinomen. Daraus resultierte ein schlechtes Ansprechen auf die entsprechende medikamentöse Behandlung. Weiterhin berichten sie, dass im Maus-Modell eine Deaktivierung der $A B C$ Transporter zu einer erhöhten Akkumulation von diversen Medikamenten führte. Aktuell haben sich tierexperimentell in der Behandlung der Depression erste Erfolge bei der Steigerung der Medikamenten-Effektivität unter Inhibition des $A B C$-vermittelten Effluxes ergeben (Uhr et al. 2008).

Ein gut bekannter $A B C$-Transporter ist das P-Glykoprotein, das in überexprimierenden, Chemotherapie-resistenten Krebszellen identifiziert wurde. Dieser durch das $A B C B 1$-Gen kodierte Transporter steht in Verbindung mit einer Resistenz gegen Medikamente wie MX (Juliano und Ling 1976, Marzolini et al. 2004, Roninson et al. 1986, Shen et al. 1986). Daneben beeinflusst es als immunmodulierendes Molekül die Funktion dendritischer Zellen (Kooij et al. 2009). Eine nicht P-Glykoprotein-vermittelte Resistenz gegen hohe MX-Dosen 
führte in den frühen 1990er Jahren zur Entdeckung eines neuen Efflux-Transporters. Drei Gruppen klonierten unabhängig voneinander das heute als $A B C G 2$ bezeichnete Gen (Robey et al. 2007). Doyle et al. entdeckten es 1998 als Brustkrebs-Resistenz-Protein (breast cancer resistance protein, $B R C P$ ), Allikmets et al. beschrieben im selben Jahr das Plazentaspezifische $A B C$-Protein (ABCP) und ein Jahr später nannten es Miyake et al. MX-ResistenzProtein (MRP).

Die ABCB1- und ABCG2-Transporter überlappen sich in ihrer Lokalisation und Substratspezifität (Leslie et al. 2005). Es wurden verschiedene Einzelbasenaustausche (Single Nucleotide Polymorphisms, SNPS) in der kodierenden Sequenz der $A B C$-Transporter beschrieben, die Einfluss auf die Transporterfunktion haben.

In Voruntersuchungen konnte ex vivo ein präferentieller Zelltod in CD19+-B-Zellen von MXbehandelten MS-Patienten beobachtet werden mit relativ geringeren Zelltodraten in CD56 ${ }^{+}$ Natürlichen-Killer-Zellen. Diese relative Selektivität in der Induktion vom B-Zelltod wird als ein wesentlicher immunologischer Wirkmechanismus der MX-Therapie diskutiert (Chan et al. 2005). Darüber hinaus wurde in diesen Untergruppen peripherer Blut-Leukozyten eine unterschiedliche $A B C$-Transporter-Boten-Ribonukleinsäure (messenger ribonucleic acid, $m R N A$ )-Expression beobachtet (Scharenberg et al. 2002). Es zeigte sich eine höhere Expression auf CD56 ${ }^{+}$-Zellen als auf unsortierten mononukleären Zellen und deutlich mehr im Vergleich zu CD19 ${ }^{+}$-B-Zellen. Darauf basierend entwickelten wir die Hypothese, dass die $A B C$-Transporter-Funktion in eine unterschiedliche MX-Suszeptibilität involviert sein könnte. Dieser Effekt könnte sich nicht nur auf zellulärer Ebene, sondern auch auf den Gesamtorganismus auswirken.

In der vorliegenden Analyse untersuchten wir die Prävalenz und den funktionellen Einfluss von $A B C B 1$ - und $A B C G 2-S N P S$ in MS-Patienten mit verschiedenen genetischen Hintergründen. Es wurde eine retrospektive, multizentrische Prüfung durchgeführt. Der Einfluss der $A B C B 1$ - und $A B C G 2-S N P S$ auf die klinische und paraklinsiche Ansprechrate sowie die Nebenwirkungen der Behandlung mit MX beziehungsweise einer Kombination von MX mit Glukokortikosteroiden (GS) wurde untersucht. Die Ergebnisse werden durch experimentelle Daten unterstützt. Es wurde in vitro der Einfluss der Transporteraktivität auf die MX-Akkumulation in peripheren mononukleären Leukozyten von MS-Patienten und Probanden analysiert. In in-vivo-Experimenten in Abcg2-Knock-Out-Tieren wurde ebenfalls die Rolle des ABCG2-Transporters auf die MX-Therapie untersucht in der chronischen experimentellen autoimmunen Enzephalomyelitis (EAE), die ein etabliertes Tiermodell der MS darstellt. 


\section{Material und Methoden}

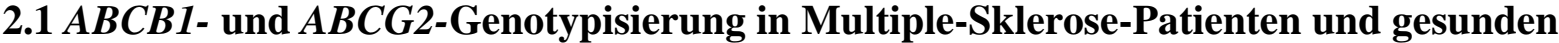 Kontrollpersonen und Quantifizierung der Boten-Ribonukleinsäure-Expression humaner Zellen und Gewebe}

Die Genotypisierung von 832 MS-Patienten aus drei deutschen Kliniken (MS-Ambulanz, Universitätsmedizin Göttingen, Göttingen, Anzahl (n)=166; Abteilung Neurologie, Universität Rostock, Rostock, n=423; Abteilung Neurologie, Marianne Strauß Klinik, Berg, $\mathrm{n}=194$ ) und einem spanischen Zentrum (Abteilung Neurologie, Hospital Universitari Vall d'Hebron, Barcelona, $\mathrm{n}=49$ ) wurde nach schriftlicher Patientenzustimmung entsprechend der Deklaration von Helsinki und Zustimmung der lokalen Ethikkommission durchgeführt. Kontrollproben wurden von Blutspendern der lokalen Blutbank (Blutspendedienst, Universitätsmedizin Göttingen, Göttingen, $n=191$ ) (von Ahsen et al. 2000) und von Freiwilligen (Göttingen, Bochum n=73) ohne Anamnese einer neurologischen Erkrankung bezogen.

Für die Genotypisierung wurde genomische DNS aus $5 \mathrm{ml}$ Ethylendiamintetraessigsäure (EDTA)-Blut isoliert unter Verwendung des Puregene DNA Purification Kits entsprechend den Herstellerangaben. Folgende SNPs wurden untersucht: Für ABCG2 fokussierten wir uns auf V12M, Q141K, Q126* (*=Stopp), E334*, R482G, R482T und für ABCB1 auf 3435C>T und $2677 \mathrm{G}>\mathrm{T}$ (Tabelle 1). Sie wurden vorhergehend in Populationen mit unterschiedlichem ethnischen Hintergrund identifiziert und als funktionell-relevant beschrieben (Bosch et al. 2005, Mizuarai et al. 2004, Sakaeda et al. 2003, Schwab et al. 2003). Die TaqMan ${ }^{\mathrm{TM}}$ Polymerase-Kettenreaktion (Polymerase Chain Reaction, PCR) wurde für ABCG2-V12M (Referenz SNP rs2231137) und -Q141K (rs2231142) auf einem 7500 Real Time PCR System (Applied Biosystems, Darmstadt, Germany) durchgeführt unter Verwendung des Platinum qPCR Super Mix-UDG (Invitrogen, Karlsruhe, Germany). Der SNP ABCB1-3435C>T (rs1045642) (ganze Kohorte) und -2677G>T (MX-behandelte Kohorte, rs2032582) wurde mit einem LightCycler Realtime PCR-System analysiert unter Zuhilfenahme von Hybridisierungsproben wie in von Ahsen et al. (2001) vorbeschrieben. 
Tabelle 1: $\quad$ Oligonukleotide zur Identifizierung von Einzelbasenaustauschen in ABCB1- und ABCG2-Genen und Primer zur Quantifizierung der Expression der Boten-Ribonukleinsäure

Die polymorphen Nukleotide sind unterstrichen.* bedeutet Stopp.

\begin{tabular}{|c|c|}
\hline Oligonukleotid & Sequenz $\left(5^{\prime} \rightarrow 3^{\prime}\right)$ \\
\hline \multicolumn{2}{|l|}{ ABCB1-Transporter } \\
\hline $3435 \mathrm{C}>\mathrm{T}$ vorwärts & CTCTGGTGGCCAGAAACAAC \\
\hline $3435 \mathrm{C}>\mathrm{T}$ rückwärts & GGTGAGCAATCACAATGCAG \\
\hline 2677G>T vorwärts & AGCAAATCTTGGGACAGGAAT \\
\hline 2677G > T rückwärts & TCAATCTTTAGTTTGACTCACCTT \\
\hline 2677G $>\mathrm{T}$ Probe 1 & TCTTATCTTTCAGTGCTTGTCCAGAC-ROX \\
\hline 2677G $>\mathrm{T}$ Probe 2 & Fluorescein-CCAGCACCTTCTAGTTCT-Phosphat \\
\hline \multicolumn{2}{|l|}{ ABCG2-Transporter } \\
\hline V12 vorwärts & AACTCTCCAGATGTCTTCCAGTAATG \\
\hline V12 rückwärts & TTAACACAGCTCCTTCAGTAAATGC \\
\hline V12 Wildtyp & FAM-TATCCCAGTGTCACAAG-MGB \\
\hline V12M & VIC-TTTATCCCAATTGTCACAAG-MGB \\
\hline Q126 vorwärts & CGACCTGCCAATTTCAAATGTA \\
\hline Q126 rückwärts & TTACCCATATAGAAACAGAGGAAACAGA \\
\hline Q126 Wildtyp & FAM-TACGTGGTACAAAGTAAGTA-MGB \\
\hline Q126* & VIC-TACGTGGTATAAGTAAGTAT-MGB \\
\hline Q141 vorwärts & GATGATGTTGTGATGGGCACTCT \\
\hline Q141 rückwärts & CATAGTTGTTGCAAGCCGAAGAG \\
\hline Q141 Wildtyp & FAM-AGAAAACTTACAAGTTCTCAG-MGB \\
\hline Q141K & VIC-AGAAAACTTAAAAGTTCTCAGCAG-MGB \\
\hline E334 vorwärts & CCAAGCAGGATAAGCCACTCA \\
\hline E334 rückwärts & TCAGCTTTTGTCTCTTTGTAGAAGGA \\
\hline E334 Wildtyp & FAM-TTAGCGGAGATTTAT-MGB \\
\hline E334* & VIC-AATTAGCGTAGATTTATGTCA-MGB \\
\hline
\end{tabular}




\begin{tabular}{|l|l|}
\hline R482 vorwärts & CTACAGAGTGTCATCTTATTTCCTTGGA \\
R482 rückwärts & TGTCCTTTTTTGTTTTGTTACATACTTACC \\
R482 Wildtyp & FAM-ATTACCCATGAGGATGTT-MGB \\
R482G & VIC-CCCATGGGGATGTT-MGB \\
R482T & VIC-TTACCCATGACGATGTT-MGB \\
\hline Kontrollprobe & \\
\hline RNA-Polymerase II vorwärts & GCACCACGTCCAATGACAT \\
RNA-Polymerase II rückwärts & GTGCGGCTGCTTCCATAA \\
\hline
\end{tabular}

Die Quantifizierung der $A B C B 1$ - und $A B C G 2-m R N A$-Expression erfolgte in verschiedenen humanen Zellen und Geweben. Nach der Isolation der Ribonukleinsäure (RNS) und der reversen Transkription (Chan et al. 2003, Kruse et al. 2001) erfolgte die relative Quantifizierung der $A B C$ - $m R N A$-Expression unter Verwendung der $\Delta \Delta \mathrm{C}_{\mathrm{T}}$-Methode ( $\Delta$ delta) (Livak und Schmittgen 2001). Für die Bestimmung der ABCG2-mRNA-Expression wurde der QuantiTect Primer Assay Hs_ABCG2_SG_1 in Kombination mit dem QuantiTect SYBR Green PCR Kit verwendet. Mit Hilfe der Platinum qPCR Super Mix-UDG und SYBR Green wurde $A B C B 1$ - und die RNS-Polymerase-II- $m R N A$-Expression analysiert. Die verwendeten Primer sind in Tabelle 1 detailliert aufgeführt. Die $m R N A$ der RNS-Polymerase II diente als endogene Kontrolle (Radonić et al. 2004). Als Kalibratorprobe wurde die humane epitheliale Brustkrebs-Zelllinie MCF7 mit stabiler $A B C-m R N A$-Expression herangezogen.

\subsection{In-vitro-Mitoxantron-Efflux-/-Zelltod-Assay in $\mathrm{CD56}^{+}$-Zellen von Multiple-Sklerose- Patienten und gesunden Kontrollen}

Der in-vitro-MX-Efflux-/-Zelltod-Assay basiert auf der Messung des fluoreszenten, intrazellulären MX im Durchflusszytometer (Fluoreszenz-aktivierter Zellsortierer, Fluorescence Activated Cell Sorting, FACS) unter Verwendung eines $635 \mathrm{~nm}$ Lasers mit einer roten Diode und einem 670nm Bandbreitenfilters (Chan et al. 2005). Mit dieser Methode wird die gleichzeitige Erfassung von Größe (Vorwärtsstreulicht, Forward Light Scatter, FSC), Granularität (Seitwärtsstreulicht, Side Light Scatter, SSC) und Fluoreszenzfarben ermöglicht. Der Assay wurde in $A B C B 1$ - und $A B C G 2$-hochexprimierenden CD56 ${ }^{+}$-Zellen durchgeführt (Chaudhary et al. 1992, Klimecki et al. 1994, Scharenberg et al. 2002).

\subsubsection{Material, Software und entsprechende Bezugsquelle}

Chemikalien, Färbemittel und Inhibitoren
Albumin Fraktion V
Carl Roth, Karlsruhe, Deutschland
Annexin-V-FITC
Roche Biochemica, Mannheim, Deutschland 
Calciumchlorid

Carl Roth, Karlsruhe, Deutschland

Di-Natriumhydrogenphosphat

Carl Roth, Karlsruhe, Deutschland

Dexa-Ratiopharm (Dexamethasondihydrogenphosphat-Dinatrium)

Ratiopharm GmbH, Ulm, Deutschland

EDTA-Dinatriumsalz-Dihydrat (Titrierkomplex 3)

Carl Roth, Karlsruhe, Deutschland

fetal-bovines Serum

HEPES

Sigma-Aldrich Chemie GmbH, Steinheim, Deutschland

Kaliumchlorid

Invitrogen (Gibco), Karlsruhe, Deutschland

Lymphozyten-Separationsmedium (LSM 1077)

PAA Laboratories GmbH, Linz, Österreich

Mitoxantron

Gry Pharma, Kirchzarten, Deutschland

Natriumazid

Carl Roth, Karlsruhe, Deutschland

Natriumchlorid

Carl Roth, Karlsruhe, Deutschland

Natrium-Hydrogencarbonat

Carl Roth, Karlsruhe, Deutschland

Natriumhydroxid

Carl Roth, Karlsruhe, Deutschland

Propidiumiodid

Insteamed Medium RPMI 1640

Salzsäure

SYBR Green

Trypan-Blau-Lösung

Urbason solubile (Methylprednisolon-21-hydrogensuccinat) 
Tabelle 2: Hemmstoffe der ABC-Transporter $\left({ }^{1}\right.$ Robey et al. 2007, ${ }^{2}$ Schinkel und Jonker 2003, ${ }^{3}$ GonzálesLobato et al. 2010)

\begin{tabular}{|l|l|l|l|l|}
\hline Hemmstoff & $\begin{array}{l}\text { Transporter- } \\
\text { Spezifität }\end{array}$ & $\begin{array}{l}\text { Konzentration } \\
\text { im } \text { in-vitro-Assay }\end{array}$ & Wirkmechanismus & Bezugsquelle \\
\hline $\begin{array}{l}\text { Elacridar/ } \\
\text { GF120918 }\end{array}$ & $\begin{array}{l}\text { ABCB1 } \\
\text { ABCG2 }\end{array}$ & $2.5 \mu \mathrm{M}$ & $\begin{array}{l}\text { ABCB1 und ABCG2 } \\
\text { Substrat, Konverter }\end{array}$ & $\begin{array}{l}\text { Glaxo Smith Kline, } \\
\text { Collegeville, PA, } \\
\text { USA }\end{array}$ \\
\hline $\begin{array}{l}\text { Valspodar/ } \\
\text { PKF215-833 }\end{array}$ & ABCB1 & $2.5 \mu \mathrm{M}$ & $\begin{array}{l}\text { ABCB1 Substrat } \\
\text { (hohe Affinität, } \\
\text { langsamer Transport } \\
\text { und Freilassung })^{2}\end{array}$ & $\begin{array}{l}\text { Novartis, Basel, } \\
\text { Schweiz }\end{array}$ \\
\hline $\begin{array}{l}\text { FTC/ } \\
\text { Fumitremorgin C }\end{array}$ & ABCG2 & $10 \mu \mathrm{M}$ & $\begin{array}{l}\text { Hemmung der } \\
\text { ATPase-Aktivität }\end{array}$ & $\begin{array}{l}\text { Alexis Biochemicals, } \\
\text { Lörrach, Deutschland }\end{array}$ \\
\hline
\end{tabular}

\section{Antikörper}

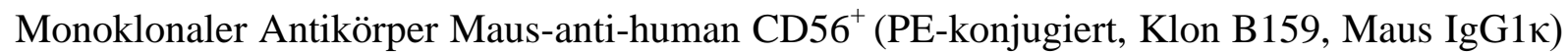
BD PharMingen, San Diego, CA, USA

Monoklonaler Antikörper Maus-anti-human CD56 ${ }^{+}$MicroBeads (Maus IgG1)

Miltenyi Biotec, Bergisch Gladbach, Deutschland

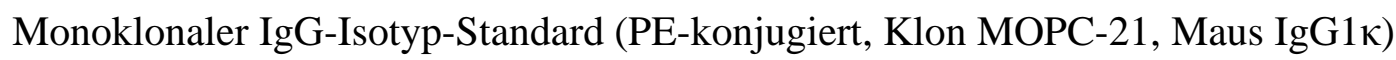

BD PharMingen, San Diego, CA, USA

Lösungen, Puffer und Medien

Annexin-V-Puffer

$1 \mathrm{ml} 1 \mathrm{M}$ HEPES/NaOH

$10 \mathrm{ml} 1.4 \mathrm{M} \mathrm{NaCl}$

$0.5 \mathrm{ml} 1 \mathrm{M} \mathrm{CaCl}_{2}$

ad. $100 \mathrm{ml}_{2} \mathrm{O}$ bidestilliert

pH-Wert 7.4 
$1 \mathrm{M} \mathrm{CaCl}_{2}$

11.1. $\mathrm{g} \mathrm{CaCl}_{2}$

ad. $100 \mathrm{ml} \mathrm{H}_{2} \mathrm{O}$ bidestilliert

FACS-Puffer

$1 \times P B S$

$0.1 \% \mathrm{BSA}$

$0.1 \%$ Natriumazid

Lymphozyten-Separationsmedium

Fertiglösung

$M A C S$-Puffer

$500 \mathrm{ml} 1 \mathrm{x} P B S$

0.5\% Bovines Serum Albumin

2mM EDTA

pH-Wert 7.2

$1.4 \mathrm{M} \mathrm{NaCl}$

$8.18 \mathrm{~g} \mathrm{NaCl}$

ad. $100 \mathrm{ml} \mathrm{H}_{2} \mathrm{O}$ bidestilliert

10xPBS

$400 \mathrm{~g} \mathrm{NaCl}$

$10 \mathrm{~g} \mathrm{KCl}$

$71 \mathrm{~g} \mathrm{Na}_{2} \mathrm{HPO}_{4}$

$69 \mathrm{~g} \mathrm{NaH}_{2} \mathrm{PO}_{4} \mathrm{xH}_{2} \mathrm{O}$

ad. $5000 \mathrm{ml} \mathrm{H}_{2} \mathrm{O}$ bidestilliert

pH-Wert 6.7

RPMI 1640, 10\% FCS

$41.6 \mathrm{~g}$ Insteamed Medium RPMI 1640

$22 \mathrm{~g} \mathrm{NaHCO}_{3}$

ad. $10 \mathrm{ml} \mathrm{H}_{2} \mathrm{O}$ bidestilliert

pH-Wert 7.4 (Einstellung mit $\mathrm{NaOH}$ oder $\mathrm{HCl}$ )

$10 \%$ inaktiviertes $F C S$ (bei $56^{\circ} \mathrm{C}$ für $30 \mathrm{~min}$ im Wasserbad erwärmen) 
$\underline{\text { Kits }}$

ABCG2-mRNA-Expression QuantiTect Primer Assay Hs_ABCG2_SG_1

Qiagen, Hilden, Deutschland

Platinum qPCR SuperMix-UDG Invitrogen (Gibco), Karlsruhe, Deutschland

Puregene DNA Purification Kit Gentra System, Minneapolis, MN, USA

QuantiTect SYBR Green PCR Qiagen, Hilden, Deutschland

\section{Geräte}

Bunsenbrenner (Typ: Flammy S) Schütt Labortechnik GmbH, Göttingen, Deutschland Durchflusszytometer (Typ: BD FACSCalibur, Basic 4-Color Flow Cytometer)

BD Immuncytometry Systems, San Jose, CA, USA

Kältetruhe (Typ: Liebherr Premium Kombi, Kühl- und Gefriereinheit $-80^{\circ} \mathrm{C}$ )

Liebherr Hausgeräte, Ochsenhausen, Deutschland

Kohlendioxid-Brutschrank (Modellnummer 300M)

MMM-Group, Planegg, Deutschland

Kühlgerät (Typ: Liebherr Premium Kombi, Kühl- und Gefriereinheit $-20^{\circ} \mathrm{C}$ )

Liebherr Hausgeräte, Ochsenhausen, Deutschland

Phasenkontrastmikroskop Carl Zeiss AG, Deutschland

LightCycler realtime PCR-System Roche Biochemicals, Mannheim, Deutschland

7500 RealTime PCR-System Applied Biosystems, Darmstadt, Deutschland

Sterilbank (Typ: Hera Safe) Kendro, Langenselbold, Deutschland

Vacuum-Pumpsystem (Typ: BVC 21, 1.9 $\mathrm{m}^{3} / \mathrm{h}, 100 \mathrm{mbar}, 230 \mathrm{~V}, 50 / 60 \mathrm{~Hz}, 1.1 \mathrm{~A}$ )

Vacuubrand, Wertheim, Deutschland

Vortex-Genie (Typ: G-560E, 230/240 V, 0.5 A, 50Hz)

Schütt Labortechnik, Heidelberg, Deutschland

Wasserbad (Typ: A100, 230V, 50/60Hz, 1.6kW)

Lauda, Lauda-Königshofen, Deutschland

Wasser-Bidestgerät (Typ: Destamat)Heraeus, Hanau, Deutschland

Zentrifuge (Typ: Multifuge 1S-R, kinetische Energie: $34.3 \mathrm{kNm}$, Leistung: $1.52 \mathrm{~kW}$ )

Kendro, Langenselbold, Deutschland 


\section{Labormaterialien}

Combitips plus $(0.5 \mathrm{ml}, 1 \mathrm{ml}, 2.5 \mathrm{ml}, 5 \mathrm{ml}, 10 \mathrm{ml})$

Eppendorf-Netheler GmbH, Hamburg, Deutschland

Desinfektionsspray Braun, Melsungen, Deutschland

EDTA-Monovetten (9ml)

Sarstedt, Nümbrecht, Deutschland

Einmalpipetten (serologisch, 5ml, 10ml, 25ml)

Sarstedt, Nümbrecht, Deutschland

FACS-Rundboden-Falkon (Polystyrol, 5ml)

BD Falkon, Schütt Labortechnik GmbH, Heidelberg,

Deutschland

Gewebekulturplatte (6-Loch, 24-Loch)

Cellstar, Greiner Bio-One, Frickenhausen, Deutschland

Gewebekulturschale (60x15mm, 100x20mm)

Sarstedt, Nümbrecht, Deutschland

Handschuhe (aus Nitril, Typ: Nitra-Tex EP)

Ansell, München, Deutschland

Handschuhe (Peha-soft (puderfrei)) Hartmann, Heidenheim, Deutschland

Kanister (Typ: Behroplast) Behr-Labortechnik, Düsseldorf, Deutschland

Kanülen mit Adapter (Typ: Multifly)

Sarstedt, Nümbrecht, Deutschland

MACS-Multi Stand Miltenyi Biotec, Bergisch Gladbach, Deutschland

MACS-Separationssäulen (MS, LS) Miltenyi Biotec, Bergisch Gladbach, Deutschland

Mini-MACS-Separationseinheit Miltenyi Biotec, Bergisch Gladbach, Deutschland

Neubauer-Zählkammer (0.100MM, 0.0025 mm²)

Optik Labor, Friedrichsdorf, Deutschland

Papiertücher (Typ: Cloths-Quarter Fold Pack/ Wypall X70)

Kimberly-Clark (Professional), Koblenz, Deutschland

Parafilm (10cmx38m)

Pechiney (Plastic Packaging), Chicago, IL, USA

Pasteur-Pipette

Hirschmann EM, Eberstadt, Deutschland

Pipetten (Glas, 5ml, 10ml, 20ml)

Hirschmann EM, Eberstadt, Deutschland

Pipetten (serologisch, 5ml, 10ml)

BD Falkon, Schütt Labortechnik GmbH, Heidelberg,

Deutschland 
Pipettierhilfe (Typ: Pipetboy acu) Integra Bioscience GmbH, Fernwald, Deutschland Pipettierhilfe (Typ: Dispenser Multipette ${ }^{\circledR}$ plus)

Eppendorf-Netheler GmbH, Hamburg, Deutschland

Pipettenspitze $(10 \mu 1,200 \mu 1,1000 \mu 1$ Hubvolumen $)$

Sarstedt, Nümbrecht, Deutschland

Falkon-Ständer

BD Falcon, Schütt Labortechnik GmbH, Heidelberg,

Deutschland und

Eppendorf-Netheler GmbH, Hamburg, Deutschland

Rollenpflaster (Typ: Leukoplast) BSN medical, Hamburg, Deutschland

Schraubflaschen (vierkantig, weithalsig, aus Kalk-Soda-Glas, 100ml, 250ml, 500ml, 1000ml)

Schott Duran, Wertheim/ Main, Deutschland

Stauschlauch Prämeta, Troisdorf, Deutschland

Steril-Filter Steritop $(0.22 \mu \mathrm{m}$, GP Express PLUS Membrane)

Millipore GmbH, Schwalbach, Deutschland

Timer

Oregon Scientific, Neu-Isenburg, Deutschland

Vacutainer CPT/Na-Citrat

Becton Dickinson, Heidelberg, Deutschland

Zentrifugenfalkon $(15 \mathrm{ml}, 50 \mathrm{ml})$

Sarstedt, Nümbrecht, Deutschland

Zentrifugen Falkon (Typ: Safe-Lock Tubes, 1.5ml, 2ml)

Eppendorf-Netheler GmbH, Hamburg, Deutschland

\section{$\underline{\text { Software }}$}

BD-Cell Quest Pro-Software (Version: 348193)

BD Immuncytometry Systems, San Jose, CA, USA

Graph Pad Prism 4-Software Graph Pad Software Inc., CA, USA

Microsoft Office Professional Edition 2003

Microsoft, Deutschland

SDS-Sequence Detection-Software (Version: 1.2, 7500 System SDS Software)

Applied Biosystem, Foster City, CA, USA

Win MDI (Version: 2.8)

Windows Multiple Document Interface

SPSS (Version: 16.0)

SPSS GmbH Software, München, Deutschland 


\subsubsection{Zellseparation der humanen CD56 ${ }^{+}$-Zellen}

Es wurde darauf geachtet, dass die Spender zum Zeitpunkt der Blutentnahme stets infektfrei waren und zuvor keine Medikamente eingenommen hatten. Die CD56 ${ }^{+}$-Zellen wurden aus 10ml EDTA-Blut isoliert unter Zuhilfenahme der Ficoll-Hypaque-Technik für die Separation von mononukleären Zellen (Lymphozyten-Separationsmedium LSM 1077, PAA Laboratories $\mathrm{GmbH}$, Linz, Österreich). Im Anschluss wurde das MACS-Verfahren (Magnetic Activated Cell Sorter) (Miltenyi Biotec, Bergisch Gladbach, Deutschland) entsprechend den Herstellerangaben angewendet (Geiselhart et al. 1996-1997).

Die Ficoll-Hypaque-Isolation stellt eine mögliche Technik für die Seperation von mononukleären Zellen aus Vollblut dar und trennt die Zellen über einen Flüssigkeits-DichteGradienten mit Hilfe eines Mediums aus Ficoll und Natrium-Metrizoat- oder NatriumDiatrizoat-Lösung (Böyum 1968, Fotino et al. 1971, Ting und Morris 1971). Für die Aufreinigung der mononukleären Zellen wurde das antikoagulierte Blut aus einer $10 \mathrm{ml}$ EDTA-Monovette in ein mit 10ml 1xphosphatgepufferter Salzlösung (Phosphate Buffered Saline, $P B S$ ) befülltes 50-ml-Falkon-Röhrchen gegeben. 10ml Trennmedium wurden vorsichtig unter das Gemisch geschichtet. Beim Pipettieren des Blutes wurden stets EinmalPipetten verwendet. Das Gemisch wurde für 20min bei 1600rpm (rounds per minute, Umdrehungen pro Minute) und $20^{\circ} \mathrm{C}$ zentrifugiert, wobei zur besseren Schichtausbildung die Zentrifugenbremse ausgestellt wurde. Der hohe Zuckergehalt des Trennmediums bewirkte das Absetzen der Erythrozyten, da diese aufgrund der eisenhaltigen Häm-Gruppe schwerer sind als die anderen Blutzellen. Die obere, gelbe Schicht setzte sich aus dem Blutplasma zusammen, die zur Hälfte verworfen wurde, gefolgt von einer grauen Interphase, in der sich die mononukleären Zellen befanden. Darunter bildete das Trennmedium eine milchig, weiße Phase aus, unter der sich die rot-schwarze Schicht der Erythrozyten befand. Bei genauerer Betrachtung konnte man direkt auf der Erythrozytenschicht eine weitere, sehr dünne, weißgraue Schicht erkennen, die die Granulozyten enthielt. Die Schicht der mononukleären Zellen wurde mit einer $5 \mathrm{ml}$ Einmal-Pipette vorsichtig und möglichst ohne das zytotoxische Ficoll abgetragen und in ein 50-ml-Falkon-Röhrchen überführt. Im Anschluss an zwei Reinigungsschritte wurde die Zellsuspension auf $2 \times 10^{6}$ Zellen pro Milliliter RPMI (Roswell Park Memorial Institut) 1640/10\% FCS (Fresh Calf Serum, frisches Kälberserum)-Medium verdünnt und auf Eis beziehungsweise in Gewebekulturplatten (24-Loch, 1x10 ${ }^{6}$ Zellen pro Loch) im $\mathrm{CO}_{2}$ - Brutschrank gelagert. Als Variation wurde $15 \mathrm{ml}$ steriles $1 \mathrm{x} P B S$ mit frischem Blut aus zwei EDTA-Monovetten vermischt und mit 12ml Lymphozytenseperationsmedium unterschichtet.

Zur Trennung der Zellen für die Quantifizierung der ABCB1- und ABCG2-mRNA- Expression wurden die BD-Vacutainer-CPT-Zellpräperation-Falkons mit Natriumcitrat verwendet. Diese kombinieren ein Blut-Sammel- Falkon, das Citrat als Antikoagulanz enthält, mit einem FicollHypaque-Medium, dass durch eine Polyester-Gel-Barriere separiert wird. Nach der Blutentnahme in das Falkon wurde dieses innerhalb von zwei Stunden entsprechend den Herstellerangaben zentrifugiert und aufgearbeitet. 
Zur Isolation der $A B C B 1$ - und $A B C G 2$-hochexpremierenden $C D 56^{+}$-Zellen wurde das $M A C S$ Verfahren (Magnetic activated cell sorter) entsprechend den Herstellerangaben angewendet. $10^{7}$ mononukleären Zellen wurden in $1 \mathrm{ml}$ MACS-Puffer gereinigt. Nach dem Verwerfen des Überstandes wurde das Zellplättchen in 1-2ml MACS-Puffer resuspendiert und erneut für $10 \mathrm{~min}$ bei 300xg (Erdanziehungskraft) und $4^{\circ} \mathrm{C}$ zentrifugiert. Je $10^{7}$ Zellen wurden in $80 \mu 1$ MACS-Puffer resuspendiert und mit $20 \mu 1$ Micro-beads für $15 \mathrm{~min}$ bei $4^{\circ} \mathrm{C}$ im Dunkeln inkubiert. Nach zwei Reinigungsschritten in 1-2ml MACS-Puffer für $10^{7}$ Zellen und einer erneuten Zentrifugation $\left(300 \mathrm{xg}, 10 \mathrm{~min}, 4^{\circ} \mathrm{C}\right.$ ) wurden $10^{7}$ Zellen in 500 $\mu 1$ MACS-Puffer resuspendiert. Zwischenzeitlich wurde das MACS-Multi Stand mit Magnet und Säule

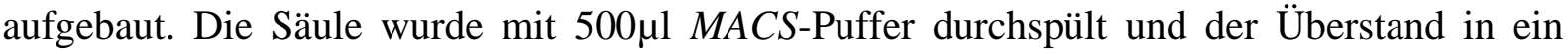
darunter befindliches 50-ml-Falkon-Röhrchen aufgefangen. Im Anschluss wurde die Zellsuspension auf die Säulen pipettiert, wobei die mit Micro-beads-markierten Zellen in der

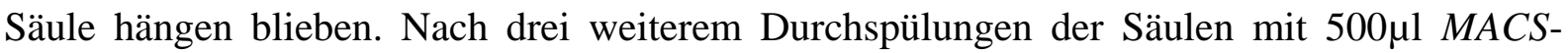
Puffer wurde diese von der Wand entfernt und in ein 15-ml-Falkon-Röhrchen gestellt. Mit $1000 \mu 1$ Puffer und unter zur Hilfenahme des Stopfens wurden die Zellen heruasgespült. Die Zellsuspension wurde auf $2 \times 10^{6}$ Zellen pro Milliliter RPMI/10\% FCS-Medium verdünnt und auf Eis beziehungsweise in einer Gewebekulturplatte im $\mathrm{CO}_{2}$-Brutschrank gelagert (24-LochGewebekulturplatten, $1 \times 10^{6}$ Zellen pro Loch). Es wurde darauf geachtet, dass die verwendeten Lösungen auf $4^{\circ} \mathrm{C}$ vorgekühlt waren, die Zellen zwischenzeitlich möglichst auf Eis gelagert wurden und schnell gearbeitet wurden um unspezifische Zellbindungen zu vermeiden.

Zum Nachweis der erfolgreichen magnetischen Zelltrennung diente die durchflusszytometrisch-ermittelte Reinheitskontrolle. Hierfür wurde zur Bestimmung des Fluoreszenzspektrums der Zellen eine Probe mit $1 \times 10^{6}$ (x=multipliziert mit) Zellen in $250 \mu 1$ FACS-Puffer mit dem Durchflusszytometer analysiert (Negativprobe). Gemessen wurde dies im Kanal des FSCs gegen das Phycoerythrin (PE, FL-2), dem vom Hersteller verwendeten Fluoreszenz-Farbstoff des Antikörpers (Abbildung 1). Die gleiche Zellzahl wurde zusätzlich mit der entsprechend vom Hersteller angegebenen Menge monoklonalem Immunglobulin GIsotypkontrolle des Antikörpers markiert. Es diente zum Ausschluss der unspezifischen Bindungen des Antikörpers. Als Resultat konnte ein Quadrant festgelegt werden, der die gewünschte Zellpopulation beinhaltete. Eine dritte Probe wurde mit dem Fluoreszenzmarkiertem monoklonalen Antikörper Maus-anti-human CD56 ${ }^{+}$markiert. Damit konnte die $\mathrm{zu}$ ermittelnde Zellpopulation und entsprechend die Reinheit des MACS-Verfahrens dargestellt werden.

Für die Markierung wurden 2 bis $10 \times 10^{5}$ Zellen in ein FACS-Rundbodenfalkon-Röhrchen überführt und in FACS-Puffer (1xPBS), 0.1\% bovines Serumalbumin, 0.1\% Natriumazid) gereinigt (siehe nächster Abschnitt). Die $P B S$-Lösung wurde zuvor zehnfach konzentriert angesetzt und entsprechend vor dem Gebrauch verdünnt. Sie enthielt eine Mischung aus 400g Natriumchlorid $(\mathrm{NaCl}), 10 \mathrm{~g}$ Kaliumchlorid $(\mathrm{KaCl}), 71 \mathrm{~g}$ Dinatriumhydrogenphosphat $\left(\mathrm{Na}_{2} \mathrm{HPO}_{4}\right)$ und $69 \mathrm{~g}$ Natriumdihydrogenphosphat $\left(\mathrm{NaH}_{2} \mathrm{PO}_{4} \mathrm{xH}_{2} \mathrm{O}\right)$, die auf $5000 \mathrm{ml}$ mit 
bidestilliertem Wasser $\left(\mathrm{H}_{2} \mathrm{O}\right)$ aufgefüllt wurde (pH-Wert 6.7). Nach der Reinigung wurde der zelluläre Überstand in $100 \mu 1$ FACS-Puffer resuspendiert und mit $10 \mu 1$ des Fluoreszenzmarkiertem monoklonalen Antikörpers Maus-anti-human $\mathrm{CD}^{+} 6^{+}$(PE-konjugiert, Klon B159, Maus Immunglobulin G1 kappa, Becton Dickinson PharMingen, Becton Dickinson Bioscience Pharmingen, San Diego, CA, USA) beziehungsweise der monoklonalen Immunglobulin G-Isotypkontrolle (Phycoerythrin-konjugiert, Klon MOPC-21, Maus Immunglobulin G1 kappa, Becton Dickinson PharMingen, Becton Dickinson Bioscience Pharmingen, San Diego, CA, USA) des Antikörpers für 30min bei $4^{\circ} \mathrm{C}$ im Dunkeln inkubiert. Die Herangehensweise beruhte auf Empfehlungen des Herstellers. Danach folgten zwei Reinigungsschritte, bei denen die Zellen in einem FACS-Rundbodenfalkon-Röhrchen mit 4ml FACS-Puffer gewaschen wurden. Im Anschluss wurden die Zellen in 250 $\mu 1$ FACS-Puffer resuspendiert.

Die Reinigung beziehungsweise das Waschen von Zellen erfolgte folgendermaßen: Die Zellen wurden in ein 50-ml-Falkon-Röhrchen überführt und mit entsprechendem Medium aufgefüllt. Anschließend wurden die Falkon-Röhrchen für $8 \mathrm{~min}$ bei $4^{\circ} \mathrm{C}$ und 1200 Umdrehungen pro Minute zentrifugiert. Der Überstand wurde verworfen und das FalkonRöhrchen auf einem Papiertuch abgetropft. Der auf dem Boden des Falkon-Röhrchens befindliche zelluläre Überstand wurde erneut durch Auf- und Abpipettieren beziehungsweise durch Vortexen in 50ml Medium resuspendiert und der Vorgang einmal wiederholt.

Bei allen Zwischenschritten wurden die Proben auf Eis und im Dunkeln gelagert. Die Messung erfolgte am Becton Dickinson FACS Calibur mit einer Mindestzellzahl von 5000 Ereignissen unter Ausschluss von Zelltrümmern im Vorwärts- und Seitwärtsstreulicht. Die Auswertung erfolgte über die Software WinMDI (Microsoft) oder Cell-Quest-Pro (Becton Dickinson). 
Die CD56 ${ }^{+}$-Zellen wurden unter Verwendung der Ficoll-Hypaque- und der MACS-Technik aus EDTA-Blut gewonnen. Die Reinheitskontrolle erfolgte mittels FACS-Messung. Die Negativprobe zeigt die unmarkierten Zellen. Mit Hilfe der Markierung mit der entsprechenden monoklonalen Immunglobulin G-Isotypkontrolle des Antikörpers konnten unspezifische Bindungen ausgeschlossen werden und ein Quadrant festgelegt werden, in dem sich ausschließlich die gesuchte Zellpopulation der $\mathrm{CD}_{56}{ }^{+}$-positiven Zellen befanden.

Die Darstellung erfolgte im Kanal des Vorwärtsstreulichts (FSC, Abszisse) und der Fluoreszenzfarbe des Antikörpers (Phycoerythrin, FL2, Ordinate). In den Quadranten ist der prozentuale Anteil der einzelnen Zellen dargestellt. Im vorliegenden Beispiel enthält die gewonnene Zellpopulation einen Anteil von 98.2\% CD56 ${ }^{+}$ Zellen.
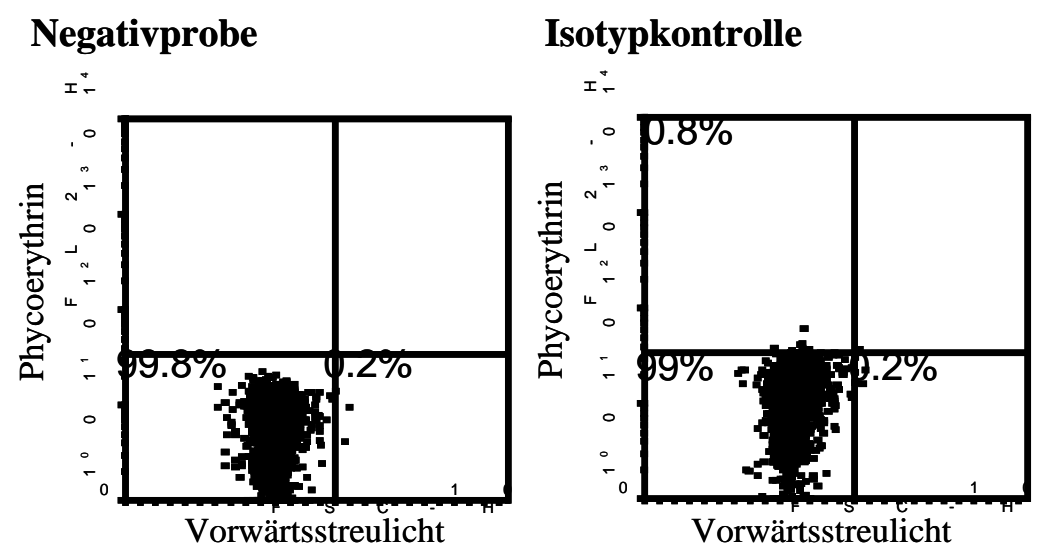

Vorwärtsstreulicht

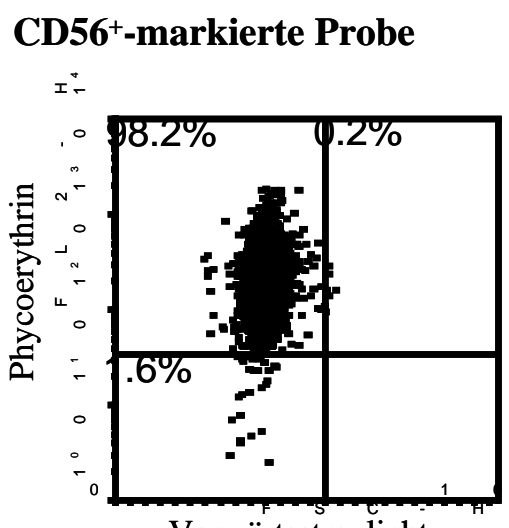

Vorwärtsstreulicht

\subsubsection{Mitoxantron-Efflux-Assay}

Nach der Aufreinigung der Zellen wurde der MX-Efflux-/-Zelltod-Assay durchgeführt. Dieser basierte auf der Modifikation vorbeschriebener Protokolle (Hitzl et al. 2001) und erfolgte in der Gegenwart/Abwesenheit von spezifischen $A B C$-Transporter-Inhibitoren in etablierten Konzentrationen (Tabelle 2).

Es wurden 600000 Zellen (2 000000 Zellen pro 1ml RPMI 1640/10\% FCS-Medium) mit/ohne Inhibitorlösung in 15-ml-Falkon-Röhrchen für $15 \mathrm{~min}$ im Brutschrank bei $37^{\circ} \mathrm{C}$ und $5 \% \mathrm{CO}_{2}$ präinkubiert. Anschließend wurde die $1 \mu \mathrm{M}$ MX-Lösung (Gry Pharma, Kirchzarten, Deutschland) zugegeben und eine erneute Inkubation für $30 \mathrm{~min}$ bei $37^{\circ} \mathrm{C}$ und $5 \% \mathrm{CO}_{2}$ durchgeführt. Die MX-Konzentration korrespondiert mit der Serumkonzentration nach intravenöser Administration von $12 \mathrm{mg} / \mathrm{m}^{2}$ Körperoberfläche (KOF) (Hu et al. 1992).

Für den anschließenden MX-Efflux wurden die Zellen gereinigt wie vorhergehend beschrieben. Dann erfolgte die Resuspensation in $4 \mathrm{ml}$, bei $37^{\circ} \mathrm{C}$ vorgewärmtem Medium RPMI 1640/10\% FCS entsprechend mit/ohne Inhibitor. Das Gemisch wurde in 6-LochGewebekulturplatten überführt, um für weitere $10 \mathrm{~min}$ inkubiert $\left(37^{\circ} \mathrm{C} / 5 \% \mathrm{CO}_{2}\right) \mathrm{zu}$ werden. 
Ebenfalls wurde der Effekt von GSs (Methylprednisolon (MP), Sanofi-Aventis, Frankfurt, Deutschland; Dexamethason (DEX), Ratiopharm GmbH, Ulm, Deutschland) auf die MX-

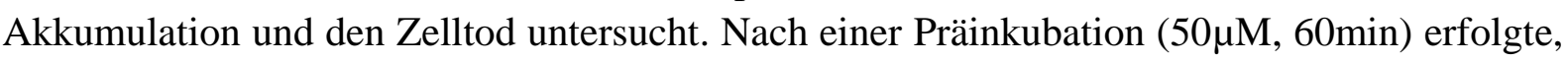
der oben beschriebene MX-Efflux in Gegenwart des entsprechenden GS (abgewandelt nach Pavek et al. 2005).

Nach einem Waschvorgang wurden mit Hilfe der Propidiumiodid-Färbung (PI, $0.1 \mu \mathrm{g} / \mathrm{ml}$, Sigma-Aldrich, Steinheim, Deutschland) Zellen mit einer beschädigten Plasmamembranintegrität ausgeschlossen (typischerweise <1.6\%). Die Markierung erfolgte entsprechend den Herstellerangaben. Hierfür wurden 2 bis $10 \times 10^{5}$ Zellen in ein FACSRundbodenfalkon-Röhrchen überführt und mit $1 \mathrm{x} P B S$ gereinigt. Der nach der Zentrifugation

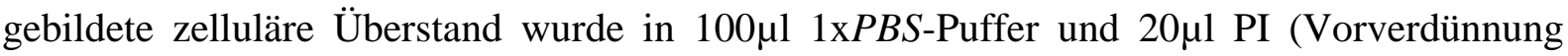
$50 \mu \mathrm{g} / \mathrm{ml}$ ) resuspendiert und für 10min auf Eis und unter Lichtausschluss inkubiert. Danach wurden die Zellen erneut zentrifugiert, mit $1 \times P B S$ gereinigt und in $250 \mu 1 \mathrm{x} P B S$ resuspendiert. Ein Minimum von 5000 PI-negativen Zellen wurde durchflusszytometrisch (FACSCalibur/Cell Quest-Software, Becton Dickinson) analysiert.

\subsubsection{Mitoxantron-Zelltod-Assay}

Die Analyse des Zelltods basiert auf dem MX-Efflux-Assay. Zu Beginn erfolgte die Präinkubation von 600000 Zellen in RPMI 1640/10\% FCS mit/ohne Inhibitorlösung für $15 \mathrm{~min}, 37^{\circ} \mathrm{C} / 5 \% \quad \mathrm{CO}_{2}$ mit der sich anschließenden Zugabe der $1 \mu \mathrm{M}$ MX-Lösung. Nun erfolgte wahlweise eine Inkubation der Zellen mit MX für 30 ( $\mathrm{n}=6$ Individuen) beziehungsweise $60 \mathrm{~min}(\mathrm{n}=4)$ bei $37^{\circ} \mathrm{C} / 5 \% \quad \mathrm{CO}_{2}$. Dann wurden die Proben über Nacht mit/ohne Inhibitorlösung in $4 \mathrm{ml}$ RPMI $1640 / 10 \% \quad\left(37^{\circ} \mathrm{C} / 5 \% \quad \mathrm{CO}_{2}\right)$ in 6-LochGewebekulturplatten inkubiert.

Die Bestimmung der Anzahl früh-apoptotischer Zellen erfolgte mittels einer Fluoresceinisothiocyanat (FITC)-markierten Annexin-V-Färbung (Roche Biochemicals, Mannheim, Deutschland). Eine simultane DNS-Markierung mit PI, das nicht Zellmembranpermeabel ist, trennte früh-apoptotische von spät-apoptotischen und früh-nekrotischen Zellen (Vermes et al. 1995).

Die Markierung erfolgte entsprechend den Herstellerangaben. Es wurden 2 bis 10x10 Zellen in ein FACS-Rundbodenfalkon-Röhrchen überführt und mit Annexin-V-Puffer gereinigt. Der Annexin-V-Puffer setzte sich aus 1ml 1M HEPES Natriumhydroxid ( $\mathrm{NaOH})(\mathrm{pH}-$ Wert 7.4), $10 \mathrm{ml} 1.4 \mathrm{M}$ Natriumchlorid $(\mathrm{NaCl})$ und $0.5 \mathrm{ml} 1 \mathrm{M}$ Calciumchlorid $\left(\mathrm{CaCl}_{2}\right)$ zusammen, das auf $100 \mathrm{ml}$ mit bidestilliertem Wasser aufgefüllt wurde. Der nach der Zentrifugation entstandene zelluläre Überstand wurde anschließend in 100 $\mu 1$ Annevin-V-Bindungspuffer, 2.5 $\mu 1$ AnnexinV-FITC und $20 \mu 1$ PI (Vorverdünnung $50 \mu \mathrm{g} / \mathrm{ml}$ ) resuspendiert und für 10min auf Eis und unter Lichtausschluss inkubiert. Nun wurden die Zellen erneut zentrifugiert, mit Annexin-V- 
Bindungspuffer gereinigt und in $250 \mu \mathrm{l}$ Annexin-V-Bindungspuffer resuspendiert. Anschließend erfolgte die FACS-Messung.

\subsection{In-vivo-Analyse: Induktion der experimentellen autoimmunen Enzephalomyelitis, Mitoxantron-Behandlung und Histologie}

Die Tierexperimente als in-vivo-Analyse wurden zuvor durch die Tierschutzbeauftragten der Medizinischen Fakultät Göttingen und dem Herrn Regierungspräsidenten von Braunschweig geprüft und genehmigt. Die Abcg2-Knock-Out-Tiere wurden zum C57BL/6-Hintergrund zurückgekreuzt und die entsprechenden Geschwister-Kontrollmäuse (littermates) von Harlan (Borchen, Deutschland) erworben.

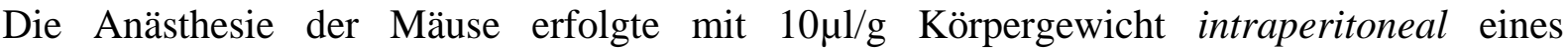
Gemisches aus 2ml Ketamin, 500 $\mu \mathrm{l}$ Xylazin/Rompun und 10ml Natriumchlorid. Zur Initiierung der EAE wurden sie immunisiert mit einer subkutanen Injektion rechts und links des Schwanzes von je 50 $\mathrm{g}$ einer Mischung aus Myelin-Oligodendrozyten-Glykoprotein-, $\mathrm{MOG}_{35-55}$-Peptid und kompletten Freund Adjuvanz. Zusätzlich erhielten die Tiere an Tag null und zwei 200ng Pertussistoxin intraperitoneal (List Biological Laboratories, Campbell, CA, USA). Sie wurden täglich verblindet gewogen und nach ihrem klinischen Verlauf beurteilt. Die Schwere der Erkrankung wurde anhand einer Skala untersucht, die von 0 bis 10 reicht (Hartung et al. 1988): 0, gesund; 1, reduzierter Tonus der Schwanzspitze; 2, schlaffer Schwanz; 3, Gangataxie, wackelnder Gang; 4, Stand- und Gangataxie; 5, Parese eines Beines bis leichte Paraparese; 6, mittelschwere Paraparese oder Plegie eines Hinterbeines; 7, schwere Paraparese oder Paraplegie; 8, Tetraparese, Bewegung nur schleichend; 9, schwere Tetraparese, morbibund; 10, tot. Bei Krankheitsbeginn an Tag zwölf bis 14 und an Tag 16 wurde MX injiziert (0.5mg/kg Körpergewicht). Die Rückenmarkquerschnitte der an Tag 23 oder 29 perfundierten Mäuse wurden mit Luxol fast blue gefärbt. Mit Hilfe der Image Processing Software und einem Olympus-Mikroskop wurden die demyelinisierenden Areale als prozentualer Anteil von der gesamten weißen Substanz berechnet.

\subsection{Retrospektive klinische Korrelation funktionell-relevanter Einzelbasenaustausche in $A B C$-Transportern mit der therapeutischen Mitoxantron-Ansprechrate}

Die retrospektive, klinische Analyse der MX-Ansprechrate wurde von verschiedenen Untersuchern durchgeführt und verblindet ausgewertet. Patientenproben wurden genotypisiert für $A B C B 1-2677 \mathrm{G}>\mathrm{T},-3435 \mathrm{C}>\mathrm{T}$ und $A B C G 2-\mathrm{V} 12 \mathrm{M},-\mathrm{Q} 141 \mathrm{~K}$ und anschließend mit den klinischen Daten korreliert.

Bei allen Patienten wurde eine gesicherte MS diagnostiziert entsprechend den Poser- oder McDonald-Kriterien (McDonald et al. 2001, Poser et al. 1983). Es wurden Patienten mit einem schubförmigen, einem sekundär progredienten oder einem atypischen Krankheitsverlauf (Neuromyelitis optica/Devic-Syndrom, $n=1$ ) sowie eine mögliche MS (nach den Poser-Kriterien) eingeschlossen. Die Behandlung erfolgte nach etablierten 
Protokollen, wobei $85.1 \%$ des Gesamtkollektivs und alle nach der Ansprechrate analysierten MX-Monotherapie Patienten die MX-Zyklen dreimonatlich erhielten. Die restlichen 14.9\% wurden mit einer initial dreimaligen monatlichen Behandlung therapiert, gefolgt von drei Monaten Therapieabstand. (Edan et al. 1997, Hartung et al. 2002) Patienten mit einer primär progredienten MS (PPMS) wurden aufgrund eines unterschiedlichen Pathomechanismus, der der Erkrankung zugrunde liegt, sowie fehlender Daten zur therapeutischen Effektivität von MX von der Analyse ausgeschlossen (Stüve et al. 2004).

155 Patienten (Göttingen $n=11$, Rostock $n=37$, Berg $n=107$ ) wurden mit einer MXMonotherapie intravenös $\left(5-12 \mathrm{mg} / \mathrm{m}^{2} \mathrm{KOF}\right)$ in drei-monatlichen Abständen entsprechend des MIMS (Mitoxantron in Multipler Sklerose)-Protokolls behandelt (Hartung et al. 2002). In dieser Kohorte wurde eine GS-Puls Therapie lediglich während der Exazerbationen verabreicht. Weitere 154 Patienten erhielten eine MX/GS-Kombinationstherapie (Göttingen/Rostock n=57, Barcelona $n=46$, Berg $n=51$, MX/GS). Die deutschen MX/GSPatienten wurden mit drei-monatlichen MX-Zyklen in Kombination mit einer drei- bis fünftägigen Behandlung mit 1g MP intravenös therapiert. Die spanischen MX/GS-Patienten erhielten im Gegensatz 4mg DEX intravenös gefolgt von den MX-Infusionen. Die ersten drei MX-Zyklen wurden in dieser Kohorte monatlich verabreicht und alle weiteren in drei Monatsintervallen. Die Entscheidung für die MX/GS-Kombination erfolgte aus klinischen Gründen, wie zum Beispiel kontinuierlicher klinischer Aktivität trotz bestehender MXTherapie oder besserer Tolerabilität.

Die klinische Analyse nach der Ansprechrate auf MX entsprechend in Responder oder NonResponder wurde mit Hilfe von quantitativen Skalen als Einteilungskriterien durchgeführt (Tabelle 3): Expanded Disability Status Score (EDSS)-Stabilität/Verbesserung (im Fall von Therapieversagen wurde die EDSS-Verschlechterung um einen Punkt $(E D S S<6.0)$ beziehungsweise um 0.5 Punkte $(E D S S \geq 6.0$ ) gewertet; $\mathrm{n}=165$ bestätigt an mindestens zwei verschieden Zeitpunkten mit einem Mindestabstand von drei Monaten), Verbesserung der Schubrate, Stabilität/Verbesserung der Multiple Sclerosis Functional Composite (MSFC)Skala, magnetresonanztomografischer Aktivität (MRT, Gadolinium-Aufnahme) und einer ärztlichen Einschätzung der Krankheitsprogression. Bei 63 Patienten dienten zusätzlich motorisch-evozierte Potentiale als Bestätigung der Einteilung nach der Therapie-Ansprechrate (Untersuchung der zentralen motorischen Leitungszeit, Amplitude und Konfiguration). Mindestens 150 der 309 Patienten erfüllten für die Klassifikation mehr als eines der genannten Kriterien. Die Einteilung erfolgte größtenteils nach zwölf Monaten $189.3 \%$ der Patienten). Wenn zu diesem Zeitpunkt ausreichende klinische Daten fehlten, wurden sie nach neun Monaten Therapie (10\%) erhoben. Für weitere $0.7 \%$ wurde die Ansprechrate am Therapieende ermittelt (21-24 Monate). 
Tabelle 3: $\quad$ Übersicht der Einteilungskriterien

Einteilungskriterien mit deren Hilfe Multiple-Sklerose-Patienten nach der Mitoxantron-Ansprechrate klassifiziert wurden (n=309) und entsprechende Patientenanzahl, für die dieses Merkmal herangezogen wurde.

\begin{tabular}{|l|l|}
\hline Einteilungskriterium & Patientenanzahl \\
\hline EDSS & 294 \\
\hline Schubrate & 110 \\
\hline MSFC-Skala & 10 \\
\hline MRT-Aktivität & 15 \\
\hline Krankheitsprogression & 157 \\
\hline motorisch-evozierte Potentiale & 63 \\
\hline
\end{tabular}

Eine separate Gruppe von Patienten mit schwerwiegenden kardiologischen $(n=28$, echokardiographisch dargestellte linksventrikuläre Dysfunktion, kongestive Herzinsuffizienz, mediane kumulative MX-Dosis $72 \mathrm{mg} / \mathrm{m}^{2}$ ) oder hämatologischen Nebenwirkungen ( $\mathrm{n}=8$, therapieassoziierte Leukämie, Agranulozytose, mediane kumulative MX-Dosis $72 \mathrm{mg} / \mathrm{m}^{2}$ ) wurde ebenfalls retrospektiv mit dem $A B C$-Transporter-Genotyp korreliert. Proben von zehn dieser Patienten mit einer MX-assoziierten Kardiotoxizität wurden separat von einem Berliner Zentrum bereitgestellt (NeuroCure Clinical Research Center, Charité-Universitätsmedizin Berlin, Berlin, Deutschland).

\subsection{Statistische Auswertung}

Die beschreibende Statistik wurde als Median und entsprechendes 25. und 75. Perzentil dargestellt. Die entsprechenden Daten wurden unter Verwendung des exakten Wilcoxon-Tests verglichen. Die Analyse der in-vitro-Apoptose-Raten erfolgte mit Hilfe der einseitigen Varianzanalyse unter Verwendung des post-hoc-Student-Newman-Keuls-Test für Gruppierungen. Die p-Werte wurden zweiseitig dargestellt.

Kreuztabellen der Forschungsdaten führten oft zu Zellen mit einer erwarteten Frequenz von kleiner als fünf. Dafür wurde die exakte Inferenzstatistik verwendet. Das war der exakte Fisher 's-Test für die 2x2-Fälle, der Fisher-Freeman-Halton-Test für die $2 \times 3$-Fälle und der exakte Cochran-Armitage-Test für Trends der Genotypeinteilung in dem zusätzlichen Modell $0-1-2$.

Die exakte Statistik wurde unter Zuhilfenahme von SPSS 16 für Windows berechnet. Das exakte Quotenverhältnis/Odds Ratio für die Assoziation zwischen Responder/Non-Responder und der Genetic Burden Score für den Vergleich unterschiedlicher ABCB1/ABCG2-Genotyp- 
Konstellationen wurde in R 2.9.0 unter Verwendung des Elrm Package (Zamar et al. 2007) mit einer Markov Chain Size von $2.5 \mathrm{e} 6$ berechnet.

Der Cochran-Armitage-Test wurde mit einseitigen p-Werten berechnet, da nur eine Richtung des Trends von Interesse war und die Plausibilität aus den in-vitro- und EAE-in-vivoErgebnissen resultierte (Zheng et al. 2003, Zheng 2008).

Die Inhibition des MX-Effluxes durch GSs wurde unter Verwendung der KolmogorovSmirnov-Statistik D getestet (Leith et al. 1999). Um Unterschiede im EAE-Kurs durch den Mann-Whitney $U$-Test zu bestimmen, wurde die Analyse vom Einsetzen der Erkrankung bis zum Ende der Beobachtung anstatt von individuellen Zeitpunkten durchgeführt. 


\section{Ergebnisse und Diskussion}

\subsection{ABCB1- und ABCG2-Transporter sind hoch polymorph in Multiple-Sklerose- Populationen aus zentral-europäischer Abstammung ohne große Unterschiede im Vergleich zu gesunden Spendern}

Bei der Genotypisierung haben wir uns auf die prominentesten SNPs der ABCB1- und ABCG2-Transporter konzentriert, die in vorherigen Prüfungen funktionellen Einfluss auf den MX-Transport zeigten (Gottesman et al. 2002, Schinkel und Jonker 2003). Den am besten validierten Effekt auf die Medikamenten-Disposition hat die ABCB1-3435C>T-Mutation. Sie ist assoziiert mit der Transporter-Funktion und deren Expressionshöhe im Duodenum (Hoffmeyer et al. 2000, Sakaeda et al. 2003). Der genaue Wirkmechanismus ist jedoch unklar, da es sich um eine intronische Mutation handelt. Die 2677G $>\mathrm{T} A B C B 1$-Mutation, die zu einem Aminosäure-Austausch führt, ist im funktionellen Vergleich weniger relevant (Kerb 2006, Schwab et al. 2003). Es wird jedoch eine klinische Bedeutung vermutet, da sie die ATPase-Aktivität und Substratspezifität verschiedener Medikamente beeinflusst (Sakurai et al.2007). Von sechs untersuchten ABCG2-SNPs (V12M, Q141K, Q126*, E334*, R482G, R482T) konnten lediglich zwei Polymorphismen in unserer MS-Population detektiert werden. Der SNP V12M führt zu einer veränderten apikalen Plasmamembranlokalisation im ABCG2Transporter und Q141K zu einer erniedrigten ATPase-Aktivität (Bosch et al. 2005, Mizuarai et al. 2004).

Die klinischen Basischarakteristika der MS-Patienten und der gesunden Kontrollen sind in Tabelle 4 sowie in Tabelle $1 \mathrm{im}$ Teil B aufgeführt. Bei den Kontrollen handelt es sich vor allem um gut voruntersuchte Blutspender. Sie wurden nicht in Geschlecht und Alter übereinstimmend mit den MS-Patienten selektiert und gesammelt, deshalb sind sie jünger als die untersuchten MS-Patienten. 
Tabelle 4: Zusammenfassung der klinischen Charakteristika der ABCB1- und ABCG2-genotypisierten Multiple-Sklerose-Kohorte (Barcelona, Berg, Göttingen, Rostock) und des Kontrollkollektivs (Bochum, Göttingen)

$m$ steht für männlich, $w$ für weiblich. ' unter Berücksichtigung eines transsexuellen Patienten (weiblich zu männlich). Erstmanifestation fehlend für $n=54$ Patienten, Erstdiagnose fehlend für $n=198$. Die atypischen Fälle $(n=6)$ sind Patienten mit einer Neuromyelitis optica/Devic-Syndrom. Der Krankheitsverlauf fehlt von einem Patienten (Göttingen)

\begin{tabular}{|l|l|l|}
\hline & Multiple-Sklerose-Patienten & Kontrollpersonen \\
\hline Geschlecht, Anzahl (\%) & $\mathrm{m}: 268(32.2)$, & m: $152(57.6)$, \\
\hline Alter, Median (25\%-75\% Perzentile) & $\mathrm{w}^{1}: 564(67.8)$ & w: $112(42.4)$ \\
\hline Erstmanifestation, Median (25\%-75\% Perzentile) & $31(24-39)$ & $38(30-46)$ \\
Erstdiagnose, Median (25\%-75\% Perzentile) & $34(27-42)$ & \\
\hline Verlaufsform, Anzahl (\%) & $45(38-52)$ & \\
Schubförmig wiederkehrend & $423(50.8)$ & \\
Sekundär progredient & $346(41.6)$ & \\
Primär progredient & $56(6.7)$ & \\
Atypisch & $6(0.7)$ & 264 \\
\hline Gesamt & 832 & \\
\hline
\end{tabular}

Wie in Abbildung 2A im Teil $\mathrm{B}$ dargestellt, wurde der $A B C$-Transporter-vermittelte MXEfflux in MS-Patienten mit wildtypischen ABCB1/ABCG2-Allelen (ABCB1-2677GG, 3435CC, $A B C G 2-12 \mathrm{VV},-141 \mathrm{QQ})$ mit einem MS-Patienten, Träger für Allelvarianten in beiden Genen (ABCB1-2677TT, -3435TT, ABCG2-12VM, 141QQ) verglichen. Die Zellen mit den wildtypischen Sequenzen zeigten unter Verwendung des dualen $A B C B 1-/ A B C G 2$ Inhibitors Elacridar einen höheren MX-Efflux als der letztere Genotyp. Der wildtypische Genotyp wurde deshalb als $A B C B 1 / A B C G 2-\mathbf{H}$ (igh Efflux) bezeichnet, während der Genotyp mit heterozygot oder homozygot mutierten Allelvarianten in beiden Genen, $A B C B 1 / A B C G 2$ L(ow Efflux) genannt wurde (Tabelle 5). 
Tabelle 5: $\quad$ Überblick zur Nomenklatur der Allelkombinationen resultierend aus dem in-vitro-Mitoxantronund Zelltod-Assay und damit der funktionellen Transporteraktivität

\begin{tabular}{|l|l|l|l|}
\hline Genotyp & Allele & Transporterfunktion & Bezeichnung \\
\hline SNPs & $A B C B 1-2677 \mathrm{GG},-3435 \mathrm{CC}$, & hoch/ & $A B C B 1 / A B C G 2-\mathbf{H}$ \\
in $A B C B 1$ und $A B C G 2$ & $A B C G 2-12 \mathrm{VV},-141 \mathrm{QQ}$ & high Efflux & \\
\hline SNPs & & intermediär/ & $A B C B 1 / A B C G 2-\mathbf{I}$ \\
entweder in $A B C B 1$ oder $A B C G 2$ & & intermediate Efflux & \\
\hline keine $S N P s$ & $A B C B 1-2677 \mathrm{TT},-3435 \mathrm{TT}$, & niedrig/ & $A B C B 1 / A B C G 2-\mathbf{L}$ \\
in $A B C B 1$ und $A B C G 2$ & $A B C G 2-12 \mathrm{VM},-141 \mathrm{QQ}$ & low Efflux & \\
\hline
\end{tabular}

Lediglich $14.8 \%$ der MS-Patienten zeigten $A B C B 1 / A B C G 2-\mathbf{L}-A$ llele in beiden Transportern ( $A B C B 1-2677 \mathrm{GG},-3435 \mathrm{CC}, A B C G 2-12 \mathrm{VV},-141 \mathrm{QQ}$ ) (Tabelle 2, Teil B: Publikation). 22.2\% waren heterozygot oder homozygot mutiert für die Kombination von Allelvarianten in $A B C B 1$ und $A B C G 2$ ( $A B C B 1 / A B C G 2-\mathrm{I}, A B C B 1-2677 \mathrm{TT},-3435 \mathrm{TT}, A B C G 2-12 \mathrm{VM}, 141 \mathrm{QQ})$ und schließlich $63.1 \%$ der Fälle in entweder $A B C B 1$ oder $A B C G 2$ ( $A B C B 1 / A B C G 2-\mathbf{H})$.

Zwischen MS-Patienten und gesunden Kontrollen wurden für die Allelfrequenzen $A B C B 1$ $3435 \mathrm{C}>\mathrm{T}$ und $-2677 \mathrm{G}>\mathrm{T}$ keine Unterschiede detektiert. Für die SNPs des ABCG2Transporters war die Häufigkeit der verschiedenen Allele im V12-Kodon mit $0.03 \%$ bei den MS-Patienten und $0.05 \%$ bei den gesunden Spendern sehr niedrig $(p=0.023)$. Dieser Unterschied kann am besten durch die hohe Varianz erklärt werden, die bei dem selten vorkommenden Allel in dem kleinen untersuchten Kollektiv zu erwarten ist. Es wurden keine gegensätzlichen Genotypfrequenzen für Q141K entdeckt.

Auch im Vergleich der Allelfrequenzen der MS-Kohorte und dem gesunden Kontrollkollektiv mit der HapMap-CEU-Population (Das Internationale HapMap-Konsortium 2007) zeigten sich keine Abweichungen. Die Genotypverteilung der unselektierten MS-Kohorte (Göttingen, Rostock) stimmte mit der MX-behandelten MS-Kohorte (Barcelona, Berg) überein.

Es wurde ein hoher Grad des Linkage Disequilibriums zwischen ABCG2-V12M und -Q141K (Linkage Disequilibrium=0.854) detektiert, was definitionsgemäß auf eine häufige Kombination der beiden SNPs hinweist. Die Ursache könnte sowohl in der gemeinsamen Geschichte der Mutationen und der Rekombinationen $\mathrm{zu}$ finden sein als auch in zugrundeliegenden anderen Faktoren, wie beispielsweise einem Gendrift oder dem Wachstum einer Population (Gaunt et al. 2007).

Die Ergebnisse zeigen, dass potentiell funktionelle Allelvarianten für $A B C B 1$ und $A B C G 2$, häufig bei MS-Patienten vorkommen, vermutlich aber ohne eine Rolle in der Krankheitssuszeptibilität zu spielen. 


\subsection{Verschiedene, potentiell von der Mitoxantron-Therapie beeinflusste Gewebe und Organe zeigen eine hohe $A B C B 1-/ A B C G 2$-Boten-Ribonukleinsäure-Expression}

Es konnte eine hohe $A B C B 1-/ A B C G 2-m R N A$-Expression in verschiedenen, potentiell von der MX-Therapie beeinflussten Zellen und Geweben nachgewiesen werden (Abbildung 1, Teil B: Publikation). So zeigte die Analyse der $A B C$-Transporter-mRNA eine 3.9-fach höhere $A B C G 2$-Expression in Immunzellen (CD56 ${ }^{+}$-Zellen) im Vergleich $\mathrm{zu}$ unsortierten mononukleären Leukozyten. Diese Ergebnisse bestätigen vorhergehende Untersuchungen von Scharenberg et al. (2002) und führten zur Verwendung von CD56 ${ }^{+}$-Zellen in den in-vitroExperimenten. Ebenfalls wurde eine hohe ABCG2-mRNA-Expression in humanen ZNSZellen, vor allem im frontalen, kortikalen Gehirngewebe (53-fach höher im Vergleich zu mononukleären Leukozyten), Oligodendrozyten (19-fach) und Mikroglia (17-fach) beobachtet, was eine Bedeutung der Transporter beispielsweise in der Behandlung neurologischer Erkrankungen nahe legt. Auch im humanen Myokard (16-fach höher im Vergleich zu mononukleären Leukozyten) und im Lebergewebe (76-fach) konnte eine hohe Expression detektiert werden. Da das Herzgewebe eine wichtige Rolle im Nebenwirkunsspektrum der MX-Therapie spielt, ist dieses Ergebnis bedeutsam. Die hepatobiliäre Ausscheidung ist ein Eliminationsweg von MX aus dem menschlichen Körper (Neuhaus et al. 2007). Deshalb könnte die $A B C$-Transporter-Expression in der Leber Einfluss auf die Pharmakokinetik von MX nehmen. Alle untersuchten Zellen und Gewebe zeigten ähnliche Ergebnisse bei der Analyse der $A B C B 1-m R N A$-Expression mit den höchsten Werten in $\mathrm{CD}_{56}{ }^{+}$-Zellen, Oligodendrozyten, der Leber und dem Kortex.

In einer Subanalyse wurden die unterschiedlichen Allele $A B C B 1-3435 \mathrm{C}>\mathrm{T}$ (-CC n=14, -CT $\mathrm{n}=36,-\mathrm{TT} \mathrm{n}=11)$ und $A B C G 2-\mathrm{V} 12 \mathrm{M}(-\mathrm{VV} \mathrm{n}=21,-\mathrm{VM} \mathrm{n}=10)$ und -Q141K (-QQ n=21, -QK $\mathrm{n}=25)$ mit der Höhe $m R N A$-Transporterexpression korreliert. Es wurden keine statistisch signifikanten Unterschiede detektiert. Darüber hinaus konnten keine Hinwiese für eine mögliche Genotyp-abhängige Expression gefunden werden, wie näher von Hitzl et al. (2004) oder Moriya et al. (2002) beschrieben. Diesbezüglich und im Hinblick auf einen Vergleich der $m R N A$-Expression von gesunden Spendern und MS-Patienten sind weitere Untersuchungen nötig, da eine Regulation der Transporter durch das Krankheitsgeschehen (Evseenko et al. 2007, Jansen et al. 2003, Tamura et al. 2006, van de Ven et al. 2009) oder die Gabe von MX (Nieth und Lage 2005), aber auch durch andere Medikamente (zum Beispiel Demeule et al. 1999) nicht ausgeschlossen werden kann.

Die Proteinexpression von $A B C B 1$ und $A B C G 2$ wurde nicht separat untersucht wie beispielsweise von Owen et al. (2005). Die Ergebnisse hätten keine weiteren Rückschlüsse auf die Funktionalität der Transporter geboten. Für diesen Nachweis entwickelten wir den MX-Efflux- und -Zelltod-Assay. 


\subsection{Der ABCB1-/ABCG2-Transporter-Genotyp bestimmt in vitro den Mitoxantron- Efflux und den Mitoxantron-induzierten Zelltod in Multiple-Sklerose-Patienten und gesunden Spendern}

In der vorliegenden retrospektiven Prüfung wurde in Immunzellen (CD56 ${ }^{+}$-Zellen) der Nachweis erbracht, dass der $A B C B 1 / A B C G 2$-Genotyp in vitro Einfluss auf den MX-Efflux und MX-induzierten Zelltod in MS-Patienten und gesunden Spendern nimmt.

Es wurde besonders darauf geachtet, dass die Patientenproben stets parallel und gleich behandelt wurden. Das Resultat war eine Reproduzierbarkeit des Vergleichs zwischen $A B C B 1-/ A B C G 2-\mathbf{L}-$ und $A B C B 1-/ A B C G 2-\mathbf{H}-S p e n d e r$ trotz der Varianz im Bioassay und interindividuellen Schwankungen der MX-Akkumulation.

Der $A B C$-Transporter-vermittelte MX-Efflux in MS-Patienten mit $A B C B 1 / A B C G 2-H-A l l e l e n$ zeigte unter Verwendung des dualen $A B C B 1$-/ABCG2-Inhibitors Elacridar einen höheren $\mathrm{MX}$ Efflux als Induviduen mit $A B C B 1 / A B C G 2-\mathbf{L}-A$ llelen (Abbildung 2A, Teil B: Publikation)). Nachdem ein gleichförmiges Verhalten des Genotyp-abhängigen MX-Efflux beobachtet und der Nachweis des Wirkprinzipes in MS-Patienten erbracht wurde, schlossen wir zusätzlich gesunde Spender in die Analyse ein.

Die Abbildung 2B im Teil B fasst die kumulativen Daten von zwölf Individuen (sechs Paare mit unterschiedlichem Genotyp) zusammen. Der $A B C$-vermittelte MX-Efflux des $A B C B 1 / A B C G 2$-L-Genotyps war um $37.7 \%$ geringer (mittlere Fluoreszenzintensität (MFI) 164.3) als bei entsprechenden Trägern des -H-Genotyps (MFI 263.5, p=0.031). Erste Daten weisen darauf hin, dass Individuen, die entweder in $A B C B 1$ oder $A B C G 2$ polymorph sind, einen intermediären MX-Efflux aufweisen ( $A B C B 1 / A B C G 2-\mathbf{I}$ (ntermediate Efflux), Tabelle 5). Die Rangfolge des $A B C$-mediierten MX-Effluxes, die aus den $A B C B 1 / A B C G 2-\mathbf{H} / \mathbf{I} / \mathbf{L}-$ Genotypen resultieren, argumentiert für den Einfluss der ABCB1- und ABCG2-Transporter auf die MX-Akkumulation.

Die Hemmung mit den monospezifischen Inhibitoren PSC-833 (ABCB1-selektiv) und Fumitremorgin $\mathrm{C}$ (ABCG2-selektiv) führte nicht zu signifikanten Unterschieden des $\mathrm{MX}$ Effluxes zwischen $A B C B 1 / A B C G 2-\mathbf{L}-$ und -H-Genotypträgern. Es zeichnete sich bei der Verwendung von PSC-833 allerdings ein statistischer Trend mit $\mathrm{p}=0.062$ entsprechend der Hemmung mit dem dualen Inhibitor Elacridar ab. Da die Unterschiede erst unter Zuhilfenahme des ABCB1- und ABCG2-Hemmstoffs Elacridar signifikant wurden, wird eine zusammenhängende Rolle von ABCB1 und ABCG2 beim MX-Efflux vermutet. Die Ergebnisse bestätigen den Effekt in transgenen Mäusen, in denen die Transporter eine additive, funktionell nicht-redundante Protektion gegen den MX-induzierten Zelltod bilden (Zhou et al. 2003).

Weitere Hinweise auf die funktionelle Relevanz der untersuchten SNPs konnte mit Hilfe des MX-induzierten Zelltods in MS-Patienten und gesunden Spendern erbracht werden. 
In Vorexperimenten wurde ein toxischer Effekt der Inhibitoren auf die CD56 ${ }^{+}$-Zellen ausgeschlossen (Abbildung 2).

\section{Abbildung 2: $\quad$ Erste Daten: Ausschluss der Toxizität der Inhibitoren}

Nach Zugabe von Fumitremorgin C oder PSC-833 (n=5, ein Multiple-Sklerose-Patient/vier gesunde Spender; drei Träger des ABCB1/ABCG2-H-Genotyps, zwei gesunde Spender Träger des ABCB1/ABCG2-L-Genotyps) beziehungsweise von Elacridar (ein MS-Patient/zwei gesunde Spender; zwei Träger des ABCB1/ABCG2-HGenotyps, ein gesunder Spender Träger des ABCB1/ABCG2-L-Genotyps) wurden keine Differenzen der geometrischen mittleren Fluoreszenzintensität der Zelltodrate (Annexin- $V^{+}-Z e l l e n$ und PI $I^{+}$-Zellen) im Vergleich zu einer unbehandelten Probe (Negativprobe, neg) detektiert. Die CD56 ${ }^{+}$-Zellen durchliefen den MitoxantronEfflux-Assay ohne Zugabe von Mitoxantron. Anschließend wurden sie mit den entsprechenden Inhibitoren über Nacht inkubiert und durchflusszytometrisch analysiert. Fisher`s exakt-Test, zweiseitig. ns bedeutet nicht signifikant.

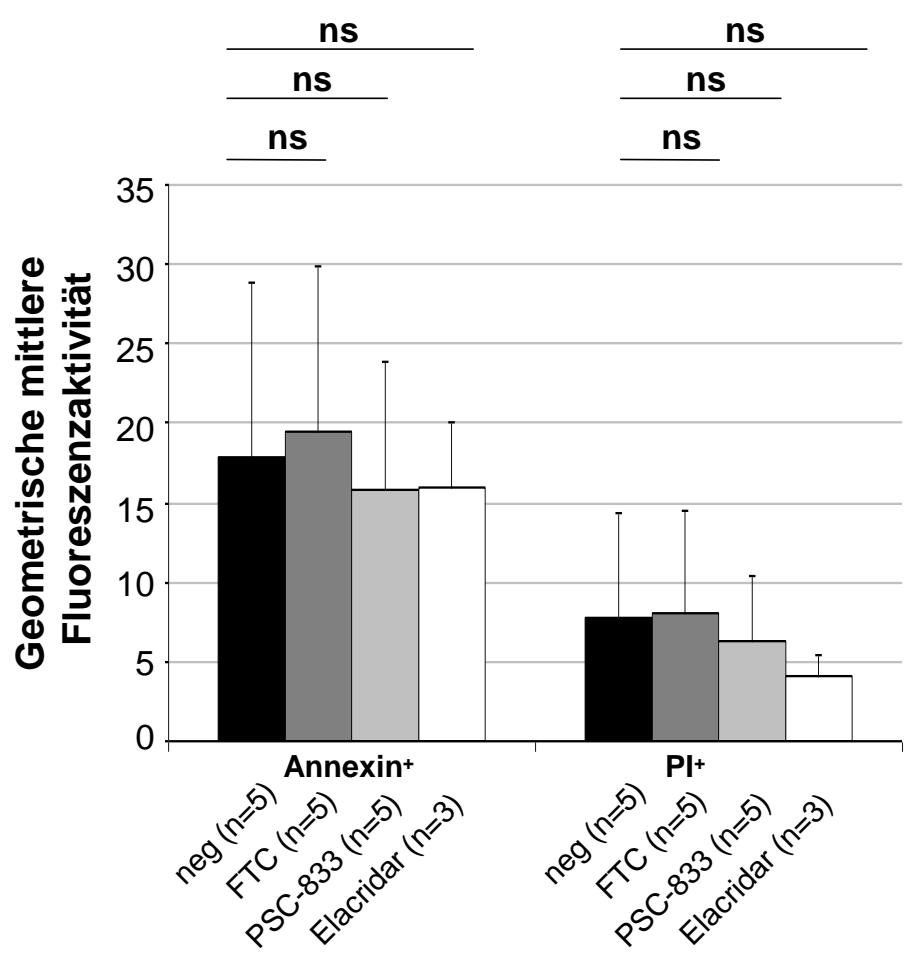

Im MX-Efflux-Assay konnte eine erhöhte intrazelluläre MX-Akkumulation in $A B C B 1 / A B C G 2-L-M S-P a t i e n t e n$ im Vergleich zu ABCB1/ABCG2-H-MS-Patienten nachgewiesen werden. Die Auswirkung der Genotyp-abhängigen unterschiedlichen intrazellulären MX-Ansammlung zeigte sich in den Zelltod-Assay-Experimenten: Die $A B C B 1 / A B C G 2-\mathbf{L}-M S-P a t i e n t e n$, die intrazellulär, quanitativ mehr MX aufwiesen, hatten auch eine höhere Zelltodrate $\left(\mathrm{MX}^{+} /\right.$Annexin- $\mathrm{V}^{+}$-Zellen) im Vergleich zu $A B C B 1 / A B C G 2-\mathbf{H}-$ 
MS-Patienten. Erneut wurden ähnliche Effekte bei gesunden Spendern beobachtet (Abbildung 3A, Teil B: Publikation). Zusammenfassend erbrachte die Analyse von einem MS-PatientenPaar und vier Paaren gesunder Kontrollen folgende Ergebnisse: $A B C B 1 / A B C G 2-\mathrm{L}-$ Individuen besaßen 22.9\% mehr $\mathrm{MX}^{+} /$Annexin- $\mathrm{V}^{+}$- (Abbildung 3B, Teil B: Publikation, $\mathrm{p}<0.05$ ) und $16.1 \%$ mehr $\mathrm{MX}^{+} / \mathrm{PI}^{+}$-doppelt-positive Zellen (Abbildung 3, $\mathrm{p}=$ nicht signifikant (ns)) als Träger des $A B C B 1 / A B C G 2-H-G e n o t y p s$.

Abbildung 3: Der ABCB1/ABCG2-Genotyp bestimmt den Mitoxantron-induzierten Zelltod in MultipleSklerose-Patienten und gesunden Spendern: In vorläufigen Experimenten folgt die Höhe der $\mathrm{MX}^{+} / \mathrm{PI}^{+}$-doppeltpositiven Zellen der Höhe der $M X^{+} /$Annexin- $V^{+}$-doppelt-positiven Zellen

Träger des ABCB1-/ABCG2-L-Genotyps zeigten höhere Anteile spät-apoptotischer und früh-nekrotischer Zellen $\left(\mathrm{MX}^{+} / \mathrm{PI}^{+}\right)$, die Mitoxantron enthalten, im Vergleich zu Individuen mit dem -H-Genotyp ( $p=n s$, Anova). Jeder Genotyp enthält einen Multiple-Sklerose-Patienten und vier gesunde Spender. Die FACS-Messung erfolgte 24 Stunden nach dem Mitoxantron-Efflux entsprechend mit beziehungsweise ohne den dualen ABCB1/ABCG2-Inhibitor Elacridar. Dargestellt sind die Mittelwerte der prozentualen Anteile $\mathrm{MX}^{+} / \mathrm{PI}^{+}$-doppeltpositiver Zellen mit der Standardabweichung (Ordinate) für die Träger des ABCB1-/ABCG2-L und des $\boldsymbol{H}$ Genotyps (Abszisse).

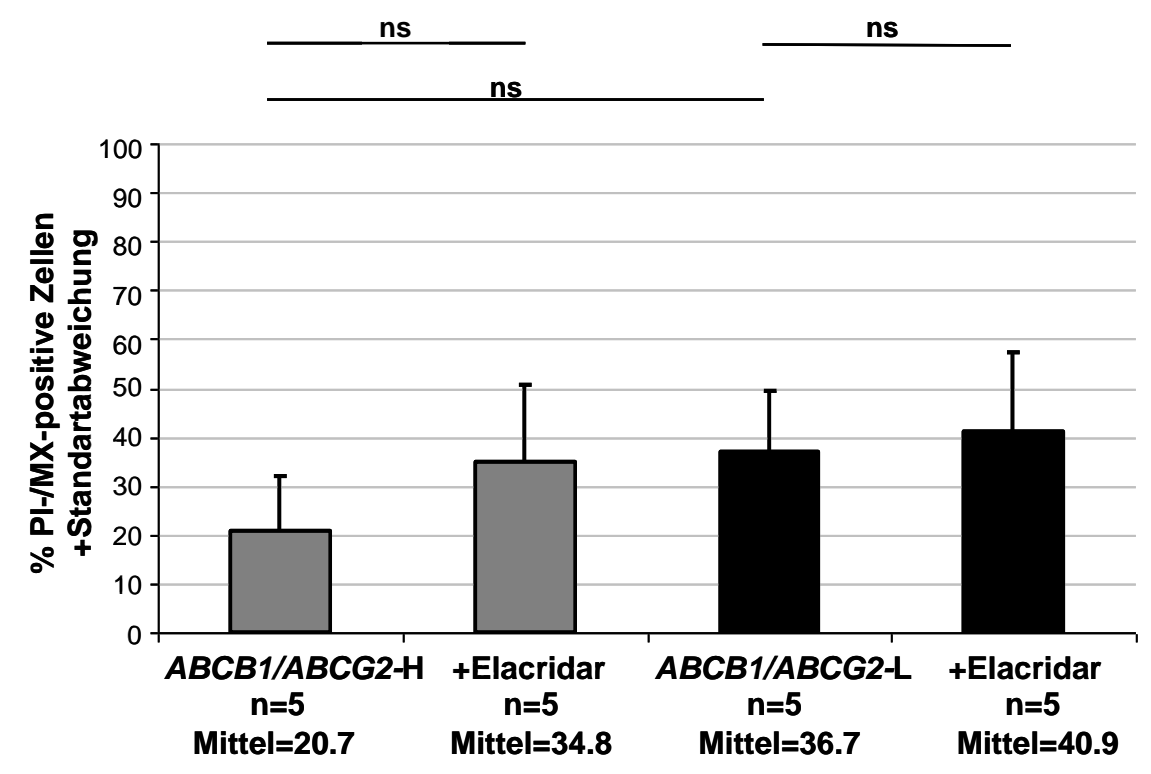

Darüber hinaus führte die Inhibition des MX-Effluxes durch den ABCB1/ABCG2-Inhibitor Elacridar zur Steigerung des Zelltods in $A B C B 1 / A B C G 2-H-I n d i v i d u e n ~ u m ~ 21.9 \%$ $\left(\mathrm{MX}^{+} /\right.$Annexin- $\mathrm{V}^{+}$-Zellen, $\left.\mathrm{p}<0.05 \%\right)$. Dieser Anstieg betrug lediglich $3.5 \%$ in den $-\mathbf{L}-$ genotypisierten Individuen ( $\mathrm{p}=\mathrm{ns}$ ) (Abbildung 3B, Teil B: Publikation). Die Anzahl der spätapoptotischen und früh-nekrotischen Zellen $\left(\mathrm{MX}^{+} / \mathrm{PI}^{+}\right)$verhielt sich im Trend gleichförmig 
(Abbildung 3). Da die Wirkung auf den dualen Hemmstoff Elacridar zurückzuführen ist, weist dies auf einen $A B C$-Transporter-vermittelten Effekt hin. Der untersuchte Zeitpunkt umfasst das Apoptoseprogramm der Zellen, dass innerhalb von vier bis fünf Stunden beendet wird. Sogar hier gezeigte kleine quantitative Differenzen des Zelltodes können in bestimmten Geweben unter definierten Bedingungen zu den in der Studie analysierten Zeitpunkten zu einem großen Zellverlust über die Zeit führen (Bursch et al. 1990).

Die Ergebnisse argumentieren für eine unterschiedliche Suszeptibilität des MX-induzierten Zelltods abhängig vom entsprechenden $A B C B 1 / A B C G 2$-Transporter-Genotyp. Vermutlich ist dies bedingt durch die Höhe der MX-Akkumulation.

Die klinisch weit verbreitete Anwendung der MX/GS-Kombination folgt der empirischen Rationale einer potentiellen Steigerung der Effektivität und Tolerabiltät (Morrissey et al. 2005). Zingler et al. (2005) berichteten über eine bessere Verträglichkeit der kombinierten MX/GS-Therapie mit weniger Nebenwirkungen wie Müdigkeit und Abgeschlagenheit. Das führt letztlich zur Erhöhung der Kooperation der Patienten im Rahmen der Therapie.

Dies veranlasste uns dazu, in einem nächsten Schritt den Einfluss von den GSs MP und DEX auf die intrazelluläre MX-Akkumulation und den $\mathrm{MX}$-induziertem Zelltod zu untersuchen. In CD56 ${ }^{+}$-Zellen von Individuen mit $A B C B 1 / A B C G 2-H-G e n s e q u e n z e n$ inhibierten sowohl MP als auch DEX signifikant den MX-Efflux (Abbildung 3C, Teil B: Publikation). Dies resultiert vermutlich aus komplexen GS-Interaktionen mit $A B C$-Transportern, im Besonderen die Inhibition der ATPase-Aktivität der $A B C$-Transporter durch Steroide (nicht genomischer Effekt), die Rolle der GS als Substrat oder der Einfluss auf die Regulation der $A B C$ Transporter-Expression (Evseenko et al. 2007, Jansen et al 2003, Kim und Benet 2004, Pavek et al. 2005, Schmid et al. 2000). Nach 24h führte die zusätzliche Inkubation mit MP zu einem Anstieg von $8 \%$ der $\mathrm{MX}^{+} /$Annexin- $\mathrm{V}^{+}$-Zellen in $A B C B 1 / A B C G 2-\mathrm{H}-$ Genträgern und mit DEX von $2.9 \%$. Dieser Effekt war vermutlich abhängig von der Hemmung des MX-Effluxes und nicht direkt GS-vermittelt, da nur vernachlässigbare Unterschiede in zwei entsprechenden $A B C B 1 / A B C G 2-\mathbf{L}-I n d i v i d u e n$ beobachtet wurden (für $\mathrm{MP}+0.52 \% \mathrm{MX}^{+} /$Annexin- $\mathrm{V}^{+}$-Zellen, für DEX $+2.0 \%)$. Hypothetisch könnte der auf in-vitro-Ebene beobachtete Effekt zu einer höheren Effektivität von MX führen. Andererseits könnte eine Risikostratifizierung von Nebenwirkungen zumindest in unterschiedlichen $A B C$-Genotyp-Subpopulationen erfolgen.

Der mögliche Einfluss weiterer Faktoren, wie zum Beispiel die potentielle Prädominanz eines $A B C$-Transporters in vivo oder die Rolle anderer Mechanismen kann durch die vorliegenden Experimente nicht ausgeschlossen werden und bedarf weiterer Erforschung. Beispielsweise könnten andere $M D R$-Transporter, wie $\mathrm{ABCC} 1$, von Bedeutung sein (Borst und Elferink 2002, Morrow et al. 2006). 
Die Transporter-Expression könnte durch die MX-Gabe beeinflusst worden sein, wie 2005 von Nieth und Lage beschrieben. Dieser Störfaktor kann vermutlich durch den begrenzten zeitlichen Verlauf des Experimentes ausgeschlossen werden, da die durchschnittliche Zeit von der Induktion bis hin zur Expression auf der Zelloberfläche die Dauer des Versuchs übersteigt.

Aktuell fehlt es darüber hinaus an validen Daten zu möglichen Arzneimittelinteraktionen. Potentielle Kandidaten dafür sind 5- $\mathrm{HT}_{3}$-Rezeptor-Antagonisten wie beispielsweise Ondansetron. Er wird regelmäßig im Rahmen der MX-Infusionen als potentes Antiemetikum verabreicht und ist ein bekanntes Substrat des ABCB1-Transporters (Babaoglu et al. 2005, Schinkel et al. 1996). Ebenso wurde in den letzten Jahren eine Hemmung dieses Transporters durch den Protonenpumpeninhibitor Pantoprazol diskutiert (Pauli-Magnus et al. 2001).

\subsection{Der $A b c$-Transporter-Genotyp beeinflusst die therapeutische Ansprechrate auf Mitoxantron in der experimentellen autoimmunen Enzephalomyelitis}

Um die funktionelle Signifikanz des $A b c$-Transporter-Genotyps näher zu untersuchen wude eine in-vivo-Analyse durchgeführt. Hierfür verwendeten wir ein etabliertes Tiermodell der MS in Mäusen: die chronische EAE. Sie spiegelt die wichtigsten Meilensteine der Erkrankung wider und ähnelt den pathologischen Grundlagen der MS. (beispielsweise zusammengefasst von Mix et al. 2008) Für die Behandlung der EAE wird MX hocheffektiv eingesetzt (Weilbach et al. 2004).

In Abcg2-Knock-Out-Mäusen und entsprechenden wildtypischen Tieren wurde die Ansprechrate der Behandlung der EAE auf die MX-Therapie analysiert. Unter Verwendung einer subtherapeutisch, niedrig titrierten MX-Dosis von $0.5 \mathrm{mg} / \mathrm{kg}$, die nicht effizient in Wildtyp-Tieren ist, konnten der Krankheitsverlauf und die Histopathologie in Abcg2-KnockOut-Mäusen enorm verbessert werden (Abbildung 4, Teil B: Publikation). Damit konnte in vivo eine funktionelle Relevanz der ABCG2-Transporter nachgewiesen werden. Das ähnelt den Resultaten von Zhou et al. (2003), die eine differenzierte Sensibilität von MX in hämatopoetischen Zellen von Abcb1/Abcg2-Knock-Out-Mäusen zeigen. Die Ergebnisse argumentieren darüber hinaus dafür, dass der ABCG2-Transporter eine Hauptrolle bei den Behandlungserfolgen der EAE mit MX spielt. Kodaira et al. (2010) konnten eine Kooperation von $\mathrm{ABCB} 1$ und $\mathrm{ABCG} 2$ in kinetischen Analysen der Mitoxantron-Penetration über die BlutHirn- und Blut-Testis-Schranke im Mausmodell nachweisen.

\subsection{Der $A B C$-Transporter-Genotyp hat einen Effekt auf das therapeutische Ansprechen von Mitoxantron}

In einer retrospektiven Analyse wurde der Einfluss des $A B C$-Transporter-Genotyps auf die therapeutische Ansprechrate mit MX untersucht. Obwohl klinische Charakteristika, die mit einem bevorzugten Response assoziiert sind, bereits identifiziert wurden (zum Beispiel das Alter zu Therapiebeginn, der Krankheitsverlauf/die Schubrate, die Basis-EDSS) (Le Page et 
al. 2007), gibt es bisher keine Biomarker, die einen klinischen Effekt beziehungsweise ein individuelles Risiko-Profil vorhersagen können. In der vorliegenden Prüfung konnte gezeigt werden, dass die MX-Responder überrepräsentiert waren unter den $A B C B 1 / A B C G 2-\mathbf{L}-$ Patienten in der MX-Monotherapie-Gruppe, die in den in-vitro-Experimenten die höhere MX-Akkumulation aufwiesen. Im Vergleich dazu sprachen die ABCB1/ABCG2-HGenotypträger weniger gut auf die MX-Therapie an.

Für die Klassifikation nach der Ansprechrate auf die MX-Therapie wurden konservative, klinische Untersuchungskriterien und standardisierte Parameter gewählt wie die EDSS, die Schubrate und die $M S F C$-Skala, assistiert von elektrophysiologischen und magnetresonanztomografischen Daten. Die quantitative Erfassung klinischer Befunde erfolgt im neurologischen Alltag mit Hilfe etablierter Verlaufssklalen wie der EDSS und der MSFCSkala (MSTKG und Rieckmann 2006). Die EDSS bildet den Goldstandard bei der Bestimmung des Behinderungsgrades anhand acht funktioneller Systeme: Pyramidenbahn, Kleinhirn, Hirnstamm, Sensorium, Blasen- und Mastdarmfunktion, Sehfunktion, zerebrale Funktion und andere Systeme (Kurtzke 1983). Die MSFC-Skala erhebt Daten über eine zeitlich ermittelte Gehstrecke (7.6m), einen Steckbretttest nach der Zeit zur Quantifizierung der Armfunktion und einen Aufmerksamkeits-/Konzentrationstest, der Paced Auditory Serial Addition-Test. Sie erlaubt einen inter- und intraindividuellen Vergleich (Cutter et al. 1999, Schwid et al. 2002). Wenn vorhanden wurden zusätzlich motorisch evozierte Potentiale zur Bestätigung der Einteilung untersucht. Diese umfasste eine Analyse der zentral-motorischen Leitungszeit, der Amplitude und der Konfiguration.

Als Resultat standen von 323 vollständig genotypisierten und mit MX behandelten Patienten 309 aus vier Zentren zur Verfügung.

Es wurde eine weitere Untergruppierung in eine MX-Monotherapie- und eine MX/GSKombinationstherapie-Kohorte vorgenommen. Dies erfolgte angesichts der deutlichen Effekte von GSs auf den MX-Efflux in vitro sowie grundlegend unterschiedlicher Behandlungsregime und Basischarakteristika der Gruppen (Tabelle 4, Teil B: Publikation).

Insgesamt profitierten 68.6\% der MX-behandelten Kohorte von der Therapie. 78.1\% der MXMonotherapie-Patienten $(\mathrm{n}=155)$ wurden als Responder klassifiziert und lediglich $31.4 \%$ als Non-Responder (Tabelle 3A, Teil B: Publikation). Die ABCB1/ABCG2-H-Genotyp-Träger zeigten die niedrigste Ansprechrate (15/24, 62.5\%). Die Träger der Allelvarianten in entweder $A B C B 1$ oder $A B C G 2$ ( $A B C B 1 / A B C G 2-I)$ nahmen eine intermediäre Position ein (78/98, 79.6\%). 28 von 33 Patienten (84.8\%) mit dem $A B C B 1 / A B C G 2-\mathbf{L}-G e n o t y p$ respondierten auf MX (p=0.039). Das Quotenverhältnis/Odds Ratio für die positive Behandlungsansprechrate zwischen $A B C B 1 / A B C G 2-\mathbf{H}$ - und -I-Genotyp betrug 1.9 (95\% Konfidenzintervall 1.0-3.5) und entsprechend 3.5 zwischen dem $A B C B 1 / A B C G 2-\mathbf{H}-$ und -L-Genotyp. Das bedeutet, dass der Zusammenhang zwischen $A B C$-Transporter-Genotyp und dem Ansprechen auf die MXTherapie höher bei Trägern des $A B C B 1 / A B C G 2-H-G e n o t y p s$ ist im Vergleich zu den Trägern 
des -I- oder -L-Genotyps. Zur strikten Kontrolle des Typ Eins Fehlers wurde der exakte Test als stringente statistische Untersuchung ausgewählt.

Bei der Analyse der Basisdaten der MX-Monotherapie-Gruppe zeigte sich eine niedrigere MX-Dosis der Behandlungs-Responder im Vergleich zu den Non-Respondern zum Zeitpunkt der Klassifikation (Tabelle 4, Teil B: Publikation). Da die niedrigeren Dosen in der Responder-Gruppe gefunden wurden, bestätigt dies die Validität des $A B C$-Genotyp-Effekts. Darüber hinaus wurden keine statistisch signifikanten Unterschiede zwischen den Basischarakteristika der Responder und Non-Responder beobachtet. $\mathrm{Zu}$ den potentiellen Störfaktoren würden zum Beispiel das Alter oder die Krankheitsdauer bis zur MX-Therapie, die Basis-EDSS beziehungsweise der Verlaufstyp/der Krankheitsaktivität zählen (Le Page et al. 2007). Eine prospektive Validierung dieser Ergebnisse in einer größeren Kohorte ist trotzdem erstrebenswert, um ausführlichere Rückschlüsse ziehen zu können.

In der MX/GS-Kombinationstherapie-Kohorte respondierten 59.1\% der Patienten. Es konnte kein klarer Genotyp-abhängiger Effekt beobachtet werden (Tabelle 3B, Teil B: Publikation). Bereits innerhalb dieser Gruppen gab es große Unterschiede in den Behandlungsprotokollen und der Basischarakteristika der Patienten, so dass keine weiteren sicheren Schlussfolgerungen gezogen werden können.

Eine prospektive, multizentrische Bestätigungsprüfung wurde 2009 in Deutschland von unserer Gruppe mit einer Prüfungsdauer von drei Jahren eingeleitet. In dieser soll die Rekrutierung einer größeren und homogenen Patienten-Gruppe im Rahmen des Kompetenznetzwerkes Multiple Sklerose und entsprechender Kontrollen erfolgen (,ABC in Multipler Sklerose“). Es soll unter anderem potentiellen Störfaktoren und gleichförmigen Behandlungsprotokollen Rechnung getragen werden.

Der unterschiedliche MX-Efflux könnte auch mit Organ-spezifischen Nebenwirkungen einhergehen. Deshalb wurde eine separate Kohorte mit kardiologischen und hämatologischen Nebenwirkungen selektiert und bezüglich der $A B C$-Transporter-Genotyp-Verteilung analysiert. Statistische Auswertungen dieser Gruppe sind jedoch durch kleine Anzahlen und heterogene Behandlungsschemata begrenzt aussagekräftig.

Auf einem deskriptiven Level zeigten 30 von insgesamt 36 Patienten heterozygote Allelvarianten in mindestens einem $A B C$-Transporter-Gen, was vergleichbar mit den Genotypfrequenzen der gesamten MS-Population war. Bei Patienten mit schweren Nebenwirkungen wurde im Vorfeld häufig eine MX/GS-Kombinationstherapie durchgeführt: elf von 28 Patienten mit kardiologischen Nebenwirkungen einschließlich Herzversagen und sieben von acht Patienten mit schweren hämatologischen Nebenwirkungen einschließlich Therapie-assoziierter Leukämie.

Von zehn separat gesammelten Proben des Berliner Zentrums zeigten drei einen signifikanten Abfall der echokardiografischen linksventrikulären Ejektionsfraktion $(\geq 10 \%)$ und sechs 
Patienten eine diastolische Dysfunktion. Eine Patientin mit einem in unserer unselektierten MS-Kohorte seltenen $A B C$-Genotyp entwickelte ungewöhnlich schwere Nebenwirkungen (0.55\%, Tabelle 2, Teil B: Publikation): Die 28-jährige MS-Patientin mit einem schubförmig wiederkehrenden Verlaufstyp erlitt ein schweres Herzversagen nach bereits $24 \mathrm{mg} / \mathrm{m}^{2} \mathrm{KOF}$ MX (biventrikuläre Ejektionsfraktion 10\%, Multi-Organ-Versagen, Biopsie-Exklusion aus anderen Gründen) (Dörr et al. 2010). Die Patientin ist Trägerin eines Genotyps mit einer extrem niedrigen Häufigkeit in unserer MS-Kohorte. Sie besitzt homozygote Allelvarianten in beiden untersuchten Gen-loci der ABCB1- und ABCG2-Transporter und zusätzlich in einer Allelvariante in einem weiteren $A B C$-Transporter namentlich $A B C C 2$ (rs717620) ( $A B C B 1$ 2677 TT, 3435 TT, $A B C G 2-141 \mathrm{KK}, A B C C 2-C T)$. MX ist auch ein bekanntes Substrat des $A B C C 2$-Transporters (Schinkel und Jonker 2003). Dieser Fallbericht steigert das Interesse an der Assoziation der $A B C$-Transporter-Genpolymorphismen mit ungewöhnlich schweren Nebenwirkungen in der Behandlung der MS mit MX.

Meissner et al. berichteten 2004 und 2006 von einer unterschiedlichen Expression von

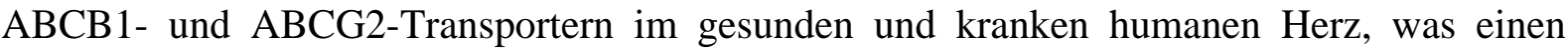
möglichen Einfluss der Transporter bei dem Krankheitsgeschehen vermuten lässt. $A B C$ Transporter-Genotyp abhängige Effekte wurden bereits von Wojnowski et al. (2005) beschrieben mit einer Anthrazyklin-induzierten Kardiotoxizität in Non-Hodgkin-LymphomPatienten. In dieser Kohorte könnte allerdings eine Vielzahl anderer Risikofaktoren für die Entwicklung einer Kardiotoxizität eine Rolle gespielt haben (zum Beispiel mediastinale Bestrahlung, zusätzliche Behandlung mit kardiotoxischen Substanzen und hohes Alter der Patienten). MS-Patienten sind jedoch typischerweise jünger, kardiologisch gesund und nicht andersweitig vorbehandelt. In-vitro-Untersuchungen könnten potentiell die These bekräftigen, dass der $A B C$-Genotyp ein Risiko-Biomarker für schwerwiegende Nebenwirkungen in der Behandlung der MS mit MX sein kann. Obwohl dies durchaus durchführbar für die Kardiomyozytenfunktion scheint, gibt es bisher kein geeignetes in-vitro-Modell, um die hämatologischen Nebenwirkungen zu untersuchen. In diesem Kontext ist eine von Hasan et al. (2008) veröffentlichte Prüfung von Interesse für die MS. Sie zeigt, dass in der MXTherapie-assoziierten akuten promyelozytischen Leukämie in MS-Patienten bevorzugte Stellen bei der Schädigung der DNS existieren. Dieses könnte dazu führen, dass sich nach der Medikamenten-Exposition vor allem dieser bestimmteSubtyp der Leukämie entwickelt.

Das Vorkommen von schwerwiegenden kardiologischen und hämatologischen Nebenwirkungen während der MX/GS-Kombinationstherapie in Verbindung mit den entsprechenden Genotypen verlangt eindeutig eine prospektive Evaluation. 


\section{Zusammenfassung}

Das Ziel der vorliegenden Arbeit war die Untersuchung der Häufigkeit von $A B C$-TransporterGenpolymorphismen, der Transporter-Expression auf potentiellen Zielorganen der Mitoxantron-Therapie, der funktionellen Rolle in vitro und in vivo und eine retrospektive, klinische Analyse des potentiellen Einflusses auf die Mitoxantron-Ansprechrate in Multipler Sklerose.

Es konnte eine hohe Prävalenz von funktionell relevanten Allelvarianten in $A B C$-TransporterGenen von Multiple-Sklerose-Patienten detektiert werden, die den Mitoxantron-Efflux und den Mitoxantron-induzierten Zelltod in Immunzellen in vitro bestimmen. Eine hohe $A B C$ Transporter- $m R N A$-Expression im ZNS- sowie im kardialen Gewebe argumentiert für die Relevanz der $A B C$-Transporter bei Mitoxantron-behandelten Multiple-Sklerose-Patienten. In Mitoxantron-behandelten Abcg2-Knock-Out-EAE-Mäusen konnte in vivo ein funktioneller Einfluss der $A B C$-Transporter-Genpolymorphismen gezeigt werden. In einer retrospektiven, klinischen Assoziation wurde ein Zusammenhang zwischen dem Ansprechen auf die Mitoxantron-Therapie und dem $A B C$-Transporter-Genotyp detektiert in Multiple-SklerosePatienten. Träger des $A B C B 1 / A B C G 2-H$-Genotyps, deren Immunzellen in vitro einen höheren Mitoxantron-Efflux und damit verbunden eine höhere Transporteraktivität zeigten, wiesen eine niedrigere positive Mitoxantron-Behandlungsansprechrate/Response auf im Vergleich zu Trägern des -I- oder -L-Genotyps. Daneben konnte eine in-vitro-Inhibition des MitoxantronEffluxes durch Glukokortikosteroide nachgewiesen werden, die klinisch oft in Kombination mit Mitoxantron verwendet werden.

Zusammengefasst, eröffnen unsere Daten die Möglichkeit, das individuelle Risiko-/BenefitProfil von Mitoxantron zu optimieren und damit die therapeutische Effektivität zu steigern. Auf der Grundlage solcher potentiellen pharmakogenetischen Biomarker könnte beispielsweise direkt Einfluss auf die individuelle Titration der Dosis, der Intervalle oder der Sicherheitsüberwachung genommen werden. Das ist von besonderem Interesse, da nicht erwartet wird, dass in naher Zukunft Mitoxantron durch andere Substanzen ersetzt werden kann und Untersuchungen zur Optimierung der Mitoxantron-Therapie, wie die additive Gabe von kardioprotektiven Agenzien, noch im experimentellen Stadium sind (Bernitsas et al. 2006, Weilbach et al. 2004, Zecca et al. 2011).

Die vorliegende Arbeit bildet die Grundlage einer bereits eingeleiteten prospektiven Untersuchung des Kompetenznetzwerks Multiple Sklerose (,ABC in Multipler Sklerose“). Daneben findet aktuell eine retrospektive Prüfung der Ansprechrate Mitoxantron-behandelter primär progredienter Multiple-Sklerose-Patienten in Abhängigkeit von klinischen Charakteristika und $A B C$-Transporter-Genpolymorphismen statt. Weitere Analysen könnten explizitere Untersuchungen der Patienten mit schwerwiegenden unerwünschten Ereignissen unter Mitoxantron-Therapie sowie die Rolle weiterer $A B C$-Transporter, wie $\mathrm{ABCC}$, umfassen. 


\section{Literaturverzeichnis}

(Allikmets et al. 1998) = Allikmets R, Schriml LM, Hutchinson A, Romano-Spica V, Dean M (1998): A human placenta-specific ATP-binding cassette gene (ABCP) on chromosome 4q22 that is involved in multidrug resistance. Cancer Res $\underline{58}, 5337-5339$

(Babaoglu et al. 2005) = Babaoglu MO, Bayar B, Aynacioglu AS, Kerb R, Abali H, Celik I, Bozkurt A (2005): Association of the ABCB1 3435C>T polymorphism with antiemetic efficacy of 5-hydroxytryptamine type 3 antagonists. Clin Pharmacol Ther $\underline{78}$, 619-626

(Bernitsas et al. 2006) = Bernitsas E, Wei W, Mikol DD (2006): Suppression of mitoxantrone cardiotoxicity in multiple sclerosis patients by dexrazoxane. Ann Neurol $\underline{59}$, 206-209

(Borst und Elferink 2002) = Borst P, Elferink RO (2002): Mammalian ABC transporters in health and disease. Annu Rev Biochem 71, 537-592

$($ Bosch et al. 2005) $=$ Bosch TM, Kjellberg LM, Bouwers A, Koeleman BP, Schellens JH, Beijnen JH, Smits PH, Meijerman I (2005): Detection of single nucleotide polymorphisms in the ABCG2 gene in a Dutch population. Am J Pharmacogenomics $\underline{5}$, 123-131

$($ Boster et al. 2008) $=$ Boster A, Edan G, Frohman E, Javed A, Stuve O, Tselis A, Weiner H, Weinstock-Guttman B, Khan O (2008): Intense immunosuppression in patients with rapidly worsening multiple sclerosis: treatment guidelines for the clinician. Lancet Neurol $\underline{7}, 173-$ 183

(Böyum 1968) = Böyum A (1968): Isolation of leucocytes from human blood. Further observations. Methylcellulose, dextran, and ficoll as erythrocyteaggregating agents. Scand J Clin Lab Invest Suppl 97, 31-50

(Bursch et al. 1990) = Bursch W, Paffe S, Putz B, Barthel G, Schulte-Hermann R (1990): Determination of the length of the histological stages of apoptosis in normal liver and in altered hepatic foci of rats. Carcinogenesis $\underline{11}, 847-853$ 
(Cascorbi 2006) $=$ Cascorbi I (2006): Role of pharmacogenetics of ATP-binding cassette transporters in the pharmacokinetics of drugs. Pharmacol Ther $\underline{112}, 457-473$

(Chan et al. 2003) = Chan A, Seguin R, Magnus T, Papadimitriou C, Toyka KV, Antel JP, Gold R (2003): Phagocytosis of apoptotic inflammatory cells by microglia and its therapeutic implications: termination of CNS-autoimmune inflammation and modulation by interferonbeta. Glia $\underline{43}, 231-242$

(Chan et al 2005.) = Chan A, Weilbach FX, Toyka KV, Gold R (2005): Mitoxantrone induces cell death in peripheral blood leucocytes of multiple sclerosis patients. Clin Exp Immunol $\underline{139}, 152-158$

(Chaudhary et al. 1992) = Chaudhary PM, Mechetner EB, Roninson IB (1992): Expression and activity of the multidrug resistance P-glycoprotein in human peripheral blood lymphocytes. Blood $\underline{80}, 2735-2739$

(Cohen und Mikol 2004) $=$ Cohen BA, Mikol DD (2004): Mitoxantrone treatment of multiple sclerosis: safety considerations. Neurology $\underline{63}, 28-32$

$($ Compston und Coles 2008) = Compston A, Coles A (2008): Multiple sclerosis. Lancet $\underline{372}$, $1502-1517$

$($ Cutter et al. 1999) $=$ Cutter GR, Baier ML, Rudick RA, Cookfair DL, Fischer JS, Petkau J, Syndulko K, Weinshenker BG, Antel JP, Confavreux C et al. (1999) : Development of a multiple sclerosis functional composite as a clinical trial outcome measure. Brain $\underline{122}$, 871882

(Das Internationale HapMap Konsortium 2007) = The International HapMap Consortium (2007): A second generation human haplotype map of over 3.1 million SNPs. Nature $\underline{449}$, $851-862$

(Demeule et al. 1999) = Demeule M, Jodoin J, Beaulieu E, Brossard M, Béliveau R (1999): Dexamethasone modulation of multidrug transporters in normal tissues. FEBS Lett $\underline{15}$, $208-$ 214 
(Dörr et al. 2010) = Dörr J, Bitsch A, Schmailzl KJ, Chan A, von Ahsen N, Hummel M, Varon R, Lill CM, Vogel HP, Zipp F et al. (2010): Severe cardiac failure in a multiple sclerosis patient following low-dose mitoxantrone treatment. Neurology $\underline{74}, 934$

$($ Doyle et al. 1998) = Doyle LA, Yang W, Abruzzo LV, Krogmann T, Gao Y, Rishi AK, Ross DD (1998): A multidrug resistance transporter from human MCF-7 breast cancer cells. Proc Natl Acad Sci U S A 모, 15665-15670

(Durr et al. 1983) = Durr FE, Wallace RE, Citarella RV (1983): Molecular and biochemical pharmacology of mitoxantrone. Cancer Treat Rev $\underline{10}, 3-11$

$($ Edan et al. 1997) = Edan G, Miller D, Clanet M, Confavreux C, Lyon-Caen O, Lubetzki C, Brochet B, Berry I, Rolland Y, Froment JC et al. (1997): Therapeutic effect of mitoxantrone combined with methylprednisolone in multiple sclerosis: a randomised multicentre study of active disease using MRI and clinical criteria. J Neurol Neurosurg Psychiatry $\underline{62}, 112-118$

(Esposito et al. 2010) = Esposito F, Radaelli M, Martinelli V, Sormani MP, Martinelli Boneschi F, Moiola L, Rocca MA, Rodegher M, Comi G (2010): Comparative study of mitoxantrone efficacy profile in patients with relapsing-remitting and secondary progressive multiple sclerosis. Mult Scler $\underline{16}$, 1490-1499

(Evseenko et al. 2007) = Evseenko DA, Paxton JW, Keelan JA (2007): Independent Regulation of Apical and Basolateral Drug Transporter Expression and Function in Placental Trophoblasts by Cytokines, Steroids, and Growth Factors. Drug Metab Dispos $\underline{35}$, 595-601

(Fidler et al. 1986) = Fidler JM, DeJoy SQ, Gibbons JJ (1986) : Selective immunomodulation by the antineoplastic agent mitoxantrone. I. Suppression of B lymphocyte function. J Immunol 137, 727-732

(Flachenecker 2006) = Flachenecker P (2006): Epidemiology of neuroimmunological diseases. J Neurol 253, 2-8

(Fotino et al. 1971) = Fotino M, Merson EJ, Allen FH Jr (1971): Micromethod for rapid separation of lymphocytes from peripheral blood. Ann Clin Lab Sci $\underline{1}, 131-133$ 
$($ Frohman et al. 2006) $=$ Frohman EM, Racke MK, Raine CS (2006): Multiple sclerosis--the plaque and its pathogenesis. N Engl J Med 354, 942-955

(Gaunt et al. 2007) = Gaunt T, Rodriguez S, Day I (2007): Cubic exact solutions for the estimation of pairwise haplotype frequencies: implications for linkage disequilibrium analyses and a web tool 'CubeX'. BMC Bioinformatics $\underline{8}, 428$

(Geiselhart et al. 1996-1997) = Geiselhart A, Neu S, Buchholz F, Lang P, Niethammer D, Handgretinger R (1996-1997): Positive selection of CD56+ lymphocytes by magnetic cell sorting. Nat Immun $\underline{15}, 227-233$

(Ghalie et al. 2002) = Ghalie RG, Edan G, Laurent M, Mauch E, Eisenman S, Hartung HP, Gonsette RE, Butine MD, Goodkin DE (2002): Cardiac adverse effects associated with mitoxantrone (Novantrone) therapy in patients with MS. Neurology 59, 909-913

(Gold und Rieckmann 2007) = Gold R, Rieckmann P (2007): Fortschritte im Verständnis von Pathogenese und Immuntherapie der Multiplen Sklerose. Nervenarzt 78, 15-26

(Gonsette 2007) = Gonsette RE (2007): Compared benefit of approved and experimental immunosuppressive therapeutic approaches in multiple sclerosis. Expert Opin Pharmacother $\underline{8}, 1103-1116$

(Gonzáles-Lobato et al. 2010) = González-Lobato L, Real R, Prieto JG, Alvarez AI, Merino G (2010): Differential inhibition of murine Bcrp1/Abcg2 and human BCRP/ABCG2 by the mycotoxin fumitremorgin C. Eur J Pharmacol $\underline{644}$, 41-48

$($ Gottesman et al. 2002) $=$ Gottesman MM, Fojo T, Bates SE (2002): Multidrug resistance in cancer: role of ATP-dependent transporters. Nat Rev Cancer $\underline{2}, 48-58$

(Hartung et al. 1988) = Hartung HP, Schäfer B, Heininger K, Stoll G, Toyka KV (1988): The role of macrophages and eicosanoids in the pathogenesis of experimental allergic neuritis. Serial clinical, electrophysiological, biochemical and morphological observations. Brain $\underline{11}$, 1039-1059 
$($ Hartung et al. 2002) = Hartung HP, Gonsette R, König N, Kwiecinski H, Guseo A, Morrissey SP, Krapf H, Zwingers T; Mitoxantrone in Multiple Sclerosis Study Group (MIMS) (2002): Mitoxantrone in progressive multiple sclerosis: a placebocontrolled, double blind, randomised multicentre trial. Lancet $\underline{360}$, 2018-2025

(Hasan et al. 2008) = Hasan SK, Mays AN, Ottone T, Ledda A, La Nasa G, Cattaneo C, Borlenghi E, Melillo L, Montefusco E, Cervera J et al. (2008): Molecular analysis of t $(15 ; 17)$ genomic breakpoints in secondary acute promyelocytic leukemia arising after treatment of multiple sclerosis. Blood 112, 3383-3390

$($ Hemmer et al. 2006) $=$ Hemmer B, Nessler S, Zhou D, Kieseier B, Hartung HP (2006): Immunopathogenesis and immunotherapy of multiple sclerosis. Nat Clin Pract Neurol 2, 201211

$($ Hermann et al. 2006) $=$ Hermann DM, Kilic E, Spudich A, Kramer SD, Wunderli-Allenspach H, Bassetti CL (2006): Role of drug efflux carriers in the healthy and diseased brain. Ann Neurol $\underline{60}, 489-498$

(Higgins 1992) $=$ Higgins CF (1992): ABC TRANSPORTERS: From Microorganisms to Man. Ann Rev Cell Biol $\underline{8}, 67-113$

(Hitzl et al. 2001) = Hitzl M, Drescher S, van der Kuip H, Schäffeler E, Fischer J, Schwab M, Eichelbaum M, Fromm MF (2001): The C3435T mutation in the human MDR1 gene is associated with altered efflux of the P-glycoprotein substrate rhodamine 123 from CD56+ natural killer cells. Pharmacogenetics $\underline{11}$, 293-298

$($ Hoffmeyer et al. 2000) $=$ Hoffmeyer S, Burk O, von Richter O, Arnold HP, Brockmöller J, Johne A, Cascorbi I, Gerloff T, Roots I, Eichelbaum M et al. (2000): Functional polymorphisms of the human multidrug-resistance gene: multiple sequence variations and correlation of one allele with P-glycoprotein expression and activity in vivo. Proc Natl Acad Sci USA 97, 3473-3478

(Homolya et al. 2011) = Homolya L, Orbán TI, Csanády L, Sarkadi B (2011): Mitoxantrone is expelled by the $\mathrm{ABCG} 2$ multidrug transporter directly from the plasma membrane. Biochim Biophys Acta 1808: 154-163 
$($ Hu et al. 1992) $=$ Hu OY, Chang SP, Law CK, Jian JM, Chen KY (1992): Pharmacokinetic and pharmacodynamic studies with mitoxantrone in the treatment of patients with nasopharyngeal carcinoma. Cancer $\underline{69}, 847-853$

(Jansen et al. 2003) = Jansen G, Scheper RJ, Dijkmans BA (2003): Multidrug resistance proteins in rheumatoid arthritis, role in disease-modifying antirheumatic drug efficacy and inflammatory processes: an overview. Scand J Rheumatol 32, 325-336

(Juliano und Ling 1976) = Juliano RL, Ling V (1976): A surface glycoprotein modulating drug permeability in Chinese hamster ovary cell mutants. Biochim Biophys Acta $\underline{455}, 152-$ 162

(Keegan und Noseworthy 2002) = Keegan BM, Noseworthy JH (2002): Multiple sclerosis. Annu Rev Med 53, 285-302

(Kenealy et al. 2003) = Kenealy SJ, Pericak-Vance MA, Haines JL (2003): The genetic epidemiology of multiple sclerosis. J Neuroimmunol 143, 7-12

(Kerb 2006) = Kerb R (2006): Implications of genetic polymorphisms in drug transporters for pharmacotherapy. Cancer Lett 234, 4-33

(Kieseier und Jeffery 2010) = Kieseier BC, Jeffery DR (2010): Chemotherapeutics in the treatment of multiple sclerosis. Ther Adver Neurol Disord $\underline{3}$, 277-291

$($ Kim und Benet 2004) $=$ Kim WY, Benet LZ (2004): P-glycoprotein (P-gp/MDR1)-mediated efflux of sex-steroid hormones and modulation of P-gp expression in vitro. Pharm Res $\underline{21}$, $1284-1293$

(Klimecki et al. 1994) = Klimecki WT, Futscher BW, Grogan TM, Dalton WS (1994): Pglycoprotein expression and function in circulating blood cells from normal volunteers. Blood $\underline{83}, 2451-2458$

(Kodaira et al. 2010) = Kodaira H, Kusuhara H, Ushiki J, Fuse E, Sugiyama Y (2010): Kinetic analysis of the cooperation of P-glycoprotein (P-gp/Abcb1) and breast cancer 
resistance protein (Bcrp/Abcg2) in limiting the brain and testis penetration of erlotinib, flavopiridol, and mitoxantrone. J Pharmacol Exp Ther $\underline{333}$, 788-796

(Kooij et al. 2009) = Kooij G, Backer R, Koning JJ, Reijerkerk A, van Horssen J, van der Pol SM, Drexhage J, Schinkel A, Dijkstra CD, den Haan JM, Geijtenbeek TB, de Vries HE (2009): P-glycoprotein acts as an immunomodulator during neuroinflammation. PLoS One $\underline{4}$, 8212

$($ Kopadze et al. 2006) $=$ Kopadze T, Dehmel T, Hartung HP, Stüve O, Kieseier BC (2006): Inhibition by mitoxantrone of in vitro migration of immunocompetent cells: a possible mechanism for therapeutic efficacy in the treatment of multiple sclerosis. Arch Neurol $\underline{63}$, $1572-1578$

(Kruse et al. 2001) = Kruse N, Moriabadi NF, Toyka KV, Rieckmann P (2001): Characterization of early immunological responses in primary cultures of differentially activated human peripheral mononuclear cells. J Immunol Methods $\underline{247}$, 131-139

(Kurtzke 1983) = Kurtzke JF (1983): Rating neurologic impairment in multiple sclerosis: an expanded disability status scale (EDSS). Neurology $\underline{33}, 1444-1452$

(Leith et al. 1999) = Leith CP, Kopecky KJ, Chen IM, Eijdems L, Slovak ML, McConnell TS, Head DR, Weick J, Grever MR, Appelbaum FR et al. (1999): Frequency and clinical significance of the expression of the multidrug resistance proteins MDR1/P-glycoprotein, MRP1, and LRP in acute myeloid leukemia: a Southwest Oncology Group Study. Blood 94, 1086-1099

(Le Page et al. 2007) = Le Page E, Leray E, Taurin G, Coustans M, Chaperon J, Morrissey SP, Edan G (2007): Mitoxantrone as induction treatment in aggressive relapsing remitting multiple sclerosis: treatment response factors in a 5-year follow-up observational study of 100 consecutive patients. J Neurol Neurosurg Psychiatry $\underline{79}$, 52-56

(Leslie et al. 2005) = Leslie EM, Deeley RG, Cole SP (2005): Multidrug resistance proteins: role of P-glycoprotein, MRP1, MRP2, and BCRP (ABCG2) in tissue defense. Toxicol Appl Pharmacol 204, 216-237 
(Livak und Schmittgen 2001) = Livak KJ, Schmittgen TD (2001): Analysis of relative gene expression data using real-time quantitative PCR and the 2(-Delta Delta $\mathrm{C}(\mathrm{T})$ ) Method. Methods $\underline{25}, 402-408$

(Löscher und Potschka 2005) = Löscher W, Potschka H (2005): Drug resistance in brain diseases and the role of drug efflux transporters. Nat Rev Neurosci $\underline{6}, 591-602$

(Lublin und Reingold 1996) = Lublin FD, Reingold SC (1996): Defining the clinical course of multiple sclerosis: results of an international survey. National Multiple Sclerosis Society (USA) Advisory Committee on Clinical Trials of New Agents in Multiple Sclerosis. Neurology 46: 907-911

(Lucchinetti et al. 2000) = Lucchinetti CF, Brück W, Parisi J, Scheithauer B, Rodriguez M, Lassmann H (2000): Heterogeneity of multiple sclerosis lesions: implications for the pathogenesis of demyelination. Ann Neurol 47, 707-717

(Marriott et al. 2010) = Marriott JJ, Miyasaki JM, Gronseth G, O'Connor PW; Therapeutics and Technology Assessment Subcommittee of the American Academy of Neurology (2010): Evidence Report: The efficacy and safety of mitoxantrone (Novantrone) in the treatment of multiple sclerosis: Report of the Therapeutics and Technology Assessment Subcommittee of the American Academy of Neurology. Neurology $\underline{74}$, 1410-1411

(Marzolini et al. 2004) = Marzolini C, Paus E, Buclin T, Kim RB (2004): Polymorphisms in human MDR1 (P-glycoprotein): recent advances and clinical relevance. Clin Pharmocol Ther $\underline{75}, 13-33$

(McDonald et al. 2001) = McDonald WI, Compston A, Edan G, Goodkin D, Hartung HP, Lublin FD, McFarland HF, Paty DW, Polman CH, Reingold SC et al. (2001): Recommended diagnostic criteria for multiple sclerosis: guidelines from the International Panel on the diagnosis of multiple sclerosis. Ann Neurol 50, 121-127

(Meissner et al. 2004) = Meissner K, Jedlitschky G, Meyer zu Schwabedissen H, Dazert P, Eckel L, Vogelgesang S, Warzok RW, Böhm M, Lehmann C, Wendt M et al. (2004): Modulation of multidrug resistance P-glycoprotein 1 (ABCB1) expression in human heart by hereditary polymorphisms. Pharmacogenetics $\underline{14}, 381-385$ 
(Meissner et al. 2006) = Meissner K, Heydrich B, Jedlitschky G, Meyer Zu Schwabedissen H, Mosyagin I, Dazert P, Eckel L, Vogelgesang S, Warzok RW et al. (2006): The ATP-binding cassette transporter ABCG2 (BCRP), a marker for side population stem cells, is expressed in human heart. J Histochem Cytochem 누, 215-221

(Miyake et al. 1999) = Miyake K, Mickley L, Litman T, Zhan Z, Robey R, Cristensen B, Brangi M, Greenberger L, Dean M, Fojo T et al. (1999): Molecular cloning of cDNAs which are highly overexpressed in mitoxantrone-resistant cells: demonstration of homology to $\mathrm{ABC}$ transport genes. Cancer Res $\underline{59}$, 8-13

(Mix et al. 2008) = Mix E, Meyer-Rienecker H, Zettl UK (2008): Animal models of multiple sclerosis for the development and validation of novel therapies-potential and limitations. $\mathbf{J}$ Neurol $\underline{6}, 7-14$

(Mizuarai et al. 2004) = Mizuarai S, Aozasa N, Kotani H (2004): Single nucleotide polymorphisms result in impaired membrane localization and reduced atpase activity in multidrug transporter ABCG2. Int J Cancer 109, 238-246

(Moriya et al. 2002) = Moriya Y, Nakamura T, Horinouchi M, Sakaeda T, Tamura T, Aoyama N, Shirakawa T, Gotoh A, Fujimoto S, Matsuo M et al. (2002): Effects of polymorphisms of MDR1, MRP1, and MRP2 genes on their mRNA expression levels in duodenal enterocytes of healthy Japanese subjects. Biol Pharm Bull 25, 1356-1359

(Morrissey et al. 2005) = Morrissey SP, Le Page E, Edan G (2005): Mitoxantrone in the treatment of multiple sclerosis. Int MS J $\underline{12}, 74-87$

(Morrow et al. 2006) = Morrow CS, Peklak-Scott C, Bishwokarma B, Kute TE, Smitherman PK, Townsend AJ (2006): Multidrug Resistance Protein 1 (MRP1, ABCC1) Mediates Resistance to Mitoxantrone via Glutathione-Dependent Drug Efflux. Mol Pharmacol $\underline{69}$, $1499-1505$

$($ MSTKG und Rieckmann 2006) $=$ Multiple Sklerose Therapie Konsensus Gruppe $($ MSTKG), Rieckmann P (2006): Immunmodulatorische Stufentherapie der Multiplen Sklerose. Nervenarzt $\underline{77}, 1506-1518$ 
$($ MSTKG et al. 2008) $=$ Multiple Sklerose Therapie Konsensus Gruppe (MSTKG), Wiendl H, Toyka KV, Rieckmann P, Gold R, Hartung HP, Hohlfeld R (2008): Basic and escalating immunomodulatory treatments in multiple sclerosis: current therapeutic recommendations. $\mathrm{J}$ Neurol 255, 1449-1463

(Neuhaus et al. 2005) = Neuhaus O, Wiendl H, Kieseier BC, Archelos JJ, Hemmer B, Stüve O, Hartung HP (2005): Multiple sclerosis: Mitoxantrone promotes differential effects on immunocompetent cells in vitro. J Neuroimmunol $\underline{168}, 128-137$

(Neuhaus et al. 2007) $=$ Neuhaus O, Kieseier BC, Hartung HP (2007): Pharmacokinetics and pharmacodynamics of the interferon-betas, glatiramer acetate, and mitoxantrone in multiple sclerosis. J Neurol Sci 259, 27-37

(Ni et al. 2010) = Ni Z, Bikadi Z, Rosenberg MF, Mao Q (2010): Structure and function of the human breast cancer resistance protein (BCRP/ABCG2). Curr Drug Metab 11, 603-617

(Nieth und Lage 2005) = Nieth C, Lage H (2005): Induction of the ABC-transporters Mdr1/Pgp (Abcb1), mrpl (Abcc1), and bcrp (Abcg2) during establishment of multidrug resistance following exposure to mitoxantrone. J Chemother 17, 215-223

(Noseworthy et al. 2000) = Noseworthy JH, Lucchinetti C, Rodriguez M, Weinshenker BG (2000): Multiple sclerosis. N Engl J Med 343, 938-952

(Owen et. al. 2005) = Owen A, Goldring C, Morgan P, Chadwick D, Park BK, Pirmohamed M (2005): Relationship between the C3435T and G2677T(A) polymorphisms in the ABCB1 gene and P-glycoprotein expression in human liver. Br J Clin Pharmacol 59, 365-370

(Paul et al. 2007) = Paul F, Dörr J, Würfel J, Vogel HP, Zipp F (2007): Early mitoxantroneinduced cardiotoxicity in secondary progressive multiple sclerosis. J Neurol Neurosurg Psychiatry $\underline{78}, 198-200$

(Pauli-Magnus et al. 2001) = Pauli-Magnus C, Rekersbrink S, Klotz U, Fromm MF (2001): Interaction of omeprazole, lansoprazole and pantoprazole with P-glycoprotein. Naunyn Schmiedebergs Arch Pharmacol $\underline{364}, 551-557$ 
$($ Pavek et al. 2005) $=$ Pavek P, Merino G, Wagenaar E, Bolscher E, Novotna M, Jonker JW, Schinkel AH (2005): Human breast cancer resistance protein: interactions with steroid drugs, hormones, the dietary carcinogen 2-amino-1-methyl-6-phenylimidazo(4,5-b)pyridine, and transport of cimetidine. J Pharmacol Exp Ther $\underline{312}$, 144-152

(Pearce 2005) = Pearce JM (2005): Historical descriptions of multiple sclerosis. Eur Neurol $\underline{54}, 49-53$

(Polman et al. 2005) = Polman CH, Reingold SC, Edan G, Filippi M, Hartung HP, Kappos L, Lublin FD, Metz LM, McFarland HF, O'Connor PW et al. (2005): Diagnostic criteria for multiple sclerosis: 2005 revisions to the "McDonald Criteria". Ann Neurol 58, 840-846

(Poser et al. 1983) = Poser CM, Paty DW, Scheinberg L, McDonald WI, Davis FA, Ebers GC, Johnson KP, Sibley WA, Silberberg DH, Tourtellotte WW (1983): New diagnostic criteria for multiple sclerosis: guidelines for research protocols. Ann Neurol 13, 227-231

(Radonić et al. 2004) = Radonić A, Thulke S, Mackay IM, Landt O, Siegert W, Nitsche A (2004): Guideline to reference gene selection for quantitative real-time PCR. Biochem Biophys Res Commun $\underline{313}$, 856-862

(Rieckmann et al. 2004) = Rieckmann P, Toyka KV, Bassetti C, Beer K, Beer S, Buettner U, Chofflon M, Götschi-Fuchs M, Hess K, Kappos L et al. (2004): Escalating immunotherapy of multiple sclerosis — new aspects and practical application. J Neurol 251, 1329-1339

(Robey et al. 2007) = Robey RW, Polgar O, Deeken J, To KW, Bates SE (2007): ABCG2: determining its relevance in clinical drug resistance. Cancer Metastasis Rev 26, 39-57

(Roninson et al. 1986) = Roninson IB, Chin JE, Choi KG, Gros P, Housman DE, Fojo A, Shen DW, Gottesman MM, Pastan I (1986): Isolation of human mdr DNA sequences amplified in multidrug-resistant KB carcinoma cells. Proc Natl Acad Sci USA $\underline{83}, 4538-4542$

(Sakaeda et al. 2003) = Sakaeda T, Nakamura T, Okumura K (2003): Pharmacogenetics of MDR1 and its impact on the pharmacokinetics and pharmacodynamics of drugs. Pharmacogenomics $\underline{4}$, 397-410 
(Sakurai et al.2007) = Sakurai A, Onishi Y, Hirano H, Seigneuret M, Obanayama K, Kim G, Liew EL, Sakaeda T, Yoshiura K, Niikawa N et al. (2007): Quantitative structure--activity relationship analysis and molecular dynamics simulation to functionally validate nonsynonymous polymorphisms of human ABC transporter ABCB1 (P-glycoprotein/MDR1). Biochemistry $\underline{46}, 7678-7693$

(Sarkadi et al. 2004) = Sarkadi B, Ozvegy-Laczka C, Német K, Váradi A (2004): ABCG2 - a transporter for all seasons. FEBS Lett $\underline{567}, 116-120$

$($ Scharenberg et al. 2002) $=$ Scharenberg CW, Harkey MA, Torok-Storb B (2002): The ABCG2 transporter is an efficient Hoechst 33342 efflux pump and is preferentially expressed by immature human hematopoietic progenitors. Blood $\underline{99}, 507-512$

$($ Schinkel und Jonker 2003) $=$ Schinkel AH, Jonker JW (2003): Mammalian drug efflux transporters of the ATP binding cassette (ABC) family: an overview. Adv Drug Deliv Rev $\underline{55}$, $3-29$

$($ Schinkel et al. 1996) = Schinkel AH, Wagenaar E, Mol CA, van Deemter L (1996): Pglycoprotein in the blood-brain barrier of mice influences the brain penetration and pharmacological activity of many drugs. J Clin Invest $\underline{97}, 2517-2524$

$($ Schmid et al. 2000) $=$ Schmid D, Burmester GR, Tripmacher R, Kuhnke A, Buttgereit F (2000): Bioenergetics of human peripheral blood mononuclear cell metabolism in quiescent, activated, and glucocorticoid-treated states. Biosci Rep 20, 289-302

$($ Schwab et al. 2003) = Schwab M, Eichelbaum M, Fromm MF (2003): Genetic polymorphisms of the human MDR1 drug transporter. Annu Rev Pharmacol Toxicol $\underline{43}$, 285307

$($ Schwid et al. 2002) = Schwid SR, Goodman AD, McDermott MP, Bever CF, Cook SD (2002): Quantitave functional measures in MS: what is a reliable change? Neurology $\underline{58}$, 1294-1296 
(Shen et al. 1986) $=$ Shen DW, Fojo A, Chin JE, Roninson IB, Richert N, Pastan I, Gottesman MM (1986): Human multidrug-resistant cell lines: increased mdr1 expression can precede gene amplification. Science $232,643-645$

(Stüve et al. 2004) = Stüve O, Kita M, Pelletier D, Fox RJ, Stone J, Goodkin DE, Zamvil SS (2004): Mitoxantrone as a potential therapy for primary progressive multiple sclerosis. Mult Scler $\underline{10}, 58-61$

(Tamura et al. 2006) = Tamura A, Watanabe M, Saito H, Nakagawa H, Kamachi T, Okura I, Ishikawa T (2006): Functional validation of the genetic polymorphisms of human ATPbinding cassette $(\mathrm{ABC})$ transporter $\mathrm{ABCG} 2$ : identification of alleles that are defective in porphyrin transport. Mol Pharmacol 70, 287-296

(Ting und Morris 1971) = Ting A, Morris PJ (1971): A technique for lymphocyte preparation from stored heparinized blood. Vox Sang $\underline{20}$, 561-563

(Uhr et al. 2008) = Uhr M, Tontsch A, Namendorf C, Ripke S, Lucae S, Ising M, Dose T, Ebinger M, Rosenhagen M, Kohli M et al. (2008): Polymorphisms in the drug transporter gene ABCB1 predict antidepressant treatment response in depression. Neuron $\underline{57}, 203-209$

(van de Ven et al. 2009) = van de Ven R, Oerlemans R, van der Heijden JW, Scheffer GL, de Gruij TD, Jansen G, Scheper RJ (2009): ABC drug transporters and immunity: novel therapeutic targets in autoimmunity and cancer. J Leukoc Biol $\underline{86}, 1-13$

(Vermes et al. 1995) = Vermes I, Haanen C, Steffens-Nakken H, Reutelingsperger C (1995): A novel assay for apoptosis. Flow cytometric detection of phosphatidylserine expression on early apoptotic cells using fluorescein labelled annexin V. J Immunol Meth $\underline{184}$, 39-51

(von Ahsen et al. 2000) = von Ahsen N, Lewczuk P, Schutz E, Oellerich M, Ehrenreich H (2000): Prothrombin activity and concentration in healthy subjects with and without the prothrombin G20210A mutation. Thromb Res 99, 549-556

(von Ahsen et al. 2001) = von Ahsen N, Richter M, Grupp C, Ringe B, Oellerich M, Armstrong VW (2001): No influence of the MDR-1 C3435T polymorphism or a CYP3A4 promoter polymorphism (CYP3A4-V allele) on dose-adjusted cyclosporin A trough 
concentrations or rejection incidence in stable renal transplant recipients. Clin Chem $\underline{47}$, $1048-1052$

(Weilbach et al. 2004) = Weilbach FX, Chan A, Toyka KV, Gold R (2004): The cardioprotector dexrazoxane augments therapeutic efficacy of mitoxantrone in experimental autoimmune encephalomyelitis. Clin Exp Immunol 135, 49-55

(Wojnowski et al. 2005) = Wojnowski L, Kulle B, Schirmer M, Schlüter G, Schmidt A, Rosenberger A, Vonhof S, Bickeböller H, Toliat MR, Suk EK et al. (2005): NAD(P)H oxidase and multidrug resistance protein genetic polymorphisms are associated with doxorubicin-induced cardiotoxicity. Circulation 112, 3754-3762

(Zamar et al. 2007) = Zamar D, McNeney B, Graham J (2007): elrm: Software implementing exact-like inference for logistic regression models. J Stat Software 21, 1-18

(Zecca et al. 2011) = Zecca C, Petrini L, Limoni C, Staedler C, Gobbi C (2011): Tolerability and acceptance of prolonged low/delayed mitoxantrone regimens in patients with worsening multiple sclerosis. Eur Neurol $\underline{65}, 40-45$

(Zheng et al. 2003) = Zheng G, Freidlin G, Zhaohai L, Gastwirth JL (2003): Choice of scores in trend tests for case-control studies of candidate-gene associations. Biometrical $\mathrm{J} \underline{45}, 335$ 348

(Zheng 2008) = Zheng G (2008): Analysis of ordered categorical data: two score-independent approaches. Biometrics $\underline{64}, 1276-1279$

(Zhou et al. 2003) = Zhou S, Zong Y, Lu T, Sorrentino BP (2003): Hematopoietic cells from mice that are deficient in both Bcrp1/Abcg2 and Mr1a/1b develop normally but are sensitized to mitoxantrone. BioTechniques $\underline{35}, 1248-1252$

(Zingler et al. 2005) = Zingler VC, Strupp M, Jahn K, GroßA, HohlfeldR, Brandt T (2005): Kombinierte Mitoxantron-/Methylprednisolon-Behandlung bei primär und sekundär chronisch progredienter Multipler Sklerose. Nervenarzt $\underline{76}$, 740-747 


\section{Teil B: Publikation}

Cotte S, von Ahsen N, Kruse N, Huber B, Winkelmann A, Zettl UK, Starck M, König N, Tellez N, Dörr J, Paul F, Zipp F, Lühder F, Koepsell H, Pannek H, Montalban X, Gold R und Chan A (2009): ABC-transporter gene-polymorphisms are potential pharmacogenetic markers for mitoxantrone response in multiple sclerosis. Brain 132, 1-14 


\section{$A B C$-transporter gene-polymorphisms are potential pharmacogenetic markers for mitoxantrone response in multiple sclerosis}

S. Cotte, ${ }^{1,2, *}$ N. von Ahsen, ${ }^{3, *}$ N. Kruse, ${ }^{1, *}$ B. Huber, ${ }^{1,2}$ A. Winkelmann, ${ }^{4}$ U. K. Zettl, ${ }^{4}$ M. Starck, ${ }^{5}$ N. König, ${ }^{5}$ N. Tellez, ${ }^{6}$ J. Dörr, ${ }^{7.8}$ F. Paul, ${ }^{7,8}$ F. Zipp, ${ }^{8}$ F. Lühder, ${ }^{1}$ H. Koepsell, ${ }^{9}$ H. Pannek, ${ }^{10}$ X. Montalban, ${ }^{6}$ R. Gold ${ }^{2}$ and A. Chan ${ }^{2}$

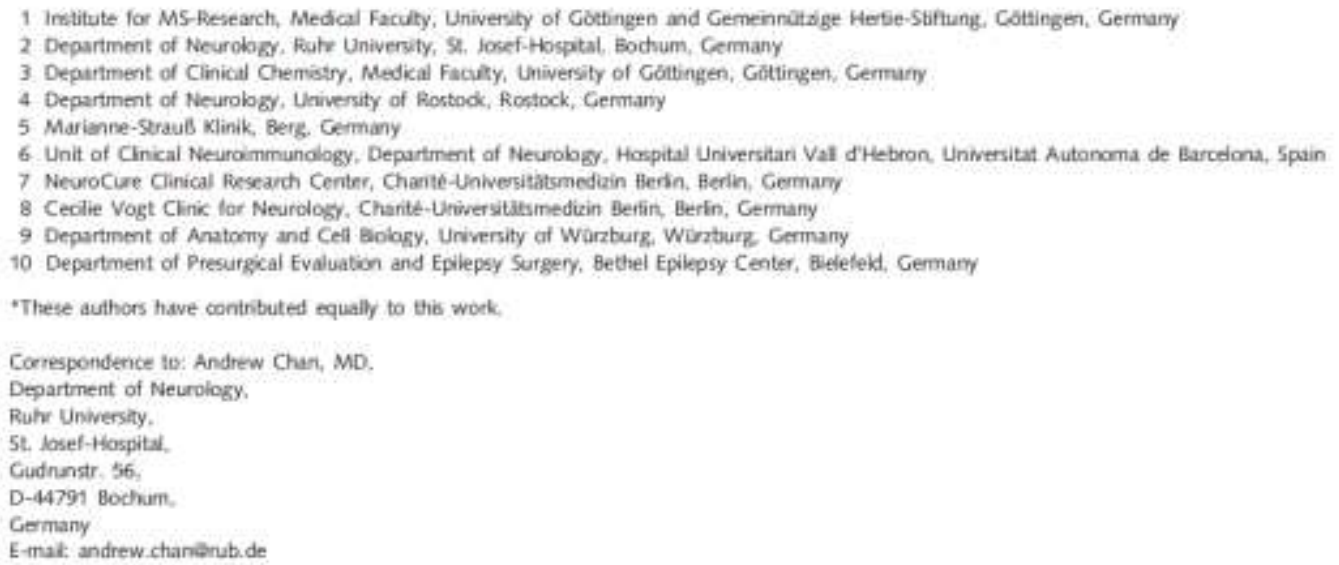

Escalation therapy with mitoxantrone (MX) in highly active multiple sclerosis is limited by partially dose-dependent side-eflects. Predictors of therapeutic response may result in individualized risk stratification and $M X$ dosing. ATP binding cassettetransporters $A B C B 1$ and $A B C G 2$ represent multi-drag resistance mechanisms involved in active cellular $M X$ efflux. Here, we investigated the role of $A B C$-gene single nucleotide polymorphisms (SNPS) for clinical MX response, corroborated by experimental in vitro and in vivo data. Ftequencies of ABCB1 2677G $>$ T, 3435C T and five ABCG2-5NPs were analysed in 832 multiple sclerosis patients (Germany, Spain) and 264 healthy donors. Using a flow-cytometry-based in vitro assay, $M X$ efflux in leukocytes from individuals with variant alleles in both ABC-genes (designated genotype ABCB1/ABCG2.L(ow), 22.2\% of patients) was $37.7 \%$ lower than from individuals homazygous for common alleles ( $A B C B 1 / A B C G 2$ - $H(i g h), P<0.05,14,8 \%$ of patients), resulting in genotype-dependent $M X$ accumulation and cell death. Addition of glucocorticostecoids (CCS) inhibited $M X$ efflux in vito. ABC-transporters were highly expressed in leukocyte subsets, glial and neuronal cells as well as myocardium. i.e. cells/tissues potentially affected by $M X$ therapy. In vivo significance was further corroborated in experimental autoimmune encephalomyelitis in $\mathrm{Abcg} \mathrm{2}^{-1-}$ animals, Using a $\mathrm{MX}$ dose fitrated to be ineffective in wild-type animals disease coune and histopathology in $\mathrm{Abcg} \mathrm{2}^{-4}$ mice were strongly ameliorated. Retrospective clinical analysis in $M X$ monotherapy patients (nu 155)

Ancerved November 9, acos. Finvined May 14,2009. Acteptod May 15, 2000

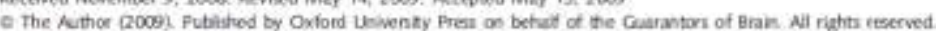

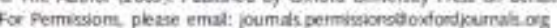


used expanded disability status scale, relapse rate and multiple sclerosis functional composite as major outcome parameters: The clinical response rate foverall 121 of 155 patients $(78.1 \%)$ increased significantly with genotypes associated with decreasIng $A B C B 1 / A B C G 2$-function $[A B C B 1 / A B C G 2-H$ 15/24 (62.5\%) responders, $A B C B 1 / A B C G 2-4$ (ntermediate) 78/98 (79.6\%), $A B C B 1 / A B C G 2+28 / 33(84.8 \%)$, exact Cochran-Armitage test $P=0.039)$. The odds ratio for response was $19(95 \% C$ 1.0-3.5) with each increase in $A B C B 1 / A B C G 2$ score (from $A B C B 1 / A B C G 2-H$ to -1 , and -1 to -4 ). In 36 patients with severe cardiac or haematological side effects no statistically relevant difference in genotype frequency was observed. However, one patient with biopsy proven cardiomyopathy only atter $24 \mathrm{mg} / \mathrm{m}^{2} \mathrm{MX}$ exhibited a rare genobype with variant, partly homazygous alleles in 3 ABC-transporter genes. in conclusion, SNPS in ABC-transporter genes may serve as pharmacogenetic markers associated with clinical response to $\mathrm{MX}$ therapy in multiple sclerosis. Combined MX/GC-treatment warrants furthet investigation.

Keywords: mult-drug resistance transporter, escalation therapy; pharmacogenetics; experimental autcimmune encephalomyefits Abbreviations: $A$ AC $=$ ATP-binding cassette transporter; $A T P=$ adenosine triphosphate; $C N S=$ central nervous system; EAE = experimental autoimmune encephalomyelitis; EDSS = expanded disabilty status scale; GC = glucocorticosteroid; $M S F C=$ multiple sderosis functional composite; $M X=$ mitoxantrone; $S N P=$ single nudeotide polymorphism

\section{Introduction}

The arthracenedione mitoxantrone $(M \times)$ is recommended as an escalation therapy for highly active multople solerosis in case of failure or intolerance to previous immunomodulatory treatment or as first ine therapy for maligrant multiple sclerosis (Rieckmann et al., 2004: Morrissey et al, 2005; Boster et al, 2008). This dinical restriction accounts for the risk profile of $M X$, most importantly cardiotoxicty, bone marrow depression, therapy related acute levkaemia and gonadal dysfurction (Cohen and Mikol, 2004). Cardiotoxioty with symptomatic congestive heart tailure in $-0.1 \%$ of patients is typicaly related to higher $M X$ doses, restricting its lifetime cumalative use to a maximum of $140 \mathrm{mg} / \mathrm{m}^{2}$ of body surtace area (Chalie et al. 2002). However, early candibtoxicity at much lower dosages and late manifestations even several years after cessation of therapy have been described (Morrissey et af., 2005; Paul et al., 2007). Thus, biomarkers that allow indevidualized risk stratification art urgently needed. In addition, response predictors that permit individualized dosing may potentially lead to longer treatment intervals, an important issue shce optimal therapy after lifetime $M X$ dosage is exhausted is still under debate (Boster et al., 2008)

ATP-binding cassette (ABC)-transporters protect cells from endo- or exogenous toxic substances by energy-dependent efflux agrinst a concentration gradient (Schinikel and Jonker, 2003; Robey et af., 2007). Widely expressed, ABC-transporters play a major role in drug absorption, distrbution and excretion. In the central nervous system (CNS), they influence the accumulation of different relevant phamacological substances $e_{.}, \mathrm{G}$ in brain cancer, intections, epilepsy and psychiatric dseases, and current efforts aim at inhbiting. ABC-mediated drug efflux with the rationale to enhance drug efficacy (Loscher and Potschica, 2005: Hermenn of af, 2006: Uhr et al, 20089. Multi-drug: resistance phenotype was first described for chemotherapyresistant cancer cels overexpressing $P$-glycoprotein encoded by the $A B C$ BI gene, for which $M X$ is a knowr substrate. Subsequent description of non-p-glycoprotein-mediated drug resistance to $M X$ led to the discovery of a novel gene, amongst others initially termed MX-resintance gene, now assigned the rame ABCG2 (Robey et al. 2007). On the hasis of our observa. tion of differential immune cell death of $\mathrm{MX}$-treated multiple scierosis patients ex uwo (Chan et al, 2005), we hypothesized that variable $A B C$-transporter function could be imvolved in differential $M X$ susceptibatity on a celular level but also in individual patients. Here we set out to imvestigate the functional role of AECB1. and AECG2-single nudeotide polymorphisms (SMPS) in dfferent multiple sclerosis populations. The predictive role of these SNes for clinical treatment, response and side effects to $M X$ in multiple sclerosis was examined in a retrospective fashion and further supported by expermental data. Additional proof in wivo was obtained in chronic experimental autoimmune encephabomyelitis (EAE), an estabished animal model reflecting major pathogenetc hallmarks of multiple sclerosis.

\section{Materials and Methods}

\section{$A B C B 1$ and $A B C G 2$ genotyping in multiple sclerosis patients and healthy controls}

Genotyping of 832 multiple scierosk patimsts from three sites in Gemrany (Gótingen, $n=166$, Rostock, $n=423$, Berg, $n=194$ ) and one site in Spain (Barceiona, $n=49$ ) (Table 1 ) was performed after informed consent according to the Dedaration of Helsink and approwal by local ethics committees. Control samples were obtained from blood donors of the bcal blood bunik (Cöttingen, $n=191$ ) (von Areen ef al., 2000) and volunters (Gottingen, Bochum $n=73$ ) without history of neurological disease. TaqMun ${ }^{M M}$ PCR was PEformed for ABCG2 V12M (treference SNP $\mathrm{m} 22231137$ ) and Q141K (n2231142) uning Platinum OPCR Supermax-UDC (invitrogen, Karkohe, Gernany) on a 7500 heal Time PCR system (Appled Biosysterns, Darmitadt, Cermany. ABCA1 34350T genotyping (is 1045642) (whole cohort) and ABCB1 2677CO.T (MX-treated cohort, n2032582) was pefformed as described before (von Ahsen $f a f, 2001)$ and detailed in the suppiementary tobie. 
Table 1 Clinical characteristics of muitiple sclerosis-cohorts genotyped for ABCB1 and ABCG2 (Göttingen, Rostocic, Barcelona, Berg)

\begin{tabular}{|c|c|c|c|c|c|}
\hline & All centres & Barcelona, Spain & Cöttingen, Germany & Berg, Germany & Rostock, Gernmany \\
\hline Gendet, $n\left({ }^{2} \mathrm{~K}\right)$ & $\begin{array}{l}\text { Male, } 268(32.22) \\
\text { femide } 563^{\circ}(67.7)\end{array}$ & $\begin{array}{l}\text { Male } 22 \text { (44.9); } \\
\text { female: } 27\langle 55.1)\end{array}$ & $\begin{array}{l}\text { Male: } 52(31,3) \\
\text { female } 114\langle 68.7\rangle\end{array}$ & $\begin{array}{l}\text { Male } 87(44.8) ; \\
\text { fenaie: } 106^{\circ}(54.6)\end{array}$ & $\begin{array}{l}\text { Male: } 107(25.3) \\
\text { female: } 316(74.7)\end{array}$ \\
\hline $\begin{array}{l}\text { Age, median (25th-75th } \\
\text { percentilis) }\end{array}$ & $45(37-52)$ & $39(34-46)$ & $44(37-51)$ & 4) (41-53) & $46(38-53)$ \\
\hline $\begin{array}{l}\text { Age at dsease onset, median } \\
\text { (25th-75th percentile) }\end{array}$ & $31(24-39)$ & n.a. & $30.5(24-40)$ & $31.05-37)$ & $31(24-39)$ \\
\hline $\begin{array}{l}\text { Age at disease diagnosis, median } \\
\text { (2sth-75th percentile) }\end{array}$ & $35(28-43)$ & $24(203-33)$ & $35(29-42)$ & na. & $35(27-43)$ \\
\hline \multicolumn{6}{|l|}{ Disease course, $n(\%)$} \\
\hline futapsing remitting & $418(50.3)$ & $22(44.9)$ & $92(55.4)$ & $23(11.9)$ & $281(66.4)$ \\
\hline Secondary progressive & $342(41.2)$ & $27(55.1)$ & 4) (2a.3) & $145(74.7)$ & $123(29.1)$ \\
\hline Frimary progressive & $65(7.89$ & & $24(14.5)$ & $25(129)$ & $16(3.8)$ \\
\hline Atypical & $6(0.7)$ & & $2(1.2)$ & $1(0.5)$ & $310 \pi$ \\
\hline Mussing & $1(0.7)$ & & $1(0.6)$ & & \\
\hline Total & 832 & 49 & 166 & $\$ 94$ & 423. \\
\hline
\end{tabular}

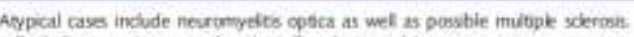
a Excluding one tronsersid patient fernale to maks

b Eeluding one gansievual patient (hmak to male)

\section{Quantification of $A B C B 1$ and $A B C G 2$ mRNA expression from human cells and tissues}

Primary human aduit gial celis (microgih, olgodendrocytes: astrocytes) of $>95 \%$ purity were solated from surgical resectates obtained from the treatment of nontumour-related intractable epiepsy as described tefore (Chan ef al, 2003). Perioheral bioed mononuckeas celk (PBMC) were isolated using BD vacutsiner CPI/Na-citrate (Becton Dickinson, Heidelberg, Geemany). Human CNS frontal cortex total RNA was purchesed from Ambion (Humtingdon United Kingdom, cDNA from cardiac tinsue was trom explamed organs of heart transplant recipients, hepatocyte CDNA originated from the resection margh of liver tumours. Relative quantification of $A B C$ MRNA expression using the $\triangle \Delta C$ method employed RNA polymerase

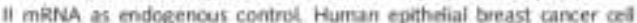
ine $M C F$ (OSMZ. Braunsciwedg Germany) with stable ABC InRNA

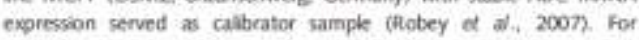
quantification of $\mathrm{ABCC} 2$ mikNA-expression Quantifect Primer Assay His_A8CC2_SG, was used (Qiagen Hiden, Germany) with Quentifect 5 YBQ Green PCR kit. ABCBT-/RNA polymerase II MRNA expression was investigated using Platinum qPCR supermix-UDG (Invitrogen) supplemented with SYBR Green OMobecular Probes. Eupene, OR. USA, ser also supplemertary tabie).

\section{In vitro $M X$ efflux/cell-death assay}

MX efflux was imestigated in freshly bolated CD56* NK-cells is98\% puity, magnetic cell sorting (MACS). Miltenyi tiotec, Bergisch Clacbach, Germanyl folowing a moditication of a previously described protocol (Hitsi et al,; 2001). The assay s based on flow cytometric quantification of intracelisiar $\mathrm{MX}$ (Chan et $a l, ., 2005)$ in the presence or absence of specific inhibitors of $\mathrm{ABC}$ transporten at establshed

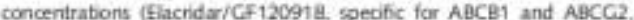
$2.5 \mu \mathrm{M}$, GlaxoSmithkline, Collegevile, PA], PSC-833/Vaispodar, ABCB1-specific $(2.5 \mu \mathrm{M}$, PKF215-833, Novartis, Basel Switzeriand). fumtremorgh C, AaCG2-specific (10 „M. FC, Avexis Bocherricak, Lörach, Germary) (Schinivel and Jonker, 2003: Robey of af., 2007). 600000 cels (RPMI 1640/10\% FCS) were pre-incubated $(15 \mathrm{~min}$, $37^{\circ} \mathrm{C} / 5 \%, \mathrm{CO}$ ) with respective hithibitors followed by $1 \mu \mathrm{M} M \times$ (Gry Pharma, Kirchzarten, Germany, $30 \mathrm{~min}$ - $37 \mathrm{C} / 5 \% \mathrm{CO}_{2}$, corresponding to the serum concentraton after intravenous administration of $12 \mathrm{mg}^{\prime} \mathrm{m}^{2} \mathrm{MX}$ OHu et al., 1992). For $M X$ efflux, washed cels were resuspended in $4 \mathrm{ml} 37 \mathrm{C}$ pre-warned medium, with or without inhibitor and incubated for another $10 \mathrm{~min}$ (3) $\mathrm{C} / 5 \% \mathrm{CO}$.

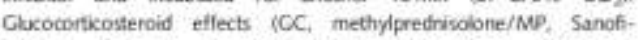
Aventis, Frankfurt, Germany, dexamethasone/DEX, Ratiopharm Gimbit Uim, Germany) on MX accumulation and cel death were

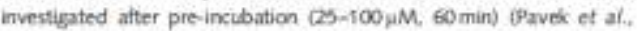
2005) folowed by MX etfilux as hidicated above in the presence of rexpective CC. After wasting, peopidum ibdide staining (PI, $0.3 \mathrm{ug} / \mathrm{m}$, Sigma Aldrich, Steinheim, Germany) excluded celts with imoaited plasma membrane integrity thpically $<1.6 \%$ ). A minimum of 5000 Pl-negative cells were analysed using FACSCaibur/Cell Questsoltware (Becton Dickinson). Cell-death anabsis (Annexiny-FiTC, F. Roche Biocherricak Mannheim, Germany) was performed after $M X$ incubation $(30 \propto 60 \mathrm{~min}$ ) and $M X$ efficix followed by ovemight incubation $37 \% \mathrm{C}, 5 \% \mathrm{CO}\rangle$

Induction of experimental autoimmune encephalomyelitis, $\mathrm{MX}$ treatment and histology

All animal experiments were approved by responsble authonties in Lower Saxonia. Germany. Abcg2-i- animals were backerossed to C7fi./6 background for at kast eght penerations, control mice were purchased from Harlan (Bonchen, Germany). Mice were anaesthetced with ketamine tydrochloride (hnress, Freiburg, Germary) and xylazine-fipdrochioride (CEVA, Düsseldorf, Germany) n $0.9 \%$ N.:C. and immunized subcutaneourily isd with $50 \mathrm{\mu g}$ myelin oligodendrocyte sycoprotein MOC, of complete Freund's adjuvant [CFA] containing Mycobacterium 
tuberculosis HBXRA (Difco, Detroit MI, USA, 1mg/mi). Pertussik torin (Lstilological Laboratories, Camptel, CA. USA $200 \mathrm{ng}$ ip.) was given on days 0 and 2. Arimals were weighed and scored daily in a blinded fashion using the following clinical soote: 0 normal, 1 reduced tail tone; 2 limp tail, impaired righting 3 absent righting; 4 gait ataxis. 5 mild paraparesis; 6 moberate paraparess; 7 severe paraparesic/ paraple pa: 8 tetraparesis; 9 monbund, and 10 death. $M X$ was injected intravenousy (iv) after disease conet on days 12-14 and 16 (0.5 mg/ $\mathrm{kg}$ body weight. Three-micrometre spinai cord paratfin cross-sections from animals perfured on day 23 or 29 were stained with Luxol fast biue Demyelinated areas were calculated as percentage from total white mutter (minimal 4 , in most cases six spinal cord sections per anima) as analysed by imagefrocessing soltware on a Oympus microscope:

\section{Retrospective clinical correlation of genotype and $M X$ response}

Patient sumples were genotyped for AACB1 2677 COT . 3435C OT. $A B C G 2$ V12M and $Q 141 \mathrm{~K}$ and retrospectively corretated with dinical MX response. Genotyping and assessment of clinical resporses were perforned blinded from each other by ditferent investgators. All patients (Table 3) had been diagnosed according to Poser-1 Moonad-oriteria (Poser and Brinar, 2004) and had been treated whth $M \times$ following established protocols itdan ef al., 1997; Hartung ef al. 2002). Due to presimably different pathopenesis and lack of therapeutic MX efficacy, primary progressive multiple sclercosk patients were not included in the andyses (5tive ef $1 ., 2004)$. One handred and filty-five patients (Götingen $n=11$, Rostock $n=37$, Berg $n=107$ ) had received MX monotherapy every 3 months folowing the MIMS protocol Hatung of of, 20002, in this cohort CC pulse therapies were only given during exacerbations. One handred and fiftyfour patents had undergone MOKCC combination therapy (Gottingen/Rostock $n=57$, flarcelona $n=46$, Beyg $n=51$ ) of these, German MX/GC patients had recrived methylorednisolione $1 \mathrm{~g}$ iv. over $3-5$ days in combination with MX every 3 months. Spanish MXICC patients had received $4 \mathrm{mg}$ desamethasone ix, immedately before three $\mathrm{MX}$ infusions every month, folowed by thee monthly intervals. Deckion for MXUCC combination was on clinical grounds, s.g. continuous canical activity or better tolerability. To dssess therapy response, at kast one of the following critera had to be fullited. expinded disability status scak (EDSS) stabilityfimprovement lin case of non-respondess EDS5 deterioration of 1 point (ED $55<6.0$ or 0.5 points (EDSS $\geqslant 6.0$ ) (number of patients dassified according to this aiterion $n=294, n=165$ confiemed at minimum 2 dfferent time pointst: improvement of relapse rate $(n=110)$; multipie scierosk func. tonal mmposite (MSFC) stabaty/improvement $(n-10)$ or magnetic resonance imaging activity (Cd-enhancement, $n=15$ ): and lack of dis: ease progession as deternined by the physician $\langle n=157$, of these 150 fulfiled at least one other criterioni). For most of the patients, asess. ment was based on several of these citeria. Where applicable, mag. netic motor evoked potentials (MEP, asessment at central motor conduction time, amplitude and configuration, $n=63$ ) served to confom assignment to response groups. Treatment response was anubsed after 12 months on trestment $(89.3 \%$ of the patients). If sufficient dita was laching at 12 months, data after 9 months treatment (10\%) was analysed if neither data after 12 nor 9 months was avaliable. response was asessed at the end of treatment (21-24 monits. $0.7 \%$ of patients). Patients with severe candiac $(n=28$, medan cumu. lative $M X$ dosage $72 \mathrm{mg} / \mathrm{m}^{2}, 56-93 ; 25 \mathrm{~h}-75$ th percertie) and patients with haematolopical side effects $(n=8$, therapy associated leukaemia, agranulocytoxis, median cumulative $M X$ dosage $72 \mathrm{mg}$ ' $\mathrm{Im}^{x}, 72-72$ ), were retrospectively conelated with $A B C$-transporter genotype. Of these, samples from 10 patients with $M X$-associated cartotoxicity were colected separately from the terin site in this group, one patient had developed a severe, biopsy-proven cardiotovioty diready after $24 \mathrm{~m} / \mathrm{m}^{2}$ ' (Dosr et af., 2009), three patients a significart decrease of echocarsiographic LVEF $(310 \%)$, and six patients a diastoic dystunction.

\section{Statistical analysis}

Descriptive statisties were reported as modian and 29th and 75th percentile unles stated otherwise. Continuous data were compared using the exact Wicoxon test. Apoptosis rates in vitno were analyged by one way andivis of variance using the post hoc Student-NewmanKeuls test for grouping. P,values were reported two-sided if not reported otherwise. Cross-tabulation of research data often led to ails with expected frequencies of $<5$. Therefore exact statistics were used for inference. Fisher's exact test was used for the $2 \times 2$ case. the forief-freernan-Halton test for the $2 \times 3$ case and the exact Cochran-Avmetage test for trend on genotype scores in the additive model 0.1.2. Eact statistics were cakulated as implemented in SPSS 16 for Windows. The exact-ake odds ratio for the association between response/non-response and the genetic burden score $(A B C B)$ I $A B C C 2+H /-U-t)$ was calculated in $R 2.9 .0$ using the elm package (Zamar et al., 2007) with a Markov chain size of $25 \mathrm{ec}$. The Coctiran-Armitage test reports the onesided. P.yalue because only one drection of trend was of interest and plasible given the in vitro and experimental autoimmune encephalomyelitis in vivo resuits (Zheng $\mathrm{A}$ al, 2003; 2008). Inheition of MX efflux by CCS was tested using the Kolmogoror-Smimor (KS) statistic $D$ (KS D) Reith et al., 1999). To determine differences in experimental autoimmune encephalomyelits course by Mann-Whitrey U-test, analysis was performed from anset of daease intil the end of observation rather than for indvidusl time points.

\section{Results}

$A B C B 1$ and $A B C G 2$ are highly polymorphic in multiple sclerosis populations of central European ancestry with no major differences to healthy donors

Clinical dats of the 832 multiple sclerosis patients genatyped are giver in Table 1. Of five different ABCC2 SNPS with potential functional significance investigated, only reference SNP (rs) 2231137 (G>A) leading to a V12M substitution and $r 2231142$ (C) $A$ ) resulting in a Q141K substitution were observed. As detailed in Table 2, $14.8 \%$ multiple scletosis patients were homozygous for the common aleies both for $A B C B 1$ and ABCCI (wild type). In contrast. $22.2 \%$ were at least heterozygous for variant aleles in both $A B C B 1$ and $A B C G 2$. Total $63.1 \%$ of the patients were at least heterozygous for variant alleles in either $A B C B 1$ or $A B C G 2$. All SNPS were found to be in HartyWeinberg equitibrium. For $A B C B$ T $2677 \mathrm{C} S \mathrm{~T}$ and $3435 \mathrm{C} T \mathrm{~T}$ no 
Table 2 Genotyping of multiple sclerosis patients and healthy controls for $A B C B 1$ and $A B C G 2$

\begin{tabular}{|c|c|c|c|c|}
\hline & Healthy donors & Multiple sderosis patients & $P$ & HapMap data \\
\hline$A B C G 2,12 \mathrm{VY}$ & $237(89.8 \times)$ & $784(94.2 \% 6)$ & & $58(96.7 \%)$ \\
\hline$A B C C 2.12 \mathrm{VM}$ & $26-(9.89)$ & $47(5.6 \%)$ & & $2(3.3 \%)$ \\
\hline$A B C G 2+12 \mathrm{MM}$ & $1(0,4 \%)$ & $1(0.1 \mathrm{x})$ & & $0(0.0 x)$ \\
\hline Fiequency of WT allese $\langle\mathrm{SO}\rangle$ & $0.95(00010)$ & $0.97(0.004)$ & & \\
\hline Total & $264(100.0 \%)$ & $832(900.0 \%)$ & 0.023 & $60(100.0 \%)$ \\
\hline$A B C G 2.141 C O$ & $214(81.1 \%)$ & $658(79.1 \%)$ & & $89(78.8 \%)$ \\
\hline ABCC2.949QK & $46(17,4 \times 6)$ & $163(19.6 \times)$ & & $23(20.4 \%)$ \\
\hline AACG2:141KK & $4\langle 15 \%\rangle$ & $11(1.3 \%)$ & & $1(0.92)$ \\
\hline Frequency of WT allede (SO) & $0.90\{0.014\}$ & $0.89(0.008)$ & & \\
\hline Total & $264(100.0 \%)$ & $832(100.0 \%)$ & 0.746 & $113(200.0 \%)$ \\
\hline$A B C B 1-2617 C G$ & $63\langle 307 \times)$ & $105(29.836)$ & & $22(19.5 \mathrm{~s})$ \\
\hline ABCBI-267TCT & $99\langle 48.3 \times)$ & $178(506 \%)$ & & $62(549 \%)$ \\
\hline$A B C B 1-267711$ & $43\{21,0 \%\}$ & $6(19.6 \%)$ & & $29(25.7 \%)$ \\
\hline Frequency of WT aliele (SD) & $0.55+0.025)$ & $0.55(0.019)$ & & \\
\hline Total & $205(900.096)$ & $352(100.0 \%)$ & 0.856 & $113(100.0 \%)$ \\
\hline$A B C B T-3435 C C$ & $58(22.0 \%)$ & $187(22.6 \%)$ & & $33(29.2 \pi)$ \\
\hline$A A C B T-3435 C T$ & $136(51.5 \%)$ & $414(50.1 \%)$ & & $63(55.8 \%)$ \\
\hline ABCBT-3435TT & 70 (265\%) & $225(27.2 \%)$ & & $17(15.0 \%)$ \\
\hline Frequency of WT allete (SO) & $0.48<00213$ & $0.48(0.012)$ & & \\
\hline Total & $264(900.02)$ & $826(1200.05)$ & 0.999 & $113(100.0 \%)$ \\
\hline \multicolumn{5}{|l|}{ Common alkes $A B C B 1$ and $A B C G 2$} \\
\hline$\triangle A B C B=1 / A B C C D 2-H 1$ & $28\{13,7 \times 6\}$ & $52\langle 14.8 \%\}$ & & \\
\hline 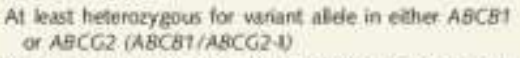 & $135(65.9 \%)$ & $222(63.18)$ & & \\
\hline $\begin{array}{l}\text { At least heteruzygous foe variant aldes in } A B C B 1 \text { and } \\
A B C C 2 \angle A B C B 1 / A B C G 2-1)\end{array}$ & $42(20.5 \%)$ & $78(222 * 6)$ & & \\
\hline Total & $200(1000.0 \%)$ & $352(100.0 \% 6)$ & 0.834 & \\
\hline
\end{tabular}

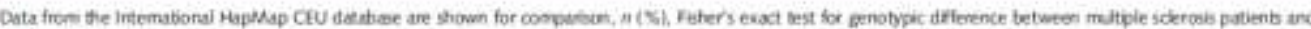
besithy caritich

difference could be detected between the mutiple sclerosis poputations and healtry donors. For $A B C O 2$, the frequency of variant allele vi2-codon was very low with $0.03 \%$ in multiple sderosic patients and $0.05 \%$ in healtihy donors $(P=0.023)$, whereas no difference was observed for Q141. There was no difference in genotype frequencies between unselected multiple scleross cohorts (Givtingen, Rostock) and MX-treated multiple sderosis cohorts (Barceiona, Berg). A high degree of linkage disequilbrium was found between $A B C G 2$ V12M and Q141K llinkage $\mathrm{D}=0.854$, (Gaunt et al., 2007). These findings demonstrate that potentially functionally variant aleles for $A B C B 7$ and $A B C C 2$ occur frequently in our multipie scierosis cohorts without indication of a role in disease susceptibility.

\section{High $A B C B 1-/ A B C G 2$ mRNA} expression in different cells/organs potentially affected by $M X$ therapy

Analysis of ABC-trarsporter mRNA expression showed 3.9-fold higher $\mathrm{ABCO}$ expression of $\mathrm{CD}^{\circ} 6^{\circ}$ cells than unsorted peripheral blood mononuclear cells and even more in comparison to CD19: B-cels (Fig. 1A). High ABCG2 mRNA expression was ako observed in human CNS-celk, especially human frontal cortical brain tissue 153 -fold in comparison to periph eral blood mononsidear cels), olgodendrocytes (19-fold). and microgla (17-fold). Also human myocardium (16-fold in comparison to peripheral blood mononudear cells) and liver tissue (76-fold) demonstrated high expression, As depicted in Fig 18, al investigated cells exhibited also high $A B C B 7$ mANA expression, with highest vatues in $\operatorname{CD56} 6^{+}$cels, oligodendrocytes, iver and cortex

\section{$A B C B 1 / A B C G 2$ genotype determines} in vitro $M X$ efflux and $M X$-induced cell death in multiple sclerosis patients and healthy donors

As depicted in Fig. 2A, AAC-transporter-mediated $M X$ efflux was compared in $\mathrm{CDS}^{\circ}$ cells of a multiple sclerosis patient with the common $A B C B$ 1/ABCC2 aleles (ABCB)-2677CG, -3435CC $A B C G 2-12 V \mathrm{~V},-14100$, wild type) with a patient carrying variant aleles in both genes (ABCB1-2677T, -3435T, ABCC2-12VM $-1410 Q$ ). Using the dual $A B C B 1-/ A B C G 2$-inthbitor Elscridar wildtype sequences determined higher $M X$ efflux in comparison to the latter genotype. The wild-type genotype was therefore designated 

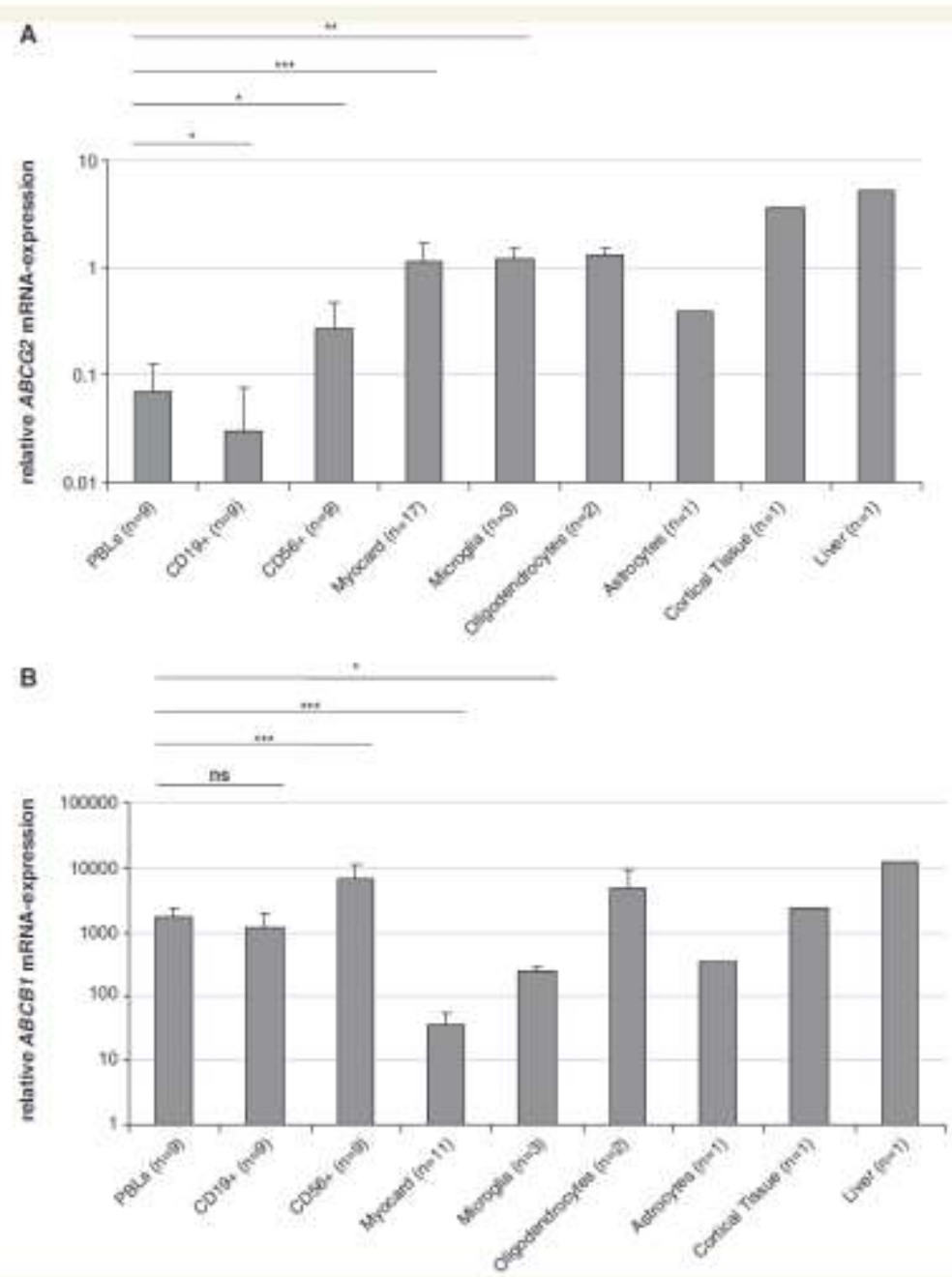

Figure 1 (A) Hgh ABCG2 mRNA expression in different cells/tissues potentially affected by MX therapy. Relative ABCG2 mRNA expression using human breast cancer cell line MCF-7 as calibrator and RNA polymerase 11 as endogenoss control. $n=$ number of different samples. $\rightarrow P<0.05, \cdots P<0.01, \cdots P<0.0001$, Mann-Whitney U-test. (B) High ABCet mRNA expression in different celk? tissues potentialy affected by MX therapy. Same samples as in Fig. 1A Relative ABCBT miNA expression using human breast cancer cell hine MCF-7 as calibrator and RNA polymerase II as endogenous control. $* P<0.05, \cdots * P<0.0001$, Mann-Whitrey U-test. PBLS: peripheraj blood mononuckar celk.

$A B C B S / A B C G 2-H($ igh) elflux in contrast to genotypes with at least heterozygous variant alleies in both genes, designated genotype $A B C B 1 / A B C G 2-L$ low efflux). The same effect of genotype-dependent $M X$ efflux was observed in healthy individuals ( $F$ is. 2A). enabling us to investigate addeional healthy controls after proof of principle in mutiple sclerosis patients. Figure 28 depicts cumulative data for 12 individuah (six pairs of different genotypes) with $37.7 \%$ lower ABC-mediated $M X$ efflux in ABCB1/ABCG2-L genotypes imean flucrescence intensity (MF) 164.3) than in respective indivduats with $+\mathrm{H}$ genotype (MFI 263.5, $P=0.031$ ). In preliminary experiments, individuals polymorphic in etther $A B C B 1$ or $A B C Q 2$ exhibited intermediate $M X$ effux (ABCB1/ABCC2-Kentermediate) 


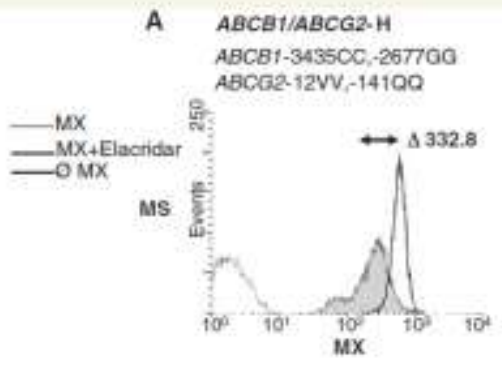

\section{ABCB1/ABCG2-L}

ABCB1-3435Tा,-267Tा

$A B C$ C2-12VM-14100
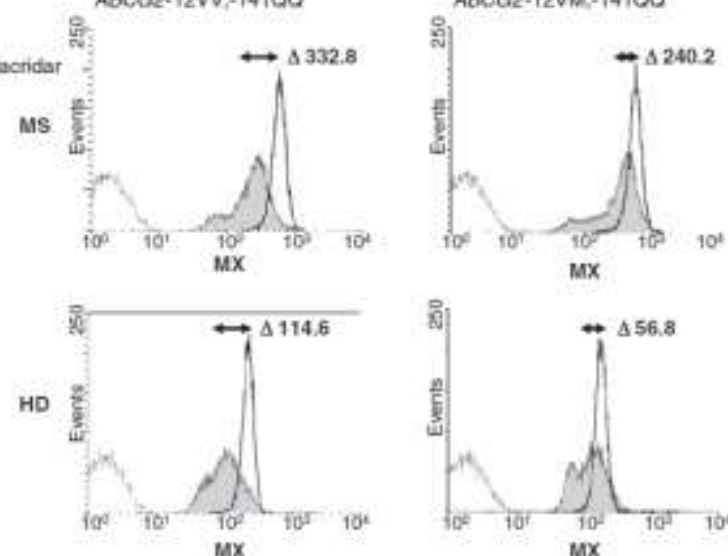

B

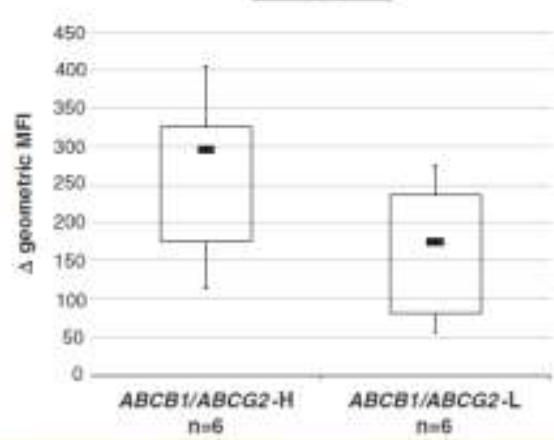

Figure 2 (A) $A B C B$ 1-/ABCC2-genotype determines in. vitro $M X$ efllux in multiple solerosis patients and healthy donors, Purifled CD56 cels of a multiple sclerosis (MS) patient homozygous for the common alleles (ABCB1-3435CC, -2677GG, ABCG2-12WV. $-141 Q Q$ ) designated $A B C B 7 / A B C G 2-H(i g h)$ exhibit higher $A B C$-transporter mediated $M X$ efflux than a multiple sclerosis patient

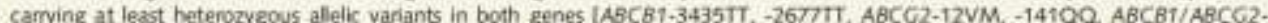
LOW)] Analogous results are obtained from a pair of healthy (HD) $A B C B 1 / A B C C 2-\mathrm{H}$ and $-L$ individuals, respectively, $\triangle$; difference of mean geometric fluoxescence intensity between histograms, higher $\triangle$ hicates move efficient $A B C$-mediated $M X$ efflux. Histograms of intracelular MX in the presence of specifo $A A C B 1-/ A B C G 2$-inhibitor Bacridar $(2.5 \mu M$, black histogram) or without nhibitor (gey filled histogram), tight grey histogram: control without $M X$. MACS-sorted $C D 56^{\circ}$ cels $(>98 \%$ purity), $14 M M X$, representathe experiments (B) $A B C B 1-/ A B C G 2$-genotype determines in vitro $M X$ effux in multiple sclerosis patients and healthy donors. CDS6' cells of multiple sderosis putients $(n=2)$ or healthy donors $(n=4)$ carrying the $A B C B 1 / A B C G 2-\mathrm{L}$ genotype (five individuals $A B C B 1-343517$, one $-3435 C T$, four -26771 , two $-2677 G$ T. two $A B C G 2-12 V M$ and four $-1410 K$ ), exhibi less $M X$ efflux than respective $A B C B 7 / A B C G 2-H$ multiple sclerosis patients $(n=2)$ /healithy donors $(n=4)$. Ordinate ( $\Delta$ geometric $M F$ ) indicates difference in geometric mean fluorescence intensity representing intracellular $M X$ concentration as caloulated by efflux inhibited by ABCB1/ABCG2-inhibitor Elacridar minus non-inhibited efflux, Higher values indicate more efficient ABC-mediated MX efflux. Different genotype carriers were investigated painwse. $* P=0.031$ (Wilcoxon test). Box plot mepresenting median (line) and upper/lower quartile

efflux, dats not shown]. In comparison to the dual ABCB1/ABCC2nhibitor Elacridar, genotype dependent reduction of $M X$ efflux was less pronounced using the $\mathrm{ABCB1-seloctwe} \mathrm{inhibitor} \mathrm{PSC-833}$ $(P=0.062, n=5$ pairs of different genotypes). No clear effect was observed using the ABCG2-specific inheitor FTC alone kdata not shown).

As depicted in Fig, $3 \mathrm{~A}$ increased intracelular $\mathrm{MX}$ accumulation in an $A B C B 1 / A B C G 2-L$ muttiple sderosis patient results in preater 

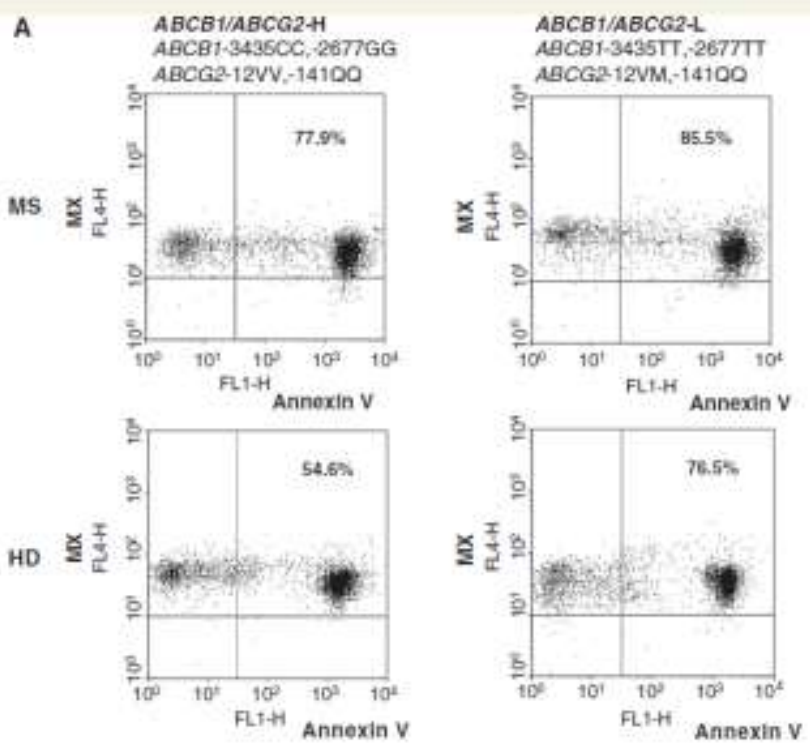

B

ns

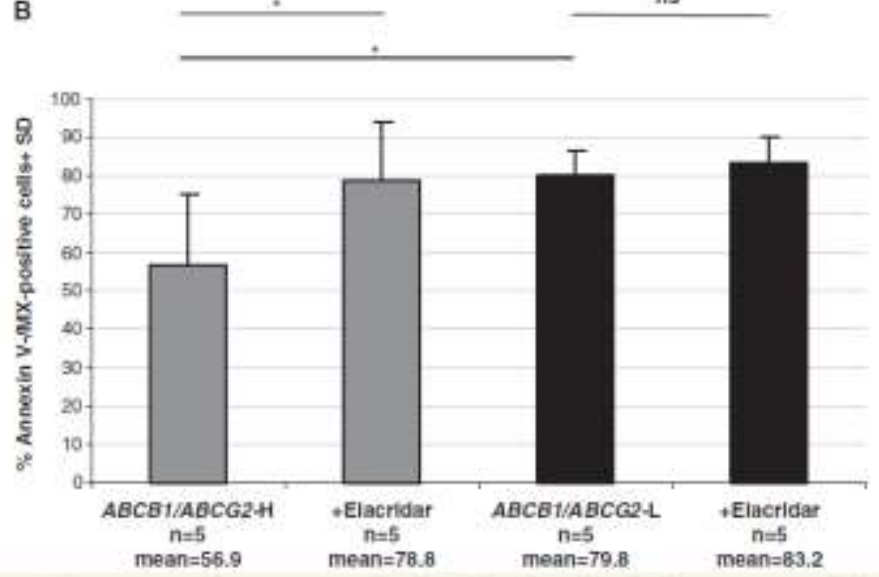

Figure 3 (A) ABCB1-1ABCG2-genctype determines $M X$-induced cell death in multiple scierosis patients and heafthy donors. CD56: cells of a $A B C B 1 / A B C G 2-L$ multiple scleross (MS) patient demonstrate higher proportion of $M X$-containing, dying cells

$\left(\mathrm{MX}^{+} / \mathrm{AnnexinV}^{*}\right)$ than cells of a $A B C B 1 / A B C C_{2} \cdot \mathrm{H}$ multiple soderosk patient. Similar results are obtained for healthy donors (HD) of respective genotypes. Twenty-four hours after $M X$ efflux, reperentative experiments, (B) $A B C B 1-1 A B C G 2$-genotype determines $\mathrm{MX}$-induced cel death in multiple sckerosis patients and healthy donork. $A B C B 1 / A B C C 2 \cdot L$ gene carrien exhibit higher proportions of $M X$-containing, dying colk $\left(M X^{+} / A n n e x i n V^{*}\right)$ than $A B C B 1 / A B C G 2 \cdot H$-genotype individuals $(P<0,05$, Anova). This is due to $A B C B 7$ $A B C G$-genotype, since inhibition of $M X$ efflux in $C D 56^{+}$cells of $A B C B 1 / A B C G 2 \cdot H$ gene carriers by dual $A B C 81 / A B C G 2$-inhibito Elacridar leads to higher proportion $M X^{-} / A m e x i n V^{\prime}$, cells $(P<0.05)$ than in $A B C B 7 / A B C G 2 \cdot L$ patients $(P=N S)$. Each genotype: 1 multiple scleross patient, 4 healthy donors (24h after $M X$ efflux). (O GCr inhibit $M X$ efflux, $M X$ efflux from CD56* cells of an $A B C C 2-/ A B C B 1$ - H healthy individual is inhibited by methylprednisolone (MP) or dexamethasone (DEX). Histogramis of intracellular $M X$ in the presence of MP ar DEX (50 $\mathrm{MM}$, black histogram) in comparison to MX effiux without GC (grey filled histograms). Light grey histogram: contral without $M X$. $\Delta$ : difference of mean geometric fluorescence intensity representing intracellutu $M X$ concentration as calculated by efflux inhibited by GC minus non-inhibited efflux. D. Kolmogorov-Smimov test statistics. One representative experiment of three (two healthy donors, one multiple sclerosis patient. $* P<0.05$. 

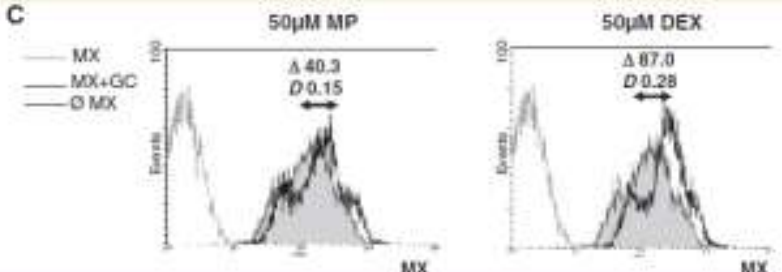

Figure 3 Continued.

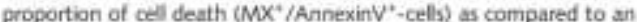
$A B C B 1 / A B C C 2-\mathrm{H}$ muliple sclerosis patient. Again, similar effects were observed in healthy donors (Fig. 3A). Andysing one pair of multiple sclerosis patients and four pairs of healithy controb; individuals with $A B C B 1 / A B C G 2+L$ genotypes had $229 \%$ more $M^{*} /$ AmexinV' Fig. 3B, $P<0.05$ ) and $16.1 \%$ more $M^{*} / P^{*}$ double positive celk (data not shown) than individuals canying the $A B C B 1 / A B C C 2 \cdot H$ genotype. Inhibition of $M X$ efflux by dual ABCB1/ABCG2-inhibitor Elacridar led to increased cel death in $A B C B 1 / A B C G 2-H$ individuals by $21.9 \%(\mathrm{MX} / /$ Annexiny" cels, $P<0.05$ ), wheress this increase was only $3.5 \%$ in the L-genotype individuals (NS), arguing for differential susceptibility to $M X$-induced cell death dependent on respective $A B C B 1 / A B C G 2$-transporter genotypes presumably via differential $M X$ accumulation.

In clinical practice, $M X$ is often combined with GCs (Morrissey et af., 2005): Thus, we next examined the influence of the GCS methylprednisolone (MP) and dexamethasone (DEX) on intracel. Lilar $M X$ accimulation and $M X$-induced cell desth. In CDS6' cells of individuals with $A B C B 1 / A B C C 2-\mathrm{H}$ gene sequences, both methylprednisolone and dexamethasone significantly inhibited $M \times$ efflux (Fig. 3C). After $24 \mathrm{~h}$ the addition of methylprednisolone led to an increase of $8 \% \mathrm{MX}^{+} / \mathrm{AnnexinV}^{+}$cel's in $A B C B 1 / \mathrm{ABCC2}-\mathrm{H}$ gene carriers $(n=2)$. This increase was presumably due to inhibition of $M X$ efflux and not to direct CC-mediated cell death, since only negligble changes $\left\{+0.52 \% \mathrm{MX}^{+} / \mathrm{Arnexin}^{\top} \text { cells }\right)_{\text {were }}$ seen in $A B C B 1 / A B C G 2+L$ individuals $(n=2)$

\section{Abc-transporter genotype determines therapeutic response to $\mathrm{MX}$ in experimental autoimmune encephalomyelitis}

To further eluodate functional significance of $A B C$-transporter genotype in vivo, treatment response to $\mathrm{MX}$ in $\mathrm{Abcg} 2^{-1-}$ mice was compared to respective wild-type animals in chronic MOGas-ss EAE MX therapeutically adninistered after onset of disease was down-titrated to a dose just not efficient in wild-type anmals as compared to respective sham-treated controls (Fig. 4A). in contrast, using this suboptimal $\mathrm{MX}$ dose, experimental autoimmune encephalomyelitis in $A B C g 2+$ mice was strongly ameliorated $(P<0.001)$. Effects on dinical course were also mirrored histologically with strangly reduced spinal cord demyelination in MX-treated

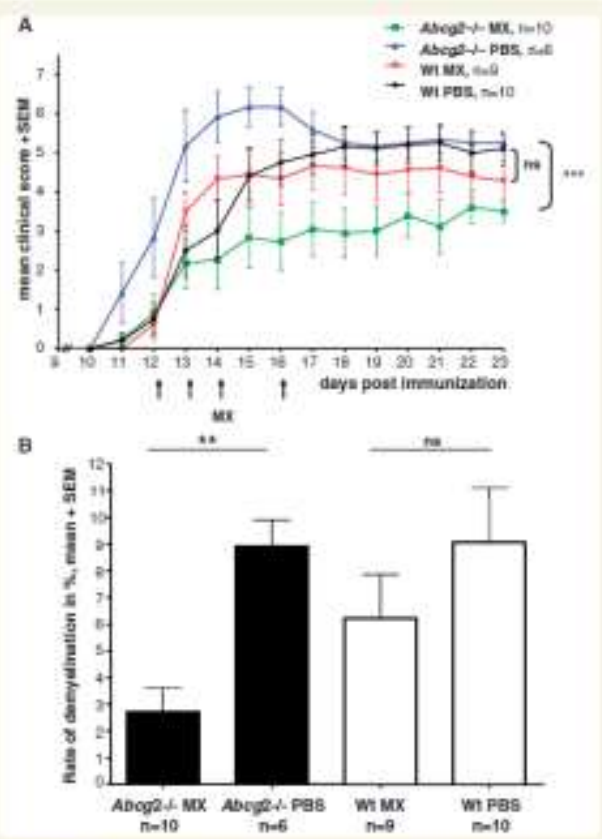

Figure 4 (A) $M X$ in suboptimal dose ameliorates dinical EAE in Abcg2 but not wild-type mice. Clinical disease course in C57Biv 6 wild-type (wt) animals is not atered using suboptimal $M X$ dose $(0.5 \mathrm{mg} / \mathrm{kg}$ body weight iv. Days $12-14$ and 16 . indicated by arrowit but strongly ameliorated in $A b c g 2^{*}$ mice in comparison to respective PBS-treated controls: $n=9 / 10$ for $M X$-treated $A b c 2^{-1}$ and $C 5784 / 6$ wt mice, $n=6$ for PBStreated $A b c g$ ? controls. Data pooled from two independent experiments showing analogous results. NS: P not significant

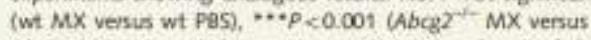
Abcg 2 PBS), Mann-Whithey U-test. (B) MX in suboptimal dose ameliorates demyelination in abcg2 EAE but not wild-type mice. Spinal cord demyelination (Luxol fast blue staining) in wt animsls is not sogrificantly altered using suboptimal $M X$ dose, but strongly reduced in $\mathrm{Abcg} 2^{2+}$ mice in compurison to sespective PBS-treated controk Duta from two independent experiments, NS: $P$ not significant, $* P<0.01$, Mann-Whitney U-test. 
Abciz $2^{-t}$ mice $(\beta<0.0 n)$, whereas wild-type animats treated with the suboptims $M X$ dose did not exhbit mejor differences in comparison to the reipective stam-treated controts (N5). In spinal cord of wild-type animals mRNA expression of the $A B C A T$ mouse anslogue $M d r / a / 1 b$ and $A b c g 2$ was not altered during experimental autoimmune encephalormelits with of without $M X$ treatment (peak of disease and chronic phase, data not shown).

\section{Effects of $A B C$-transporter genotype on therapeutic response to $M X$}

Of 353 fuly genotyped $M X$-treated patients, data of 339 patients fultiled strict assessment criteria for response dassification. Given pesumably different pathogenesis/MX response, PPMS patients were not included in the analyses. Thus, $309 m x$-treated patients from four centres were retrospectively analysed using quantitative parameters such as EDSS, relapse rate and MSFC as main outcome parameters. Of patients from all cohorts ( $M X$ monotherapy. MX/CC combination therapy), $68.6 \%$ responded to $M X$, whereas $31.4 \%$ were classified as non-responders. Among patients receiving MX monotherapy $(n=155) 78.1 \%$ were responders (Table 3, panel A). in $M X$ monotherapy patients carrying the $A B C B 1 / A B C G 2-H$ genotype had the lowest responder rate $(15 / 24,62.5 \%)$, carners of variant ascles in either $A B C B 1$ or $A B C C 2$ (ABCB1/ABCG2-1) exhbited an intermediate response $\langle 78 / 98,79.6 \%)$, whereas 28/33 (B4.8\%) with ABCA2/AACC2-t genotype were $M X$ responders $(P=0.039)$. Odds rabio for positive treatment response between $A B C B 1 / A B C G 2+H$ and - renotype was $1.9195 \% \mathrm{Cl}$ $1.0-3.5)$ and accordingly 3.5 between $A B C B 1 / A B C G 2-\mathrm{H}$ and - L-genotype. As shown in Table 4, baseline data for the $M X$ monotherapy group demonstrated a lower $\mathrm{MX}$ dosage for treat. ment responders at the time point of response classification. Other potential confounders such as age or disease duration at $M X$

Table 3 Association of ABC-transporter genotype with therapeutic response to $M X$ monotherapy, exact Cochran-Armitage test $(P=0.039)$ (panel A), or $M X / G C$ combination therapy $(P=0.348)$ (panel $B$ )

\begin{tabular}{lccc}
\hline & Total, $n$ (86) & $\begin{array}{l}\text { Responder, } \\
n(\%)\end{array}$ & $\begin{array}{l}\text { Non-Hesponder, } \\
n(\%)\end{array}$ \\
\hline A. MX monotherapy & & & \\
ABCB1/ABCG2-H & $24(15.5)$ & $15(62.5)$ & $9(37.5)$ \\
ABCB1/ABCG2-1 & $98(63.2)$ & $78(79.6)$ & $20(20.4)$ \\
ABCB1/ABCG2-L & $33(21.3)$ & $28(84.8)$ & $5(15.2)$ \\
Total & 155 & $121(78.1)$ & $34(21.9)$ \\
Bi: MX/CC Combination therapy & & \\
ABCB1/ABCG2-H & $21(13.6)$ & $12(57.1)$ & $9(42.9)$ \\
ABCB1/ABCG2-1 & $100(64.9)$ & $58(58.0)$ & $42(42.0)$ \\
ABCB1/ABCG2-L & $33(21.4)$ & $21(63.6)$ & $12(36.4)$ \\
Total & 154 & $91(59.1)$ & $63(40.9)$ \\
\hline
\end{tabular}

Retoopective analys using l0SS, relapse rate and MSC as main outcome wrameten to defire responden and non-responden, repectivety. Anaknis the

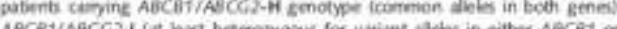

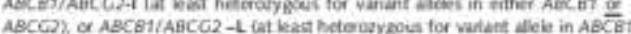
and $A B C(02)$. treatment, baseline expanded disabelity status scale of disease course/activity were not significantly different between responders and non-responders. Given profound effects of CCS on in vitro MX efflux as well as markedly different treatment protocol and baseline characteristios between MX-mono- and MX/GC cambination therapy groups (Table 4), the MX/GC combiration therapy group was andysed separately. Patients receiving MXUGC combination had a $59.1 \%$ response rate (Table 3, paned B). In the $M X / G C$ combination therapy cohort no dear genotype-dependent effect could be observed (Table 3, panel B). However, major differences in treatment protocol and basefine characteristics already within this group prectude further firm conclusions.

Since altered $M X$ efflux could also be related to organ-specific side effects, genotype distribution was analysed for severe cardac. or haematological side effects. While 30 of these 36 patients were at least heterozygous for variant aleles in at hast one $A B C$-gene. in this rebatwely small cohort there was no statistically relevant dfference in genotype frequency compared to the total multiple sclercsis population investigated. MUVOC combination therapy was often found in the cases with severe side effects: 11 of 28 patients with cardiac side effects had received GCIMX combi. nation therapy and the same heid true for seven of eight patients with severe haematological side effects in one case, unusually vevere side effects were associated with an $A B C$-genotype rarely found in the total multiple sclerosis-cohort: a 28-year-old female RRMS patient developed severe cardiac failure aiready after $24 \mathrm{mg} /$ $\mathrm{m}^{2} \mathrm{MX}$ ibiventricular ejection fraction $10 \%$, mult-organ faltire, biopsy exdusion of other causes (Dorr et al, 2009)1. The patient exhibited a genotype with homozygous variant alleles in two $A B C B 1$ - and one $A B C G 2$-locus examined in addition to a variant allow in the $A B C$-transporter $A B C C 2(r 5717620)$ ( $A B C B 1-26777$. $-3435 T$ T, ABCG2-141KK, ABCC2-116CD. This Renotype was very unusual among our unsebected multiple scherosis patients $10.55 \%$. Table 25

\section{Discussion}

Our main findinzs are a high prevalence of functionally relevant variant aleles in $A B C$-transporter genes in multiple sclenoss patients that determine $M X$ efflux and $M X$-hiduced cel death in immune cells. High ABC-transporter mRNA expression argues for a functional role also in CNS. and cardiac tissue. in who relevance. was corroborated in $\mathrm{MX}$-treated $\mathrm{Abcg} \mathrm{Z}^{-}$experimental autoimmune encephalomyelits mice. ABC-transporter genotype was associated with clinical response to $M \times$ therapy in multiple sclerosis. CCs that are clinicaly often used in combination inhibit in vitro. $M X$ efflux, suggesting synergistic effects at least in a subpopulation of patients

We have focissed on the most prominent ABC-transporters: previousily demonstrated to inffuence $M \times$ transport ischinkel and Jonker, 2003). The $A B C B 1$ 1 34350 T polymorphism is associated with intestinal expression levels and function and has the best validated effect on drug disposition (Hoffmeyer et al., 2000) For $A B C G 2$, onty V12M and Q141K polymorphems could be detected, in vitro lesding to disruption of apical membrase localization (V12M) or decreased ATPase function (Q141K) 
Table 4 Baseline characteristics according to $M X$ monotherapy and $M X / G C$ combination therapy, respectively

\begin{tabular}{|c|c|c|c|c|c|c|}
\hline & \multicolumn{3}{|l|}{ MX monotherapy } & \multicolumn{3}{|c|}{ MXUGC comthination therapy } \\
\hline & $\begin{array}{l}\text { Responder } \\
n=121(78,1 \times 4)\end{array}$ & $\begin{array}{l}\text { Nen-Responder } \\
n=34(21.9 \%)\end{array}$ & $P$ & $\begin{array}{l}\text { Pesponder } \\
n=91(59.1 \%)\end{array}$ & $\begin{array}{l}\text { Non-pesponder } \\
n=63(409 \%)\end{array}$ & p \\
\hline Gender & & & 0.310 & & & 0.033 \\
\hline Make, $n(\%)$ & $45(37.2)$ & $9(26,5)$ & & $33(96,3)$ & $34\langle(54,0)$ & \\
\hline femaic, a $(\%)$ & $76(62.8)$ & $25(73.5)$ & & $58(63 . n)$ & $29(46,0)$ & \\
\hline Centre & & & 0.041 & & & $-0,001$ \\
\hline Aarcelona, Spain & $a$ & o & & 23 & 23 & \\
\hline Gồttingen, Gemany & 6 & 5 & & 8 & 1 & \\
\hline Rostodk, Germany & 33 & 4 & & 4t & 7 & \\
\hline Berg. Cemmany & 82 & 25 & & 19 & 32 & \\
\hline $\begin{array}{l}\text { Age at disesse onset, median } \\
\text { (25th-75th percentile) }\end{array}$ & $30(23-39)$ & $32(26-39)$ & 0.367 & $29(22-35)$ & $33(27-39)$ & 0.028 \\
\hline $\begin{array}{l}\text { Age at disease dignosis" medan } \\
\text { (25th-75th percentile) }\end{array}$ & $39(31-47)$ & $36(28-44)$ & 0.494 & $32(24-40)$ & $26(22-37)$ & 0.094 \\
\hline Disense course, n $(\%)$ & & & 1.000 & & & 0.230 \\
\hline Relapsing-remitting & $17(14.0 \%)$ & $4(118)$ & & $23(25 ; 3)$ & $10(15,9)$ & \\
\hline Secondary progressive & $102(84.3)$ & $30(88.2)$ & & $68 .(74.7)$ & $53(84.1)$ & \\
\hline Atypical & $2(1,7)$ & $0 \mathrm{cos}$ & & & & \\
\hline Active patients, $n(\%)$ & $64(52.9)$ & $16(47,1)$ & 0.566 & $31(34,1)$ & $30\langle 47.6\rangle$ & 0.097 \\
\hline $\begin{array}{l}\text { Age at first } M 0 \text { infusion, medan } \\
\text { [25th-75th percentile] }\end{array}$ & $43(37-50)$ & $42(37-48)$ & 0.445 & $42(33-49)$ & $39(31-47)$ & 0.189 \\
\hline $\begin{array}{l}\text { Duration of disease at time point of first } \\
M X \text { infusion (disesse onseb), median } \\
\text { (25th-75th percentile) }\end{array}$ & $11(6-18)$ & $9(3-15)$ & 0.112 & $16(7-23)$ & $9(6-19)$ & 0.027 \\
\hline $\begin{array}{l}\text { Ouration of disease at time point of Eirst } \\
M X \text { infusion (discase diagnosib)" } \\
\text { median (25th-75th percentite) }\end{array}$ & $7(3-10)$ & $6(1-9)$ & 0.477 & $4(0-11)$ & $0(0-3)$ & 0.001 \\
\hline $\begin{array}{l}\text { EDSS at treatment arset, median } \\
\text { (25th-7sth percentile) }\end{array}$ & $60(4.0-6.5)$ & $55(4,3-6.0)$ & 0.288 & $6.0(4.5-65)$ & $2.5(4.0-6.0)$ & 0.093 \\
\hline $\begin{array}{l}\text { Number of cydes at time point of } \\
\text { response- classfication, median } \\
\text { (25th-7yth percentile) }\end{array}$ & $5(5-5)$ & $5(5-5)$ & 0.459 & $6(5-6)$ & $5(5-6)$ & 0.580 \\
\hline $\begin{array}{l}\text { MX dosage at time point of response } \\
\text { dasatication mg/m body surface, } \\
\text { median (25th-75th percentile) }\end{array}$ & $60(49.60)$ & $60(60-60)$ & $O .0 B O$ & $60(48-72)$ & $60\langle 60-72\}$ & 0.007 \\
\hline $\begin{array}{l}\text { Cumulative MX dosage ing/m² body } \\
\text { surface, mediun (25th- } 75 \text { th } \\
\text { percentile) }\end{array}$ & $90(60-114)$ & $90(60-119)$ & 0.920 & $72(54-100)$ & $72(72-419)$ & 0.419 \\
\hline
\end{tabular}

Atypical divease coune indudes neuromelies opha.

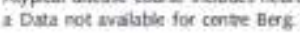

(Mizuarai et al., 2004). No major differences in genotype freqtencies were found in comparison to healthy donors and our data compared well to the HapMap CEU population The international HapMap Consortium 2007). Small differences in frequency of $A A C G 2$ variant allele V12 may best be explained by high variation that is expected for a low frequency aliele in a relatively smal sample. Therefore, our data does not indicate a role for $A B C$-transporters for disease susceptibility.

Functional significance of $A B C$-transporter genotypes was demonstrated in immune cels from multiple sclerosis patients and healthy controk. Cells from $A B C A T / A B C C_{2}-1$ genotype patients had lower in vitro $M \times$ efflux in comparison to $A B C B$ V/ $A B C G 2-H$ carriens Higher $M X$-induced cel death in $A B C B 1 /$ $A B C G 2-\mathrm{L}$ in comparison to $A B C B 1 / A B C C 2-\mathrm{H}$ and increase of $M X$-induced cell death sfter inhibition of both transporten only in $A B C B 1 / A B C G 2-H$ but not $A B C B 1 / A B C G 2-\mathrm{L}$ further supports functional relevance of investigated SNP5. Given rapid completion of the apoptotic cell death programme within $4-5 \mathrm{~h}$, at least in certain tissues and under defined conditions, even small quantitative differences in cell death at a goven bime point as shown here wil account for major cell bas over time (Pursch et al, 1990). Genotypedependent effects were demonstrated after inhibition of both ADCB1/ABCG2, while differences using monospectic inhibitors were less pronounced. This indicates an addive role of ABCB1 and $A B C G 2$ in $M X$ efflux, similar to effects in transgenic mice in which these transporters provide additive, functionally non-redundant protection agairst MX-induced cell death (Zhou et al., 2003). No condusion can be drawn from our data with regard to potential predominance of an ABC-transporter and the participation of additional mechanisms (e.g. other MOR transporters). However, even in anmats deficent only in Abcg? we could observe strong effects on therapeutic $M X$ efficacy, arguing for a major role of this transporter. 
Teil B: Publikation

Thus, together with unchanged mRNA expression of these Abctramporters in experimental autoimmune encephalomyelitis, no further evidence of redundancy could be observed. in our animal experimental approasch we tried to mirror the hypothesis that indviduals with $A B C-L$ genotype may respond to lower $M X$ dosages than other genotypes. Shice $M X$ is highly efficadious in different EAE-modeds (Weilbach et al. 2004) we down titrated the concentration to a dosage not effective any more in wild-type animals However, this dosage is fully effective in respective $A B \operatorname{cog} 2-k 0$ animaks. Whereas the aninal knock out situation may not be equivalent to gene polymorphisms, both functionally relevant $A B C$ C2-SNPS identified here interfere with either expression/bcalization and/or activity of the transporter. The levet of functional inactivation differs. widely (approximately factor 2-5) in a cel-type speofic manner (e.g. malignant cells, transfectants) (Mizuarai et al, 2004). Thus, we beleve that mechanistic conclusions can be drawn from our ia vivo animal model

Presumed drug targets of $M X$ in multiple sclerosis and experimental autoimmine encephabormelitis include peripheral immune cells, the blood-brain bartier and CNS effects in situ (Kopadze et al., 2006. Duddy et al., 2007). Instial observations of preferential cell death of $\mathrm{CD}^{2} 9^{+}$cells from $\mathrm{MX}$-treated multiple scleross patients with relative sparing of CDS6+ celk (Chan et al, 2005) led to our hypothesis that $A B C$-transporters critically influence $M X$ effects. Here, $\operatorname{COS} 6^{+}$oels showed highest $A B C$-transporter expression in comparison to $\mathrm{CD}_{19}{ }^{*}$ cels and unsorted peripheral blood mononucless cells. Recently, preferential MX-induced cell death of $\mathrm{CO}^{\circ} 9^{*} / \mathrm{CO} 2 \tau^{*}$ memory $B$ cells has been described, presumably altering the dysregulated B-cell cytokine network found in multiple sclerosis patients (Dudd et al.. 2007), however ABC-transporter expression has not been investigated in these cells yet High $A B C B 1-/ A B C G 2$ - mRNA expression in CNS-tisse, myocardium and liver indicate relevant functional roles at these sites, where $M X$ is detected up to 9 months after infusion (Mornssey et al, 2005).

MX is approved for highly active relapsing and secondary progressive multiple sderosis, with some authors promoting early use to halt aggressive disease (Gonsette, 2007). Whereas dinical characterstics that are associated with favourable therapeutic resporse have been identified (e.g, age at start of treatment, disease course/relapse rate, baseline EDSST die Page if al. 2007), thus far there are no biomarken that predict cinical efficacy and individual risk protile. Here, in $\mathrm{MX}$ monotherapy, $A B C B 7 / \mathrm{ABCC2}$. $\mathrm{L}$ patients were overnepresented among $\mathrm{MX}$ responders, whereas $A B C B 1 / A B C G 2-H$ genotype cartiers were less tikely $M X$ resporiders. Different $M X$ dosages between treatment responders and non-responders in MX monotherapy argue for validity of $A B C$-genotype effects, since lower dosage was found in the responder group No statistically significant difterencer were observed for other potential confounders fe $g$, durabion of disease, baseline expanded dsabitity status scale, disease course/activity) (Le Page et at., 2007) However, potential confounders were not controled for in this retrospective association with limited patient numbers avalable for extersive analysis even from four major academic multiple sckeross centres. Clinical assessment was canservative with semiquantitative parameters, assisted by electrophysiological or magnetic resonance imaging data. As a result, of the grotyped MX-treated patients, data from $95.7 \%$ of patients were eligible. Due to strong effects of $C C$ on $M X$ efflux in vitro, as well as profoundly different treatment regimen and taseline characteristics, subgrouping of $M X$ monotherapy and $M X / C C$ combination therapy cohorts was performed. This is further supported by demonstration of complex $C \mathcal{C}$ interaction: with ABC-transporters (e g inhbition, acting as substrate, regulation of ABC-transporter expression) (Pavek et al. 2005). Finally, the most stringent statistical approach using exact tests to strictly control for type I error was chosen. A prospective, multicentre contirmation study with recruitment of a large and homogenous patient groupp with control of potential confounders and unbiased treatment protocols will be mplemented in Cermany in 2009 by our group with a study duration of 3 years.

The clinicaly widely used GCIMx combination follows the empincal rationale of potentially increased efficacy and tolerability Morrissey et al. 2005). Here, we demonstrate an inhibitory effect of methylprednisolone and dexamethasone on $M X$ efflux in vitro, leading to increased $M X$-induced cell desth without additional CC-induced cell death. Hypothetically, this could lead to higher efficacy but also higher risk of side elfects, at least in a subpopulation e.g. chardcterized by $A B C$-genotype. Different response rates between $\mathrm{MX}$ monotherapy and $\mathrm{MX} / \mathrm{CC}$ combination therapy groups, as well as different baseline charactersistics preduded confimution of this hypothesis However, the oxcurrence of major cardiac or haematological side effects during MX/GC com bination therapy in conjunction with respective genotypes clearly warrants prospective evaluation. Statistical aralysis in pur patient group with severe side effects is limited by smal numbers and heterogeneous treatment schemes. On a descriptive level a case of very early biopsy proven $M X$-associated cardiotowicity with variant, in majority homocygous alleles in three ABC-transporter genes was identified (Dór et al., 2009). At least in our multople solerosis cohorts, frequency of this particular genotype was extremely low. further raising interest in the association with this unusually severe side effect. $A B C$-transporter genotype-dependent effects have been described in anthracydine-induced cardiotoxisity in non-Hodgkin lymphoms patents (Wajnowski et al, 2005). However, in the cohort mulbiple other risk factors for cardiatoxicity may play a tole le.g. medisstinal irradiation, cotreatment with cardiotoxic agents and oider age). In contrast multiple solerosis patients are typically younger, not treated in a polypragnatic approach and cardiologically otherwise healthy. Therefore, a larger prospective trial will be necessary to address these issues in multiple sderosis appropriately. The corroboration of $A B C$-penotypes as risk biomarkers could be supported by in witro investigations. While this appears feasible for cardionyocyte function, thus far there is no in vitro model for haematological side effects in this context, recently described potential genetic hotspots in treatment-related leukaemia in mutiple sclerosis are of interest (Hasanet at, 2008)

Is condusion, our data opens the possibitity to optimize individual risk/benefit profiles based on pharmacogenetic markers which may have a direct impact e.g. for individualized titration of dosages, intervals and safety monitoring. This is of particular interest since $M X$ is not expected to be replaced by ather wbstances in the near future and approache to optimization of $M X$ treatment such as addition of cardioprotective agents are stall experimental (Wobach et al, 2004; ilemitess et at, 2006). 


\section{Supplementary material}

Supplementary material is avalable at Brain online

\section{Acknowledgements}

The authors are grateful to Dr Phuc Nguyen and Prof. C. Hasenfus, Department of Candiology and Pneumolopy, University of Gottingen for generously peoviding CONA from cardiac tissue. PSC-833/Nalspodar was a generous gitt from Novatis, Namberg. Gemany, Elacridar/GF121909 from GlaxoSmitholine (Collegeville, PA). Nicole Grimm (Universty of Cattingen) provided some MEP data. Dr I. Haubitz. A Rosenberger (Department of Genetic Epidemiology, Univessity of Goxtingen) and Dr Lehr gave expert statistical advice. $A B C B 2^{2 /}$ mice were provided by Dr 5. Zhou, St. Jude Children's Research Hospital, Mermphis, TN. We thank S. Ruhmmann, K. Hofmann and S. Hartung for expert tectinical asistance

\section{Funding}

Merck Serono, Gemany

\section{References}

Bernitsas E, Wei W, Nikol DO Suppression of mitokantrone cardiotosi. city in multiple sclerosis patients by dexrazoxane. Ann Nieurol 2006. $59206-9$

Boster A Edan C, Fiohman E, laved A, Stuve O. Theils A, et at intenve immunosupgerssion in patients with rapidly worsening multiple sclervak: treatment puidelines for the cinician. Lancet Neurol 2008 : 7: $173-83$

Gursch W, Paffe S, Putz B, Barthed G, Schulte-Henmann R. Determination of the length of the hivtobogical stages of epoptosis in normal fiver and in altered hepatik fod of ats Carchageness 1990, 11: 847-53.

Chan A, Seguin R, Magnus T, Papadimitnou C, Toyka KV, Avtel $\mathbb{P}$, et 2 . Phagpcytosis of apoptotic inflammatory cells by microglia and its ther rpeutic implications termination of CNS-autoimmene inflammation and modulation by interleron-beta. Clis 2003, 43: 231-42.

Chan A. Welbach FX. Texka KV Gold R. Mitoxantione induces sel teath in peripheral blood leucocytes of multiple sckerosis patients. Gin Exp immund 2005; $139 ; 152-8$

Cothen BA, Misol DD. Mitoxantrore treatment of multiple sderosis: sefety considerations. Neurobogy 2004; $63,528-32$.

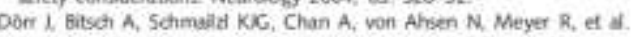
Severe cardia fahlure in a mulsple scleroxis patient folowing low-dose initoxantrone treatment Neurology 2009; in press

Duddy M, Nino $M$. Adatia F. Hebert 5 , Freedman $M$, Actions $H$, et al Distinct effectror crokine proties of memory and nave muman $B$ cell absets and implication in mulbple sclerosia. I imenunof 2007,178 : $6092-99$

Edan C, Maler D, Clanet $M$ Confasreur C. Lyon-Caen O, Lubetzik C. ef at. Therapeutic effect of mitoxantrone cambined with methylpred. nibolone in multiple sdefosk a randomised multicentre study of active disease using MRI and clinical citeria [see commens]. I Neurd

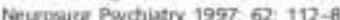

Gaunt $T$, Rodripues 5. Day L Cubic exact solubions for the estimation of panwise haplotype frequencies: implcations for linkage dsequilbrium analyses and $a$ web bol 'CubeX: BMC Bloinformatics $2007 ; 8$ : 428.
Chale AG, Edan C, Laurent M, Mauch E, Elisenman S, Hartung HP, et at Gardac adverse effects associsted with mitorantrone (Novantrone) therapy in patients with MS. Neurology 2002; 59: 909-13.

Consette RE. Compared berefit of approved and experimental imuminosuppressive therapeutic approaches in muliple sderosis Expert Oain Flamescother 2007, \& 1103-16.

Hertung HP, Gonsette R. Konig N. Kwiecirckj H, Guseo A Morrissey SP. it al Minoxantrone in progressive multiple sderosis a placebocontrolled, dowbie bind, sandomised multicente trial. Lanket 2002, 360. $2018-25$

Hasan 5X, Mays AN Ottone T, Ledda A, La NG. Cattaneo C, et d. Molecisar analyss of $t(15,17)$ genomic breakpoints in secondary acule promyelocytic buiemis ariang atter treatment of molliple xteross glood $2008,112,3393-90$

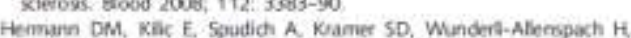
Bassetti CC. Role of drug efflux Carriers in the heaithy and diseased brain. Ann Neurol 2006; 60: 489-98

$H$ tad $M$. Dresches $S$, van der Kuip $H$, Schaffieser $E$, fincher 1 , Schiwab $M$, et al. The C3435T mutation in the human MDR1 gene is asociated with atered effux of the P-plycopestein subntrate hodamine 123 fmen CD55+ matural kiler celk Phamaco genetes 2001:11:293-8

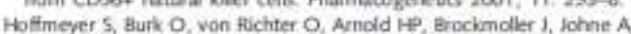
et al. Functional polymoeptisins of the human mutidugersistance gene: multiple sequence variations and carrelation of one allele with P-glycoprotein expression and activity in woo. Proc Nati Acad So USA $2000 ; 97: 3473-8$

Hu OY, Chang SP, Law CX, Ian IM Chen KY. Pharmacokinetic and pharmacodynamic studies with mitoxantrane in the treat. rent of patients with nasopharyngeal carchoms Cancer 1992;69: $847-53$

Kopadee T, Dehmel T, Hartung HP, Stuve O, Kieseier BC. Inhtibition by mitoxastrone of in witro miegration of immunocompetent cels. : poosible mecharism for therapeutic efficacy in the treatiment of multiple iderosis. Avch Neard 2006. 63: 1572-8

Le Page E. Leray E, Taurin G, Coustans M. Chaperon J, Morrissey SP. it al Mitoxistrone as induxtion treatment in agresive relapsing remitting multiple sclecosis tratment response foctors in a 5-pear folow-up obsenational study of 100 consecuetve patients, Neurol Neurosurg Psych 2007; $79: 52-6$.

Leith CP, Kopedky Ku Chen IM, Ejdems L. Slovak ML, MkConnel TS. et at Frequensy and clinical significance of the expression of the multidrug resistance protein MOR1/P-ghycoprotein, MRP1, and LPP in acute myroid leukermia: a Souttwest Onowlogy Group study Blood 1999, $94.1086-99$

Loscher $W$, Potschika H. Drug resistance in brain divezses and the role of trug efflux transportert. Nat Rev Neuroso' 2005; 6: 591-602.

Mazuarai S, Acasas N, Kotani H Single rudeotide polymorphism resert in impaired imembrane focalization and reduced atpase acthaty in multidug transporter ABCG2. Int I Cancer 2004; 109: $238-46$

Nortbsey SP. Le Page E, Edan G. Mitoxantrone in the treatment of multiple sderosis. int MS ; 2005, 12:74-87.

Paul F, Dór L. Whiffel I, Vogel HP. Zipp F. Earty mitoxantrone-induced cardiotovioty in secondary progresive muifipe sderosis. I Neurol Neurosairg Psychiatry 2007; 78. 199-200.

Pavek P, Merino C. Wasenas E, Bobchier E, Nowotna M, Jorniker JW, et al. Human beess cancer resistance protein: interaction with tercid drues, hormones, the detary ceronogen 2-amino-1-methyt6-pheryimidaro(4.5-b)pyridine. and transport of eimetdine. , Pharmacol fxp The 2005: 312: 144-52

Pharmacol fxp The 2005; 312: 144-52.
Poser CM, Brinar VV. Diagnostic oiteria for multiple sclerods an historical review. CIn Neurol Neurosurg 2004; 106: 147-58.

Rieckmann P. Toyka KV, Bassetil C, Beer K. Beer 5, suetiner U, et d Escalating immunotherapy of multiple sckerosis-oew aspects and practical applicition. I Neurol 2004, 251: 1329-39

Robey RW. Polzar O, Deeken I, To KW, Bates SE ABCC2 detemining its relevanoe in clnical drug resistance. Cancer Metastass fiev 2007; 26: $39-57$ 
Schinkel AH, Jenker $M$, Mammalian dnug efflux transporters of the ATP binding cassette (ABC) famly: an overview. Adv Drug Deiv Rev 2003 . 55: $3-29$

Stave O, Kita M, Peleter D, Fox R, Stone 1, Goodkin DE, et at Mitoxantrone as a potential therapy for primary progensive multiple sderosis Mult Sder 2004, 10 5upd 1: 558-561.

The Internationd HispMap Corsortim. A second generation humm haplotype map of over 31 millon 5NP. Nature 2007; $499851-62$.

Uhr $M$, Tontsch A, Namendort C, Ripke 5, Lutae 5, bing M, et al Polymorphisms in the deug transporter gene $\mathrm{ABCB}$ s predict antidepressant treaturent response in depression. Neuron 2008, 57 203-9

wen Ahsen N, Lewcruk P, Schutz E, Odierich M threpreid $H$ Pmothrambin activty and concentration in healthy wubjects with and pathoutin actiny and concentraten ha heathy wabjects with and 50956 . 5.49-56.

von Absen N. Richter M. Crupp C, Ringe B, Dellench M, Armstrong VW. No infiuence of the MOR-1 C343ST polymorphism of a CYP3Mt promoter polymorphism (CYP3A.A.V allek) on dase-adusted cyclosporin $A$ trough concentrations or texection incidence in statile rersal tramplant recipients. Cin Chem 2001; 47: 1068-52
Weilbach FX, Chan A. Toyka KV, Gald R. The cesdioprotector dewazovane augments therapeutic efficacy of mitoxantrone in experimental autoimmune encephadomyetitis. Cin Exp Immunol 2004: $135: 49-55$

Woinowski L. Kulle B. 5chimer M. Schoter G. Schnid A, Rosenberget $A$, et al. NADXPSH ovidase and mulidrug resitance protein genetic polymorphisms are assecisted with doxorubicin-induced cardotowicity, Orculation 2005; $1123754-62$

Zamar D, Mctieney B, Graham L, elm software implementing exact-like inference for logistic regression modets. I Stat Software 2007; 21: $1-18$

Zhers $G$. Anabisis of ordered categorical data. two socke-independent approsches Bometries 2008, 64, 1276-9

Theng $\mathrm{C}$. Fieidin $\mathrm{G}$, Zhaohai $\mathrm{L}$ Gestwirth $\mathrm{IL}$. Choice of scors in trend tests for case-control studies of canddate-gene assodiations. Diametrical J 2003; 45: 335-18

thou 5. Z $\mathrm{mg}$ Y, Lu T, Sorrentino BP. Hematopoietic cels from mice that are deficent in both Bcp 1/Abcez and Mrta/ib develop normaly but are sensitized to mitoxantrone. FroT echiniques 2003. 35. $1248-52$ 


\section{Teil C: Darlegung des Eigenanteils}

Adenosinetriphosphate-binding-casette ( $A B C$ )-Transporter stellen eine Form der Multi-DrugResistance dar. Sie beeinflussen die Pharmakologie und Toxikologie diverser Substanzen. Die Transporter spielen unter anderem eine potentielle Rolle bei der Entwicklung von Resistenzen gegen Chemotherapeutika sowie bei der Limitierung der Penetration verschiedener Medikamente in das zentrale Nervensystem.

Das Ziel der vorliegenden Arbeit war die Untersuchung der Häufigkeit von $A B C$ Genpolymorphismen, der Transporter-Expression auf Zielorganen der Mitoxantron-Therapie in der Multiplen Sklerose, der funktionellen Rolle der Transporter in vitro und in vivo und eine retrospektive, klinische Analyse des potentiellen Einflusses auf die MitoxantronAnsprechrate in Multipler Sklerose. Die Untersuchung wurde unter der Leitung von PD Dr. med. A. Chan in der ehemaligen Abteilung ,experimentelle und klinische Neuroimmunologie, Universitätsmedizin Göttingen und gemeinnützige Hertie-Stiftung“ begonnen und nach Wechsel von PD Dr. med. Chan an die Ruhr Universität beendet.

Die der Untersuchung zugrunde liegende Hypothese, dass $A B C$-Transporter zelluläre Effekte von Mitoxantron kritisch verändern könnten, wurde von Herrn PD Dr. med. A. Chan (vormals ehemalige Abteilung ,experimentelle und klinische Neuroimmunologie, Universitätsmedizin Göttingen und gemeinnützige Hertie-Stiftung“, Göttingen; aktuell Neurologische Klinik, Ruhr Universität, St. Josef-Hospital, Bochum, Direktor Prof. Dr. med. R. Gold) aufgestellt.

Die Einleitung basiert auf Literaturrecherchen durch die Autorin der Promotion Frau S. Cotte. Die weiteren Erstautoren Herr Dr. rer. nat. N. Kruse (Abteilung Neuropathologie, Medizinische Fakultät, Universität Göttingen, Göttingen) und Herr Prof. Dr. med. N. von Ahsen (Abteilung Klinische Chemie, Medizinische Fakultät, Universität Göttingen, Göttingen) beteiligten sich mit hilfreichen Anregungen.

Die Häufigkeit von zwei $A B C B 1$ - und fünf $A B C G 2$-Einzelbasenaustauschen in 842 MultipleSklerose-Patienten aus Deutschland und Spanien und 264 gesunden Spendern wurde von Herrn Dr. rer. nat. N. Kruse, Herrn Prof. Dr. med. N. von Ahsen und Frau S. Cotte wie folgend aufgeführt analysiert: Die Isolation der genomischen Desoxyribonukleinsäure erfolgte im Zentrum Barcelona (Dr. med. N. Tellez, Prof. Dr. med. X. Montalban, Einheit klinische Neuroimmunologie, Abteilung Neurologie, Hospital Universitario Vall d Hebron, Universitat Autonoma de Barcelona, Spanien, n=49), Berg (gesammelt von Dr. med. M. Starck, Dr. med. N. König, Marianne-Strauß Klinik, Berg, isoliert von Prof. Dr. med. N. v. Ahsen, n=194), Berlin (Dr. med. J. Dörr, Prof. Dr. med. F. Paul, Prof. Dr. med. F. Zipp, NeuroCure Clinical Research Center, Charité-Universitätsmedizin Berlin, Berlin, $\mathrm{n}=10$ ), Rostock (Dr. med. A. Winkelmann, Prof. Dr. med. U. K. Zettl, Abteilung Neurologie, Universität Rostock, Rostock, n=423) und Göttingen/Bochum (Dr. rer. nat. N. Kruse, n=112; Frau S. Cotte, n=54). Bei der von Herrn Dr. rer. nat. N. Kruse ( $\mathrm{n}=858$, Barcelona, Berlin, Göttingen/Bochum, Rostock) und von Frau S. Cotte (n=54, Göttingen) durchgeführten Genotypisierung für $A B C G 2$ wurden 
folgende sechs Einzelbasenaustausche fokussiert: V12M, Q141K, Q126* (*=Stopp), E334*, R482G, R482T. Die ABCB1-3435C>T (ganze Kohorte) und -2677G>T (MX-behandelte Kohorte) sowie die vorbeschriebenen $A B C G 2$ - (n=194, Berg) Einzelbasenaustausche wurden von Herrn Prof. Dr. med. N. von Ahsen genotypisiert. Die zugehörigen Abschnitte der Publikation (Material und Methoden, Ergebnisse, Diskussion) sowie Tabelle 2 der Publikation und Tabelle 1 der Dissertation wurden angefertigt in Zusammenarbeit von Herrn Dr. rer. nat. N. Kruse, Herrn Prof. Dr. med. N. von Ahsen und Frau S. Cotte.

In einem weiteren Schritt konnte von Herrn Dr. rer. nat. N. Kruse und Frau S. Cotte nachgewiesen werden, dass $A B C$-Transporter vor allem in Zellen/Geweben, die potentiell von der Mitoxantron-Therapie betroffen sind, auf Boten-Ribonukleinsäure-Ebene hoch exprimiert werden. Die komplementäre Desoxyribonukleinsäure aus kardialem Gewebe wurde freundlicherweise von Dr. med. Phuc Nguyen and Herrn Prof. Dr. med. G. Hasenfuß (Abteilung Kardiologie und Pneumologie, Universitätsmedizin Göttingen, Göttingen) zur Verfügung gestellt. Die Hepatozyten stammten aus makroskopisch unauffälligen Resektionsrändern von Lebertumoren, offeriert von Herrn Prof. Dr. med. N. von Ahsen. Die zur Quantifizierung benötigten peripheren mononukleären Blutzellen wurden in der MultipleSklerose-Ambulanz, Universitätsmedizin, Göttingen unter Herrn Prof. Dr. med. R. Gold von Herrn Dr. rer. nat. N. Kruse und Frau S. Cotte gesammelt. Die primär humanen Gliazellen stammten aus chirurgischen Resektaten, die Herr Dr. med. H. Pannek (Evangelisches Krankenhaus, Bielefeld) zusammentrug. Die Isolierung der komplementären Desoxyribonukleinsäure aus diesen Zellen/Geweben, die Aufreinigung der Ribonukleinsäure, die reverse Transkription und die relative Quantifizierung der $A B C$-Boten-RibonukleinsäureExpression wurde von Herrn Dr. rer. nat. N. Kruse mit Unterstützung von Frau S. Cotte durchgeführt. Diese beiden erstellten auch die entsprechenden Abschnitte der Publikation sowie die Abbildung 1 der Publikation.

Der funktionelle Einfluss der $A B C$-Transporter-Gen-Polymorphismen wurde auf experimenteller in-vitro-Ebene von Frau S. Cotte untersucht. Auf der Grundlage von Vorarbeiten der Gruppe und nach einer ausführlichen Literaturrecherche entwickelte sie einen durchflusszytometrisch-basierten Mitoxantron-Efflux- und -Zelltod-Assay. Nachdem die Assays in Vorexperimenten in unsortierten mononukleären Blutzellen etabliert wurden, erfolgte die Analyse in $A B C B 1$ - und $A B C G 2$ - hochexprimierenden CD56 ${ }^{+}$-Natürlichen-KillerZellen. Die Erarbeitung der in der Publikation aufgeführten Experimente (MitoxantronEfflux-Assays in Multiple-Sklerose-Patienten und gesunden Spendern ( $\mathrm{n}=6)$, Zelltod-Assays $(n=5))$ wurde von der Autorin der Promotion durchgeführt. Sie verfasste die entsprechenden Abschnitte aus Material und Methoden, dem Ergebnisteil und der Diskussion und entwarf die Abbildungen 2 und 3 der Publikation sowie die Abbildungen 1 bis 3 und die Tabellen 2 und 5 der Dissertation mit Hilfe der Microsoft-Office Exel-, -Power Point- (2003) und Win MDISoftware 2.8 (2000).

Die Untersuchung der in-vivo-Signifikanz der Mitoxantron-Wirkung in der chronischen, experimentellen autoimmunen Enzephalomyelitis in Abcg2-Knock-Out-Tieren und die 
Erstellung der dazugehörigen Abschnitte sowie der Abbildung 4 der Publikation erfolgte durch Herrn B. Huber im Rahmen von dessen Dissertationsvorhaben unter Anleitung von Herrn Dr. rer. nat. F. Lühder (ehemalige Abteilung ,experimentelle und klinische Neuroimmunologie, Universitätsmedizin Göttingen und gemeinnützige Hertie-Stiftung“, Göttingen).

In einer retrospektiven, klinischen Analyse wurde die Ansprechrate Mitoxantron-therapierter Multiple-Sklerose-Patienten mit den zuvor funktionell untersuchten $A B C$-GenPolymorphismen von Frau S. Cotte unter Supervision von Herrn PD Dr. med. A. Chan korreliert. Das Design der retrospektiven Prüfung wurde von der Autorin der Promotion in Zusammenarbeit mit Herrn Prof. Dr. med. N. von Ahsen entwickelt. Die Datenauswertung erfolgte für insgesamt 188 Multiple-Sklerose-Patienten der Göttinger Multiple-SkleroseAmbulanz von Frau S. Cotte. Die weiteren Epikrisen wurden in Form eines Reports in den entsprechenden Zentren erhoben (Barcelona $n=49$, Dr. med. N. Tellez, Prof. Dr. med. X. Montalban; Berlin n=10, Dr. med. J. Dörr, Dr. med. F. Paul, Dr. med. F.Zipp; Berg n=194, Dr. med. M. Starck, Dr. med. N. König; Rostock n=123, Dr. med. A. Winkelmann, Prof. Dr. med. U.K. Zettl). Die klinischen Daten der insgesamt 564 Multiple-Sklerose-Patienten wurden unter Koordination von Frau S. Cotte zusammengetragen und von dieser mit Hilfe konservativer Parameter bezüglich der Mitoxantron-Ansprechrate klassifiziert. Ergänzend wurde zur Response-Einteilung die Auswertung motorisch-evozierter Potentiale herangezogen, die für das Göttinger Patientenkollektiv $(n=8)$ freundlicherweise von $N$. Grimm (ehemalige Abteilung „experimentelle und klinische Neuroimmunologie, Universitätsmedizin Göttingen und gemeinnützige Hertie-Stiftung“, Göttingen) zur Verfügung gestellt wurde. Die Daten der 36 Patienten, die schwere kardiale und hämatologische Nebenwirkungen entwickelten, wurden ebenfalls wie vorhergehend beschrieben gesammelt (Barcelona $n=14$, Berg $n=7$, Berlin $n=10$, Göttingen/Bochum n=4, Rostock n=1) und auf $A B C$-Polymorphismen untersucht. Die Abschnitte der klinischen Analyse sowie die Tabellen 1, 3 und 4 der vorliegenden Publikation und die Tabellen 3 und 4 der Dissertation wurden von Frau S. Cotte unter Korrektur und mit Ergänzung von Herrn Prof. Dr. med. N. von Ahsen verfasst und erstellt.

Die beschreibende Statistik der Publikation wurde von den Autoren, die die entsprechenden Experimente und Auswertungen durchführten nach Rücksprache mit Herrn Prof. Dr. med. N. von Ahsen erstellt. Ergänzend gaben Frau Dr. I. Haubitz, Herr A. Rosenberger (Abteilung genetische Epidemiologie, Universitätsmedizin Göttingen) und Herr Dr. Lehr professionelle, statistische Ratschläge.

federführender Autor der Publikation

PD Dr. med. A. Chan
Autorin der Promotion

S. Cotte 


\section{Danksagung}

Es ist eine schöne Tradition, sich nach Abschluss der Doktorarbeit auf die vielen Menschen zu besinnen, die hilfreich und unterstützend wirkten.

Ich danke Herrn Prof. Dr. med. R. Gold und Herrn PD Dr. med. A. Chan für die Anregung und Ermöglichung dieser Arbeit. Herrn Prof. Dr. med. R. Gold danke ich darüber hinaus für die freundliche Aufnahme in das ehemalige Institut für Multiple-Sklerose-Forschung der Universitätsmedizin Göttingen sowie für die interessierte Unterstützung und Förderung, die mir entgegengebracht wurde.

Besonderer Dank gilt Herrn PD Dr. med. A. Chan für die hervorragende, engagierte und geduldige Betreuung meines Dissertationsvorhabens, für die stete Diskussionsbereitschaft und dafür, dass er mich bei meinen ersten Schritten in der „Welt der Forschung“ begleitete.

Herrn Prof. Dr. med. N. von Ahsen danke ich für die andauernde interessierte Unterstützung und Diskussionsbereitschaft. Ich empfinde es als eine große Ehre, dass ich mit Herrn PD Dr. med. A. Chan und Herrn Prof. Dr. med. N. von Ahsen zusammenarbeiten und von ihnen lernen durfte.

Herrn Prof. Dr. rer. nat. N. Kruse werde ich immer dankbar für die Einführung in die Laborarbeit sowie die fortlaufende Unterstützung auf dem Gebiet der Genotypisierung und Quantifizierung sein.

Auch allen nicht genannten Mitarbeitern des ehemaligen Instituts für Multiple-SkleroseForschung der Universitätsmedizin Göttingen gilt mein Dank für ein sehr angenehmes und motivierendes Arbeitsklima und für die vielen kleinen Hilfen.

Ich danke Herrn Dr. phil. K. H. Stubenrauch, D. Grey, S. Kirtscher und H. Franz für die korrigierenden Anmerkungen zur äußeren Form des Manuskripts. 


\section{Lebenslauf}

Steffi Cotte

Alfred-Kästner-Straße 14

04275 Leipzig

Telefonnummer: $\quad$ 0341-2230177 oder 0176-21302605

E-Mail Adresse: $\quad$ stefficotte@web.de

Am 29.01.1984 wurde ich, Steffi Cotte, in Leinefelde, Thüringen als drittes Kind meiner Eltern geboren. Ich bin deutsche Staatsbürgerin. Ich bin unverheiratet und Mutter eines Sohns, Jonathan Cotte, der am 22.09.2009 geboren wurde.

Von September 1990 bis 1994 habe ich die Konrad-Hentrich-Grundschule in Leinefelde besucht, bevor ich für weitere acht Jahre Schülerin des Gottfried-Wilhelm-LeibnizGymnasiums in Leinefelde wurde. Im Juni 2002 habe ich die allgemeine Hochschulreife erlangt.

Von Oktober 2002 bis Mai 2009 habe ich Humanmedizin studiert an der Georg-AugustUniversität zu Göttingen, wobei ich im September 2004 das erste Staatsexamen, Physikum und im Mai 2009 das zweite Staatsexamen erfolgreich absolvierte. Am 19.06.2009 wurde mir die Approbation als Ärztin erteilt.

Mein Praktisches Jahr habe ich von Februar bis Juni 2008 in der Allgemeinchirurgie des Hospital Universitario Virgen Macarena in Sevilla, Spanien und von Juni bis Oktober 2008 in der Inneren Medizin der Geriatrischen Universitätsklinik des Ziegler Spitals in Bern, Schweiz verbracht. Von Oktober 2008 bis Januar 2009 war ich in der Neurologie im National Hospital for Neurology and Neurosurgery, Queen Square in London, Großbritannien tätig.

Weitere klinische Tätigkeiten beschränken sich auf im Rahmen des Studiums stattgefundene Blockpraktika und Famulaturen.

Zwischen Februar und Oktober 2006 habe ich mein Studium für ein experimentelles Forschungspraktikum im Rahmen meines Dissertationsvorhabens unterbrochen. Die thematische Auseinandersetzung mit $A B C$-Transportern und Mitoxantron in Multipler Sklerose erfolgte unter der Betreuung von Herrn PD Dr. med. A. Chan im ehemaligen Institut für Multiple-Sklerose-Forschung (Direktor Herr Prof. Dr. med. R. Gold) der Universitätsmedizin zu Göttingen. Als Ergebnis habe ich im September 2006 die ECTRIMS in Madrid, Spanien besucht, auf der ein Poster mit dem Titel „ABC-transporter genepolymorphisms as potential predictors of therapeutic efficacy of mitoxantrone in $M S^{\text {“ }}$ vorgestellt wurde. Im September 2007 habe ich das Thema auf dem Kongress der Deutschen 
Gesellschaft für Neurologie in Berlin und im April 2008 auf dem Kongress der American Academy of Neurology in Chicago, IL, USA präsentiert. Am 15.07.2009 wurde ein Artikel mit dem Thema „ABC-transporter gene polymorphisms are potential pharmacogenetic markers for mitoxantrone in multiple sclerosis“ bei Brain (Impact-Faktor 9.603) publiziert.

Von Oktober 2002 bis August 2009 habe ich als Aushilfskraft in einer gynäkologischen Praxis gearbeitet. Weiterhin war ich von Juli bis Oktober 2007 als hilfswissenschaftliche Mitarbeiterin mit dem Führen der Multiple-Sklerose-Datenbank der ehemaligen MultipleSklerose-Ambulanz der Universitätsmedizin in Göttingen beauftragt. In den Jahren 2004 bis 2006 nahm ich ehrenamtlich an der Organisation und Planung des jährlich stattfindenden Teddy-Bär-Krankenhauses sowie des Aktionstages der Medizin der Universitätsmedizin in Göttingen teil.

Von September 2009 bis September 2010 befand ich mich in der Erziehungszeit meines Kindes. Darüber hinaus beteiligte ich mich an der Erstellung eines weiteren Manuskriptes mit dem Thema „Therapieeffekt von Mitoxantron bei primär progredienter Multiple Sklerose in Abhängigkeit von $A B C$-Transporter-Gen-Polymorphismen“".

Seit dem 27.09.10 bin ich als Assistenzärztin und wissenschaftliche Mitarbeiterin tätig in der Klinik und Poliklinik für Neurologie des Universitätsklinikums Leipzig (Leitung von Herrn Prof. Dr. med. J. Claßen). Im Besonderen obliegt mir die Betreuung der Neuroimmunologischen Ambulanz (unter Herrn PD Dr. med. F. Then Bergh). Am 8./9.10.10 absolvierte ich erfolgreich einen Kurs zur Prüfärztin (good clinical practice) am Koordinierungszentrum klinischer Studien in Leipzig (KKSL). Seit Ende 2010 bin ich als Prüfärztin für verschiedene klinische multi-centre und Klinik-eigene Studien mit Multiple Sklerose-Patienten tätig. 